\title{
Separation, Concentration, and Immobilization of Technetium and Iodine from Alkaline Supernate Waste
}

\author{
Final Report \\ March 11, 1998
}

\author{
By \\ Michael Gula \\ James Harvey
}

Work Performed Under Contract No.: DE-AC21-97MC33137

\author{
For \\ U.S. Department of Energy \\ Office of Fossil Energy \\ Federal Energy Technology Center \\ P.O. Box 880 \\ Morgantown, West Virginia 26507-0880
}

By

Eichrom Industries, Inc.

8205 South Cass Avenue

Suite 107

Darien, Illinois 60564 


\section{Disclaimer}

This report was prepared as an account of work sponsored by an agency of the United States Government. Neither the United States Government nor any agency thereof, nor any of their employees, makes any warranty, express or implied, or assumes any legal liability or responsibility for the accuracy, completeness, or usefulness of any information, apparatus, product, or process disclosed, or represents that its use would not infringe privately owned rights. Reference herein to any specific commercial product, process, or service by trade

name, trademark, manufacturer, or otherwise does not necessarily constitute or imply its endorsement, recommendation, or favoring by the United States Government or any agency thereof. The views and opinions of authors expressed herein do not necessarily state or reflect those of the United States Government or any agency thereof. 


\title{
Separation, Concentration, and Immobilization of Technetium and Iodine from Alkaline Supernate Waste
}

\author{
FINAL REPORT
}

Eichrom Industries, Inc.

8205 South Cass Avenue

Suite 107

Darien, IL 60564

March 11, 1998

DE-AC21-97MC33137--43

Michael Gula, Principal Investigator James Harvey, Project Manager 
Table of Contents

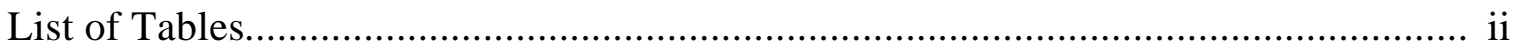

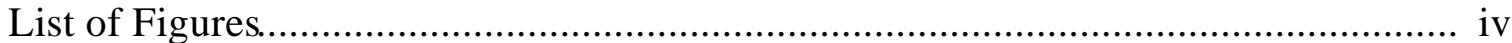

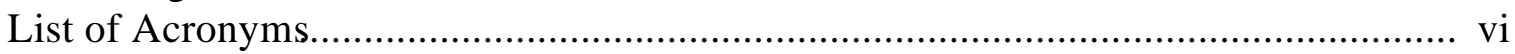

Executive Summary......................................................................................ii

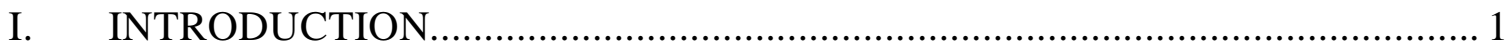

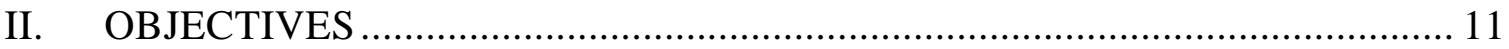

III. EXPERIMENTAL - LABORATORY SCALE SYNTHESIS............................ 12

IV. RESULTS AND DISCUSSION OF LABORATORY SCALE SYNTHESIS.... 25

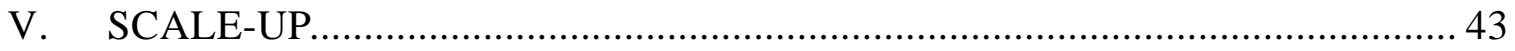

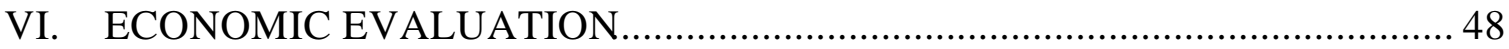

VII. SORPTION OF TECHNETIUM ONTO SILICA-BASED

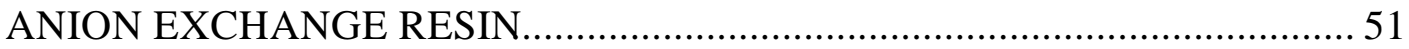

VIII. ENCAPSULATION OF SILICA-BASED ANION EXCHANGE RESIN............ 52

IX. STABILITY STUDIES OF THE ENCAPSULATED WASTE FORM............... 54

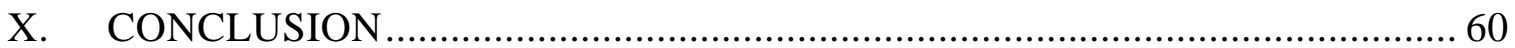

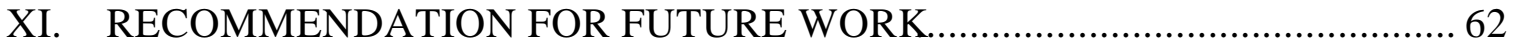

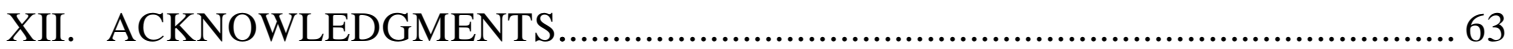

APPENDICES

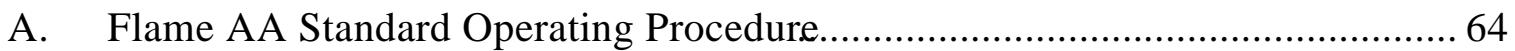

B. 110-Liter Reactor Temperature Profile........................................................... 72

C. Technetium/Iodine Selective Resin Manufacture Flowsheet.............................. 80 


\section{List of Tables}

Page

Table 1. Copolymerization Yield and Swelling Ratios for Copolymer

Beads Prepared in Substrate Studies. 26

Table 2. Formulations and Yields of ABEC-2000 Resins Prepared for Substrate Studies

Table 3. Comparison of Xero Gel and Regular Gel ABEC-2000 Resins.

Table 4. Comparison of ABEC-2000 and -5000 Resins Prepared from $2 \%$ Crosslinked, 20\% VBC Substrate. 30

Table 5. Effect of Solvent on PEG Addition Reaction. 31

Table 6. Effect of Reducing Solvent/PEG/NaH on PEG Addition Reaction 32

Table 7. Effect of Solvent Quantity on PEG Addition Reaction............................. 33

Table 8. Effect of Reaction Temperature on PEG Addition Reaction..................... 35

Table 9. Effect of Reaction Time on PEG Addition Reaction............................... 36

Table 10. Study of PEG Addition Reaction Using Copolymers with Various Levels of VBC

Table 11. Results of Replacing Sodium Hydride with Sodium Methoxide. 38

Table 12. Reactant Quantities and Synthesis Yields for Scale-Up of Copolymer Synthesis

Table 13. Comparison of ABEC-2000 Resins from Different Size Reactors............ 45

Table 14. Manufacturing Costs for ABEC Resin in 110-Liter Reactor Using Actual Quantities Purchased 50

Table 15. Uptake of Technetium by NUCLEOSIL from DI Water. 52

Table 16. Uptake of Technetium by NUCLEOSIL from DI Water Under Conditions Approaching Resin Loading Capacity. 52 
Table 17. Technetium Desorbed During Microsphere Preparations and Washing Steps..

Table 18. Test Conditions at the Start of the TCLP Leaching Tests.......................... 55

Table 19. Test Conditions at the Start of the Brine Leaching Studies......................... 55

Table 20. Results of the TCLP Leaching Tests....................................................... 57

Table 21. Results of the Brine Leaching Tests.......................................................5

Table 22. Dose Rate and Heating Calculations for Unencapsulated vs.

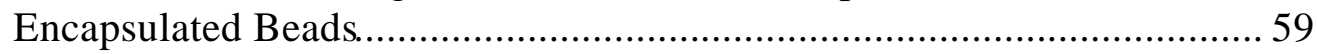

Table 23. Comparison of Required Success Criteria vs. Success Achieved............... 61 


\section{List of Figures}

Page

Figure 1. Flowsheet for the separation, concentration and immobilization of Tc/I from alkaline supernate wastes

Figure 2. $\mathrm{D}_{\mathrm{W}}$ for $\mathrm{TcO}_{4}{ }^{-}$vs. molality of salt with $\mathrm{Tc} / \mathrm{I}$ selective resin (ABEC-5000)

Figure 3. $\mathrm{D}_{\mathrm{W}}$ for $\mathrm{TcO}_{4}{ }^{-}$from three Hanford $\mathrm{HLW}$ tank simulants vs. MW of PEG on Tc/I selective resin (e.g., ABEC-500® PEG-5000 on polystyrene).

Figure 4. I-131 rinse and elution curve. Melton Valley W-3 tank supernate sample on $\mathrm{Tc} / \mathrm{I}$ selective resin.

Figure 5. Elution curve for Mo-99, loading Tc-99m. Rinse and elution of Tc-99m from Tc/I selective resin ABEC-5000. 8

Figure 6. Effect of increasing perrhenate concentration on technetium distribution ratio from $2 \mathrm{M}\left(\mathrm{NH}_{4}\right)_{2} \mathrm{SO}_{4}$ solution on $\mathrm{Tc} / \mathrm{I}$ selective resin.

Figure 7. Synthetic route to make ABEC resins

Figure 8. Comparison of ${ }^{188} \mathrm{ReO}_{4}{ }^{-}$and ${ }^{99} \mathrm{TcO}_{4}{ }^{-}$uptake with ABEC-5000 resinfrom $\mathrm{NaOH}$ solution

Figure 9. $\mathrm{TcO}_{4}{ }^{-}$uptake with $\mathrm{ABEC}-5000$ resin from $2 \mathrm{M}$ and $4 \mathrm{M} \mathrm{NaOH}$ solution vs. $\mathrm{NH}_{4} \mathrm{ReO}_{4}$ concentration.

Figure 10. Comparison of dwcf's from oven gravimetric analysis and TGA analysis. 20

Figure 11. $\mathrm{TcO}_{4}{ }^{-} \mathrm{D}_{\mathrm{w}}$ in $4 \mathrm{M} \mathrm{NaOH}$ solution vs. dwcf by oven gravimetric analysis. 22

Figure 12. $\mathrm{TcO}_{4}{ }^{-} \mathrm{D}_{\mathrm{v}}$ in $4 \mathrm{M} \mathrm{NaOH}$ solution vs. dwcf by oven gravimetric analysis.. 23

Figure 13. $\mathrm{TcO}_{4}{ }^{-} \mathrm{D}_{\mathrm{w}}$ vs. $[\mathrm{NaOH}]$ for $\mathrm{ABEC}$ resins prepared for substrate studies..... 28

Figure 14. $\mathrm{TcO}_{4}{ }^{-} \mathrm{D}_{\mathrm{w}}$ vs. $[\mathrm{NaOH}]$ for xero gel and regular gel ABEC-2000 resins..... 29

Figure 15. $\mathrm{TcO}_{4}{ }^{-} \mathrm{D}_{\mathrm{w}}$ with ABEC-5000 vs. total $\left[\mathrm{NaCO}_{3}\right]$ in BNFL Sellafield waste simulant solution. 39 
Figure 16. $\mathrm{TcO}_{4}{ }^{-} \mathrm{D}_{\mathrm{W}}$ with $\mathrm{ABEC}-5000$ vs. molarities of different biphase-forming salts added to BNFL Sellafield waste simulant solution

Figure 17. Column loading and elution of TcQ in BNFL Capenhurst waste simulant with ABEC-5000 resin

Figure 18. Column loading and elution of TcQ in BNFL Capenhurst waste simulant with resin FC-54-026-B.

Figure 19. Temperature record of copolymerization reaction in 110-liter reactor..... 44

Figure 20. $\mathrm{TcO}_{4}{ }^{-} \mathrm{D}_{\mathrm{W}}$ vs. $[\mathrm{NaOH}]$ for $\mathrm{ABEC}-2000$ resins produced from larger scale reactions

Figure 21. Column loading/elution curve for $1.1 \mathrm{~g} / \mathrm{L}$ rhenium as $\mathrm{NaRe}(\mathrm{m}$ $4 \mathrm{M}\left(\mathrm{NH}_{4}\right)_{2} \mathrm{SO}_{4}$ with resin $\mathrm{JW}-53-155$.

Figure 22. Column loading/elution curve for $0.10 \mathrm{~g} / \mathrm{L}$ rhenium as $\mathrm{NaRe}(\mathrm{m}$ $4 \mathrm{M}\left(\mathrm{NH}_{4}\right)_{2} \mathrm{SO}_{4}$ with resin $\mathrm{JW}-53-155$. 48

Figure 23. Column loading/elution curve for ${ }^{95 \mathrm{~m}} \mathrm{TcO}_{4}{ }^{-} / 0.01 \mathrm{M} \mathrm{ReO}_{4}{ }^{-}$in

$4 \mathrm{M} \mathrm{NaOH}$ with resin JW-53-155. 49

Figure 24. Technetium uptake by NUCLEOSIL as a function of solution p.H. 51 


\section{List of Acronyms}

ABEC

ABEC-5000

ABS

ANL

AW-101

BNFL

BV

$\mathrm{Ci}$

$\mathrm{Cl}$

$\mathrm{cm}$

CRADA

Cs

CST

DI

DOE

DSC

$\mathrm{D}_{\mathrm{W}}$

dwcf

EDTA

EPA

FAA

$\mathrm{fcr}$

FP

g

GRAS

HTiO

HLW

I

$\mathrm{KCoCF}$

$\mathrm{L}$

LLW

$\mathrm{mL}$

MW

NCAW

NIU

NRC

ORNL

PEG

PEG-5000

$\operatorname{Re}$

Sn

$\mathrm{Sr}$

SRR aqueous biphasic extraction chromatographic

aqueous biphasic extraction chromatographic, with 5000 MW PEG aqueous biphasic system

Argonne National Laboratory, E. P. Horwitz, Ph.D. and co-workers

a Hanford tank

British Nuclear Fuels

bed volume

curie

chloride

centimeter

Cooperative Research and Development Agreement

cesium

crystalline silica titanates, Sandia/UOP

deionized (water)

Department of Energy

differential scanning caolrimetry

weight distribution ratio

dry weight conversion factor

ethylenediaminetetraacetic acid, a chelant

Environmental Protection Agency

flame atomic absorption

free column volume

finished product

gram

generally recognized as safe

hydrous titanium oxide

high level waste

iodide/iodate

potassium cobalt hexacyano ferrate

liter

low level waste

milliliter

molecular weight

a Hanford waste form

Northern Illinois University, Robin D. Rogers, Ph.D. and co-worker

Nuclear Regulatory Commission

Oak Ridge National Laboratory

polyethylene glycol

5000 molecular weight polyethylene glycol, methyl capped

perrhenate, rhenium

tin

strontium

resorcinol-formaldehyde resin (Savannah River) 
SST

SY-101

$\mathrm{Tc}$

Tc/I

THF

UT

W-3

$\mathrm{W}-29$ single shelled tank (Hanford)

a Hanford tank

pertechnetate, technetium

technetium/iodine

tetrahydrofuran

University of Tennessee, Spiro Alexandratos, Ph.D. and co-workers a Melton Valley tank

a Melton Valley tank 


\section{Executive Summary}

Development of remediation technologies for the characterization, retrieval, treatment, concentration, and final disposal of radioactive and chemical tank waste stored within the Department of Energy (DOE) complex represents an enormous scientific and technological challenge. A combined total of over 90 million gallons of high-level waste (HLW) and low-level waste (LLW) are stored in 335 underground storage tanks at four different DOE sites. Roughly $98 \%$ of this waste is highly alkaline in nature and contains high concentrations of nitrate and nitrite salts along with lesser concentrations of other salts. The primary waste forms are sludge, saltcake, and liquid supernatant with the bulk of the radioactivity contained in the sludge, making it the largest source of HLW.

The saltcake (liquid waste with most of the water removed) and liquid supernatant consist mainly of sodium nitrate and sodium hydroxide salts. The main radioactive constituent in the alkaline supernatant is cesium-137, but strontium-90, technetium-99, and transuranic nuclides are also present in varying concentrations. Reduction of the radioactivity below Nuclear Regulatory Commission (NRC) limits would allow the bulk of the waste to be disposed of as LLW. Because of the long half-life of technetium-99 $\left(2.1 \times 10^{5} \mathrm{y}\right)$ and the mobility of the pertechnetate ion $(\mathrm{Tc} @)$ in the environment, it is expected that technetium will have to be removed from the Hanford wastes prior to disposal as LLW. Also, for some of the wastes, some level of technetium removal will be required to meet LLW criteria for radioactive content. Therefore, DOE has identified a need to develop technologies for the separation and concentration of technetium-99 from LLW streams. Eichrom has responded to this DOE-identified need by demonstrating a complete flowsheet for the separation, concentration, and immobilization of technetium (and iodine) from alkaline supernatant waste.

Both technetium, as pertechnetate, and iodine, as iodide and/or iodate, are strongly absorbed from concentrated salt solutions, such as the alkaline tank wastes, by Eichrom's

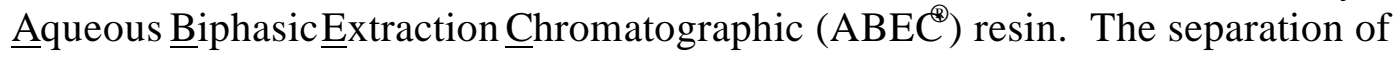
technetium and/or iodine from such waste solutions has been clearly demonstrated for a

number of simulant and actual waste streams. These waste streams include actual Hanford tank waste from tank AW-101, (a cesium decontaminated double shell slurry feed composite), three different Hanford tank waste simulants, actual waste samples from ORNL Melton Valley Storage Tanks W-29 and W-3, and waste simulant solutions from two British Nuclear Fuel (BNFL) locations-Capenhurst and Sellafield-in the United Kingdom. All of these waste streams contain high salt concentrations. Alternative technologies for the separation of technetium from tank wastes utilize anion exchange resins to sorb pertechnetate. The high concentrations of anions present in tank wastes will compete with pertechnetate and iodide/iodate for uptake by the anion exchange resin. Thus, high salt concentrations in tank wastes pose a serious potential problem for the alternative separation technologies utilizing anion exchange resins. A distinct advantage of the ABEC resin separation technology is that the high salt concentrations do not interfere with uptake of technetium and iodine (Tc/I). In fact, greater salt concentrations 
actually enhance the uptake of Tc/I by ABEC resin. Therefore, ABEC resin offers a significant advantage for the separation of Tc/I from alkaline supernate waste streams.

It has also been clearly demonstrated that Tc/I are rapidly and efficiently stripped and ABEC resin is regenerated by eluting the loaded resin with water. This offers another significant advantage over alternative technologies which require concentrated acid solutions or solutions of chelating agents (e.g., EDTA) and reductants (e.g., Sty to remove technetium from anion exchange resins. The ability to strip Tc/I from ABEC resin with water results in no additional wastes added to the concentrated Tc/I solution. It is expected that at least a 100-fold concentration of Tc/I will be achieved by loading Tc/I from tank wastes onto ABEC resin and stripping with water. For example, a capacity of $76 \mathrm{mmol}$ technetium per liter of ABEC resin has been determined as part of this effort. Assuming only a 50\% loading of the resin, 1,000 liters of alkaline supernatant waste containing $5 \times 10^{5} \mathrm{M}$ technetium would require 1.3 liters of ABEC resin to load the technetium. Greater than $95 \%$ of the technetium can be stripped in approximately 5 bed volumes (BV) of water. Thus, the original 1,000 liters of alkaline waste can be reduced to 6.5 liters of water containing $7.7 \times 10 \mathrm{M}$ technetium for a concentration factor of 150 .

The selectivity of ABEC resin for Tc/I over other tank waste constituents, combined with the ability to regenerate the resin with water, provides a clean, concentrated solution of Tc/I which may be treated further in a variety of ways. One possibility is to evaporate the water strip solution for additional concentration to any desired level prior to grouting for final waste disposal. A second option being considered by management at the BNFL Capenhurst facility is to dispose of the technetium-loaded $\mathrm{ABEC}$ resin as the final waste form. As stated in the example above, 1.3 liters of ABEC resin are required to load technetium from 1,000 liters of waste containing $5 \mathrm{x}^{-5} 1 \mathrm{M}$ pertechnetate. Assuming that the resin volume will decrease by $50 \%$ when dried before disposal, the original 1,000 liters of waste can be reduced to 0.65 liters for a final concentration factor of approximately 1,500.

Another option for technetium stabilization and disposal has been demonstrated in this research effort as part of a complete technetium control flowsheet. First, the Tc/I which has been stripped from ABEC resin with water is loaded onto a commercial silicabased anion exchange resin, NUCLEOSIL. An average Dof $1 \times 10^{4}$ was demonstrated for this process with greater than $99.5 \%$ uptake of technetium and a concentration factor of approximately 70 . Given the extremely high ${ }_{W}$ Dvalue, concentration factors of at least several hundred should be obtainable. Continuing the example given for ABEC resin above, the stated capacity for NUCLEOSIL is $1 \mathrm{mmol} / \mathrm{g}$. Assuming only $50 \%$ loading, $100 \mathrm{~g}(50 \mathrm{~mL})$ of NUCLEOSIL are required to sorb the $50 \mathrm{mmol}$ of technetium contained in 6.5 liters of water strip solution after the ABEC resin separation step. This yields a concentration factor of 130 for the NUCLEOSIL loading step. The combined concentration factor for these two steps is approximately 20,000.

As a final step, the NUCLEOSIL is then encapsulated within a hydrous titanium oxide (HTiO) matrix at a level which yields $40 \%$ NUCLEOSIL by volume after drying. 
The result is a highly stable waste form from which less than $1 \%$ of the encapsulated technetium was leached in either of two different leachability tests. Continuing the examples from above, the original 1000 liters of alkaline supernate can be reduced to approximately 125 milliliters of stable waste for an 8,000-fold reduction of initial waste volume.

Advantages of this new flowsheet are:

- $\quad$ ABEC-resin exhibits high retention of Tc/I and high selectivity for Tc/I over other species in the alkaline supernatant wastes

- $\quad \mathrm{Tc} / \mathrm{I}$ are eluted quickly and efficiently from ABEC-resin with water

- $\quad \mathrm{Tc} / \mathrm{I}$ are sorbed stongly by silica-based anmoexchange resin from the water strip solution

- $\quad$ high concentration factor $(\sim 8000)$ minimizes volume of final immobilized waste form

- $\quad$ final waste form is stable and amenable to disposal without additional treatment or can be further incorporated in a grout matrix

The successes of this development effort are summarized as follows:

- $\quad$ improved, large particle ABEC-resins exhibiting less shrinking and swelling and greater bed densities than earlier versions have been developed

- $\quad$ type of resin support polyethylene glycol (PEG) molecular weight, and synthetic parameters have been optimized to produce the desired ABECresins more economically

- $\quad$ tetrahydrofuran (THF), the original solvent for the PEG addition step, was successfully replaced with a safer solvent

- $\quad$ the improved ABEC-resins exhibit greater than required uptake performance and loading capacity and can be rapidly stripped with water

- $\quad$ successful demonstration of ABEC-resin synthesis at the 110-liter pilot reactor scale

- $\quad$ cost for manufacturing ABEC-resin at the 110-liter scale demonstrated as comparable to other specialty resins

- demonstrated loading of technetium onto commercial silica-based anion exchange resin from simulated strip solutions 
- demonstrated an improved, simplified procedure for encapsulation which greatly minimizes risks of radioactive contamination and worker exposure, and reduces costs of the process

- demonstrated high stability of the encapsulated waste form to leaching

- $\quad$ performed theoretical heating andhielding calculations which indicate the surface dose rate and heating from radioactive decay of the encapsulated, final waste form should be insignificant for all geometries and loading levels examined

Based on observations made during this phase of the effort, recommendations are made for additional studies to be accomplished as part of the next phase of the program. These additional studies can be performed within the scope and budget of the second phase.

The base phase of the program was successflity completed within a 15-month time frame. Details of the research effort are presented in this report. 


\section{Introduction}

Alkaline waste constitutes the largest portion of the HLW tank inventory at both Hanford and ORNL Melton Valley. Nearly 160 million liters of liquid, alkaline waste are currently being held in either single- or double-shelled tanks at the Hanford site. The supernate at Hanford has nitrate and nitrite concentrations ranging from 1 to 4 molar, hydroxide concentrations from 2 to 4 molar, and somewhat lower levels of other salts, such as sulfate and carbonate. The Melton Valley waste, estimated to contain 1.6 million liters of supernate, is similar to Hanford supernate with slightly higher nitrate, higher carbonate, and much lower hydroxide levels. Similar in composition to the Melton Valley waste, the ORNL Bethel Valley evaporator tanks are estimated to contain an additional 0.26 million liters of alkaline supernatant waste.

Fission products (Cs-137, Sr-90, Tc-99 and I-129) are thenajor problem radioisotopes in the alkaline supernate. The most promising technologies being tested to date have been developed for the separation of cesium and strontium. The Sandia/UOP crystalline silica titanates (CST's) have undergone broad testing and have been shown to have the high selectivity required for concentrating the cesium and achieving volume reduction targets. Similarly, a number of other inorganic absorbers, such as the hexacyanoferrates, cobalt dicarbollide, and sodium titanates, and organic absorbers, such as the Savannah River resorcinol-formaldehyde resin, have been shown to be effective in removing cesium and strontium from a number of wastes

Technetium (as $\mathrm{TcQ}^{-}$, pertechnetate) and, to a somewhat lesser extent, iodine (as $\mathrm{I}^{-}$, iodide, or, possibly, IQ-, iodate) separations have relied primarily on anion exchange resins, notably the Reillex ${ }^{\mathrm{TM}}$-HPQ, Reillex 420, and certain Purolite and Amberlite resins. Technetium (and possibly iodine) is absorbed readily by anion exchange resins, but difficulties with elution of activity from the resin, radiolytic stability, and selectivity for pertechnetate over nitrate have been identified by a number of researchers. N. Schroeder at Los Alamos has developed an improved elution method for the most promising anion exchange resin, Reillex ${ }^{\mathrm{TM}}-\mathrm{HPQ}$, which utilizes Shas a reductant and the chelating group, EDTA. This new elution process is a great improvement over the $8 \mathrm{M}$ nitric acid elution that had previously been suggested to remove technetium from anion resins.

Additional improvements in technetium (and iodine) separation, concentration and immobilization are still required. Foremost among these are a high selectivity for technetium over other anions present in the alkaline supernate due to the high nitrate and nitrite concentrations and an effective elution scheme which does not contribute to the waste volume. Elution of technetium from anion resins with the reductant $\$$ rand chelating agent EDTA, for example, will likely require an additional separation step to eliminate $\mathrm{Sn}^{+2}$ and EDTA before the technetium can be placed into a final waste form.

Eichrom Industries, Inc. has a new technetium and iodine selective resin which

meets the above-mentioned requirements. This new resin, developed jointly at Argonne National Laboratory and Northern Illinois University, shows remarkable selectivity for 
technetium and iodine over other constituents present in alkaline supernate. Most importantly, this resin has the unique advantage of being regenerated by eluting the bound technetium and iodine with water. A flowsheet based on this new Tc/I selective resin is presented in Figure 1.

As described above, a number of promising technologies already exist for the separation of cesium and strontium from alkaline supernate and other waste streams. However, significant improvements are still required in the separation processes of technetium and iodine. Our efforts with regard to this research program are concentrated on the separation, concentration and immobilization of technetium and iodine from alkaline supernate. The technologies employed will be shown to be applicable to technetium and iodine problems in a number of other waste streams. Eichrom's Tc/I selective resin works well with highly salted alkaline and neutral solutions.

In designing the flowsheet shown in Figure 1, we have combined the selectivity and the simplicity of the water elution of the Tc/I selective resin with compatible, known technologies to yield a process that delivers a Tc/I encapsulated waste in a form suitable for storage. The preparation of a stable waste for the immobilization of technetium and iodine is based on three separate but closely integrated processes. The first step involves the separation of technetium as pertechnetate and iodine as iodide or iodate from the alkaline supernatant solution contained in high-level waste storage tanks using the new Tc/I selective resin. As mentioned, the unique features of the new resin are its very high retention and selectivity for pertechnetate salts as well as iodide/iodate salts from highly alkaline salt solutions of the type and composition found in HLW storage tanks and that the technetium and iodine can be effectively and completely eluted from the resin with water.

The water elutability property of the new resin is particularly important because it enables one to quantitatively $(>99.9 \%$ ) sorb the pertechnetate and iodide/iodate species onto a small quantity of silica strong-based ion exchange resin. In this second step, a silica strong-based resin in the chloride form is used as a slurry to sorb the Tc/I from the water strip solution. Laboratory studies indicate that a presence of chloride in the strip solution has no effect on the Tc/I selective resin's performance enabling a recycle of the strip solution.

Because both Eichrom's Tc/I selective resin and the silica strong-based resin concentrate the technetium and iodine from the alkaline supernate and water strip solution, respectively, both radioisotopes should be concentrated by a factor of at least one thousand, thus minimizing the volume of the final immobilized waste form.

The third step in the immobilization process is the encapsulation of the silica strong-based anion material containing the technetium and iodine in a titania or zirconia 


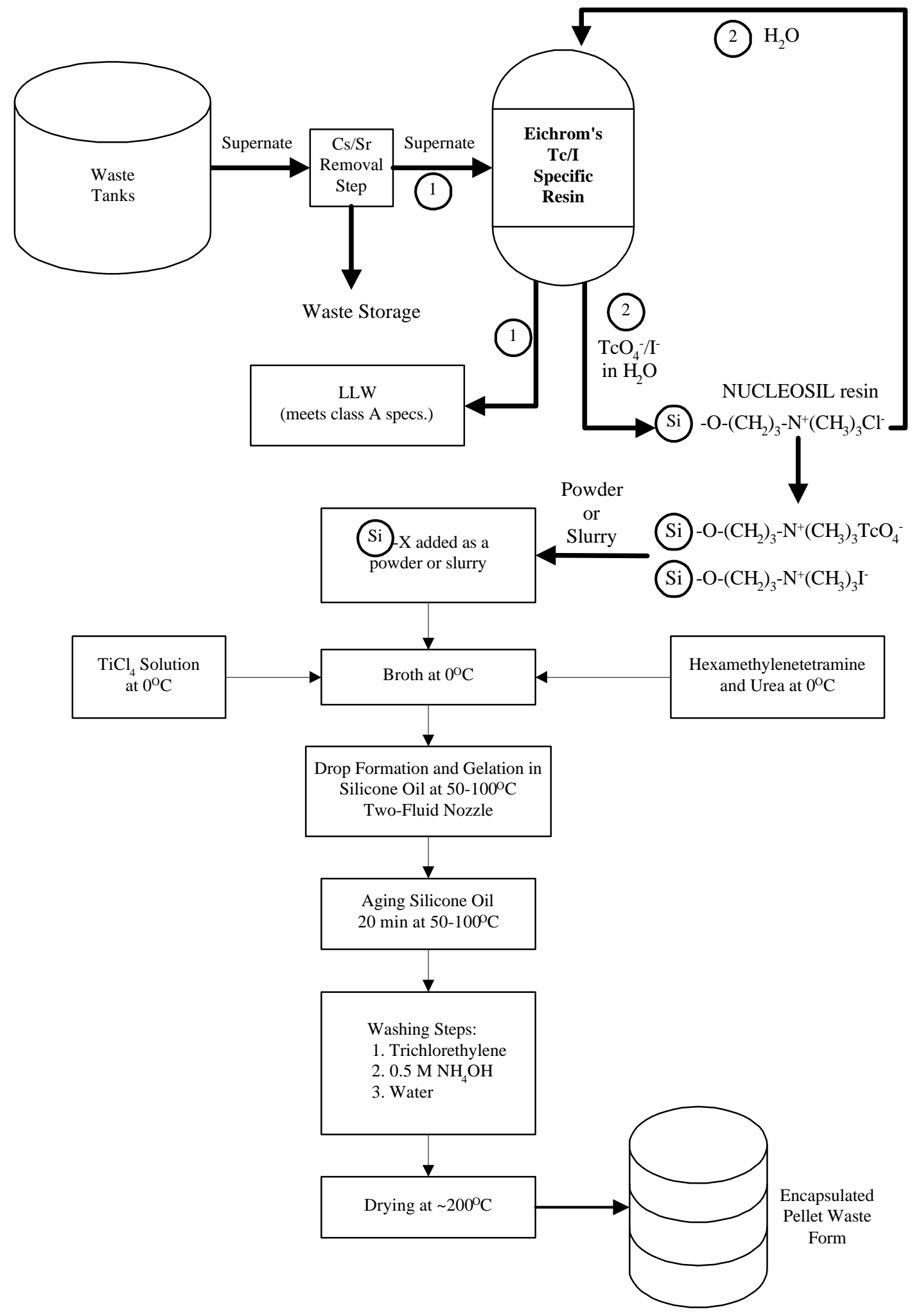

Figure 1. Flowsheet for the separation, concentration and immobilization of Tc/I from alkaline supernate wastes. 
shell. The encapsulation process is an adaptation of the work performed at ORNL by J.L. Collins in the production of composite microspheres by internal gelation. The encapsulated composite microspheres are finally heated to collapse the outer shell of titania or zirconia onto the encapsulated silica strong-based resin containing technetium and iodine. The heating also reduces the porosity of the outer shell making any leaching of technetium or iodine from the inner encapsulated particles unlikely.

Figure 1 assumes that cesium and strontium treatment is done initially by one of the technologies outlined in the prior section. The Savannah River resorcinolformaldehyde resin, the Sandia CST's, the titanates, and several other inorganic absorbers are all being tested and show promise as cesium and strontium removal technologies. The removal of cesium and strontium in an initial alkaline supernate treatment module has the obvious economic advantage of minimizing shielding requirements in subsequent technetium and iodine waste treatment systems. The Tc/I selective resin will also work in a stand-alone flowsheet. The presence of cesium and strontium have no effect on the separation of technetium and iodine by the resin.

\section{The Technology Supporting the Flowsheet}

\section{Loading and Elution of Tc/I Selective Resin.}

The new Tc/I selective resin development was based upon the observed chemistry of polyethylene glycol (PEG) based aqueous biphasic systems (ABS). ABS consist of two immiscible phases formed when certain water soluble polymers (i.e., PEG's) are combined with certain inorganic salts in specific concentrations. In $\mathrm{ABS}$, the major component of each of the two phases is water. It has been observed by R. D. Rogers and co-workers at Northern Illinois UniversityAqueous Biphasic Separations: Biomolecules to Metal Ions edited by R. D. Rogers and M. A. Eiteman, Plenum Press, New York, 1995, "Metal Ion Separations in Polyethylene Glycol-Based Aqueous Biphasic Systems") that a PEG-based ABS would have great potential as a viable metal separations technique. In particular, technetium, as pertechnetate, is observed to partition to the PEG-rich phase. In evaluating this process as a potential separation technique, it is important to note that PEG-ABS are virtually nontoxic and nonflammable. PEG is classified as a GRAS (generally recognized as safe) compound by the Food \& Drug Administration.

There are, however, two major drawbacks to aqueous biphasic separations operating in a liquid-liquid mode. These are the loss of phase forming components, PEG and salt, due to their high solubility in water and the difficulty in stripping partitioned solutes. These two drawbacks are eliminated when the PEG is attached to a polymeric support. Rogers and co-workers have found that PEG's of molecular weight between 2,000 and 5,000 could be attached to polystyrene particles and that the resultant materials would exhibit separation behavior of a magnitude similar to that observed for the liquidliquid system. Figure 2 shows weight distribution ratios $(\mathrm{D})$ for technetium versus molality of several salts. The Tc/I selective resin designated as ABEC-5000, aqueous biphasic extraction chromatographic material with PEG of molecular weight 5000, was 
made by the nucleophilic replacement of chloride on a chloromethylated polystyrene bead by a PEG-anion.

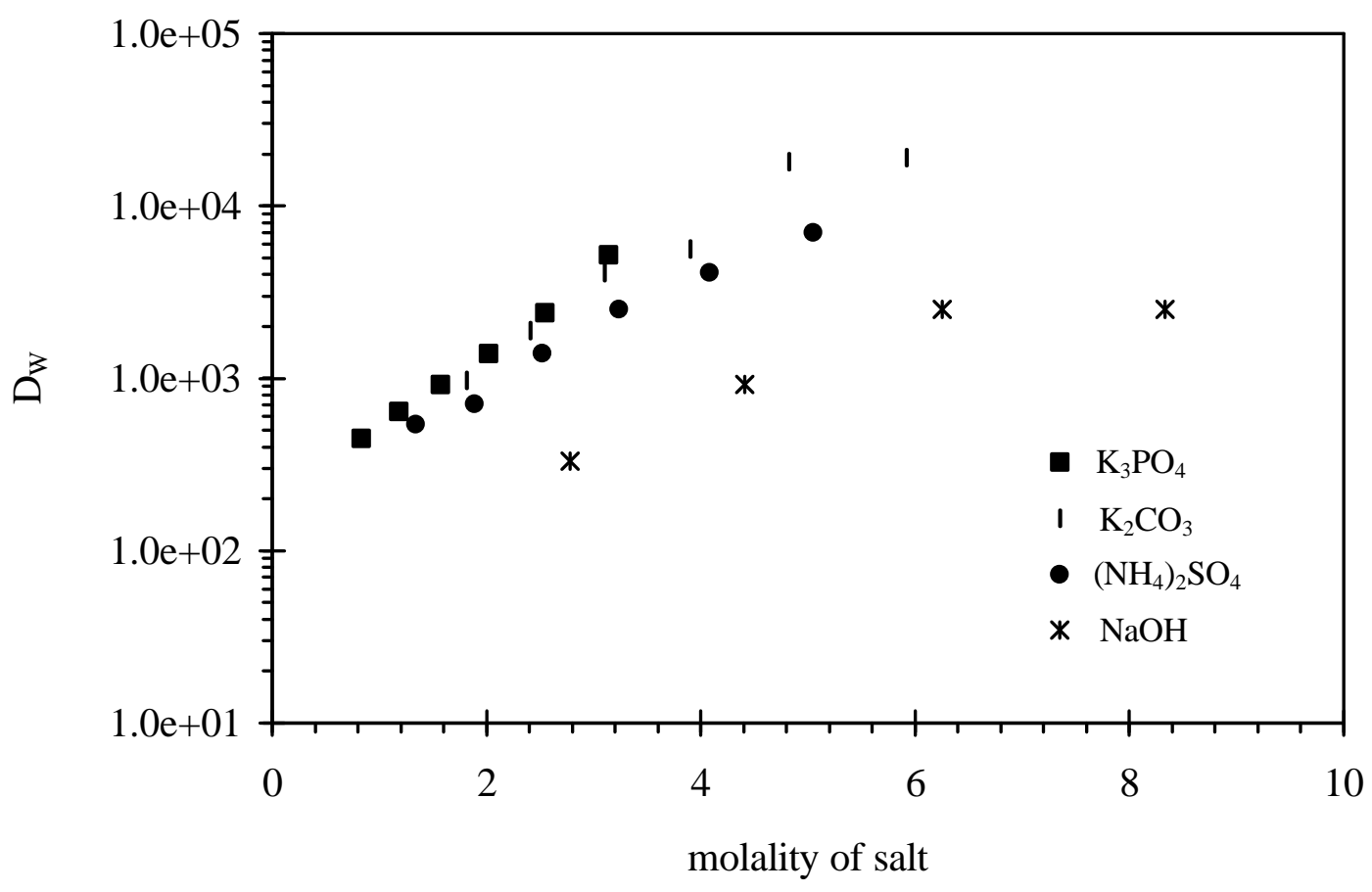

Figure 2. $\mathrm{D}_{\mathrm{w}}$ for $\mathrm{TcO}_{4}{ }^{-}$vs. molality of salt with $\mathrm{Tc} / \mathrm{I}$ selective resin (ABEC-5000).

Biphase-formation is believed to be a function of the water-structure-making or lyotropic property of an anion. An anion with a Gibbs free energy of hydrationg( $($ hyd $)$ of less than $-300 \mathrm{~kJ} / \mathrm{mole}$ will cause biphasic behavior and other anions, such as pertechnetate and iodide or iodate, will be "salted-out" to the PEG-rich phase.

A selected list of biphase-forming anions is shown below:

$\begin{array}{lll}\text { hydroxide } & \text { fluoride } & \text { carbonate } \\ \text { sulfate } & \text { phosphate } & \text { silicate } \\ \text { citrate } & \text { molybdate } & \text { thiosulfate } \\ \text { formate } & & \end{array}$

An examination of Figure 2 and the list of biphase-forming anions given above shows that the Tc/I selective resin is ideally suited for removing technetium and iodine from HLW tank supernate. Figure 3 shows the D's for $\mathrm{TcO}_{4}{ }^{-}$from three simulated Hanford tank wastes: NCAW, SST, and SY-101. The designations ABEC-5000, ABEC2000 , etc. refer to the molecular weight of the PEG attached to the polystyrene support. Comparable behavior is observed for both resins based on both the 2,000 and 5,000 molecular weight PEG's. 


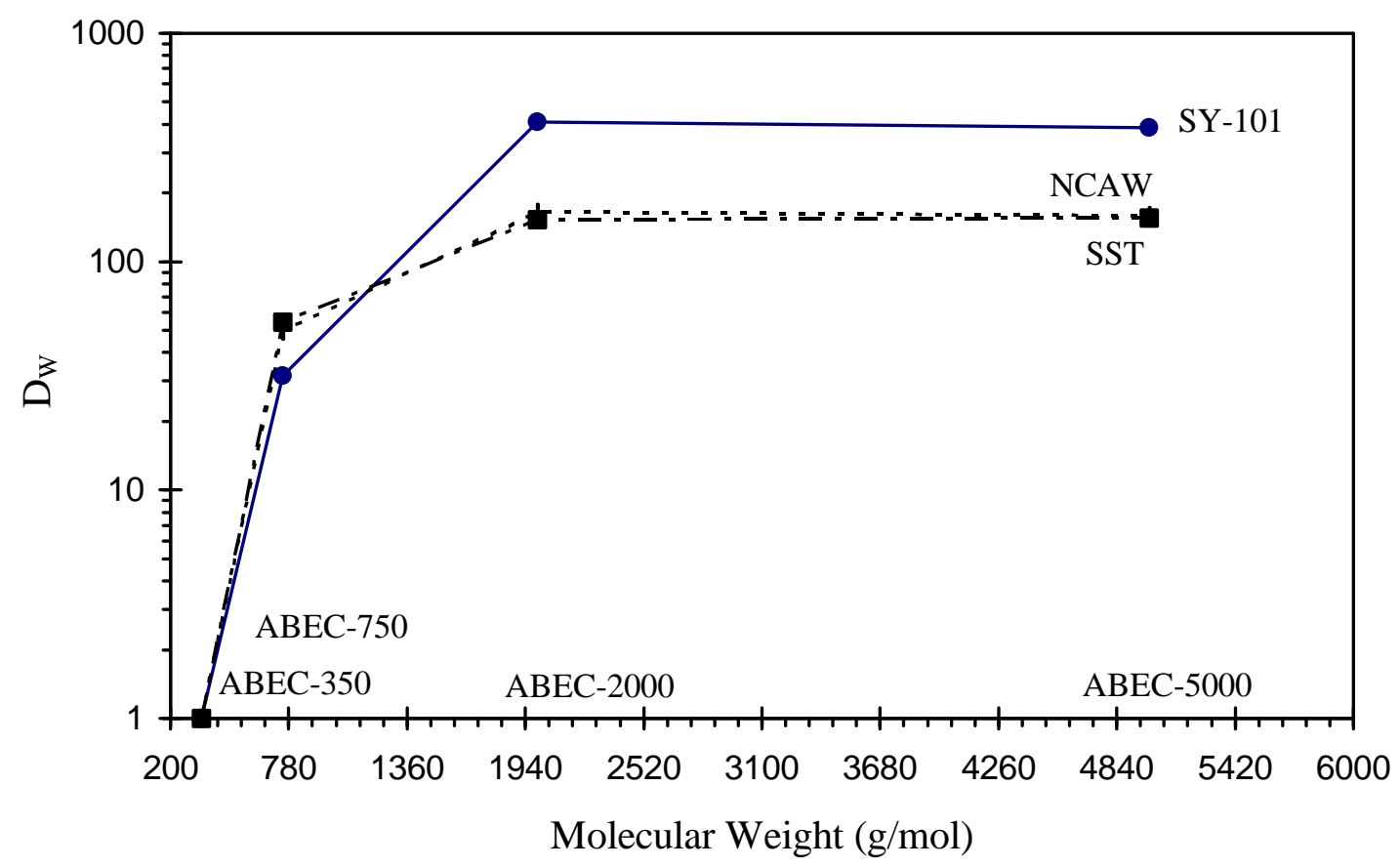

Figure 3. $\mathrm{D}_{\mathrm{W}}$ for $\mathrm{TcO}_{4}{ }^{-}$from three Hanford HLW tank simulants vs. MW of PEG on Tc/I selective resin (e.g., ABEC-500@ PEG-5000 on polystyrene).

The results, illustrated in Figure 3, with Hanford tank simulants have been confirmed in a preliminary, unpublished report by J. L. Collins at ORNL with actual waste samples from the ORNL Melton Valley Storage Tank W-29 supernate. In Collins' work, the supernate is first treated with resorcinol-formaldehyde resin (Savannah River technology) and potassium cobalt hexacyanoferrate (KCoCF) to remove all cesium and strontium activity. Ammonium pertechnetate is added to the treated samples to achieve a technetium concentration of $4.0 \mathrm{mg} / \mathrm{L}$. The adjusted technetium concentration in these studies corresponds to an average technetium concentration in several Hanford tanks. In these small-scale batch studies, technetium distribution ratios ranged from $240 \mathrm{~mL} / \mathrm{g}$ at 0.25 hours to $930 \mathrm{~mL} / \mathrm{g}$ at 72 hours. These values were slightly higher than the values obtained for the anion exchange resins included in Collins' studies. Elution studies at ORNL have not yet been completed, but preliminary results confirm our observations that the $\mathrm{Tc} / \mathrm{I}$ selective resin strips efficiently and completely with water.

The Collins' ORNL results with the Tc/I selective resirra particularly interesting when one considers the hydroxide concentration of the Melton Valley tanks, $0.3 \mathrm{M}$, versus the hydroxide concentration in the Hanford tanks, 2-4 M. Figure 2 shows increasing distribution ratios with increasing hydroxide concentration and it can be expected that the performance of the Tc/I resin will only improve with actual Hanford waste. 
Additional studies with the Tc/I selective resin have been performed at ORNL by A. Meeks and reported on at the Thirty-Sixth ORNL/DOE Conference on Analytical Chemistry in Energy Technology, Gatlinburg, TN, October 1995, "Isolation and Determination of I-129 in Waste Tank Samples Using Extraction Chromatography". In this report, there is a discussion of the development of an analytical method for iodide and iodate. Meeks examined both synthetic salt solutions and actual waste in her studies. A sample designated as Melton Valley W-3 supernate, comprised of interstitial liquid from a W-3 waste tank sludge sample and the liquid on top of the sludge in tank W-3, that was spiked with I-131 was used as a sample matrix. A 1-mL column of Eichrom's Tc/I selective resin was loaded with $1 \mathrm{~mL}$ of spiked supernate, rinsed with $10 \mathrm{~mL}$ of $3.5 \mathrm{M}$ $\mathrm{K}_{2} \mathrm{CO}_{3}$, and eluted with deionized (DI) water to generate the chart shown in Figure 4. Recovery of the spike in the elution stream was $>98 \%$ for each sample tested. In a separate experiment with synthetic solutions, $96 \%$ of an I-129 spike was recovered in 5 free column volumes (fcv) during elution with water.

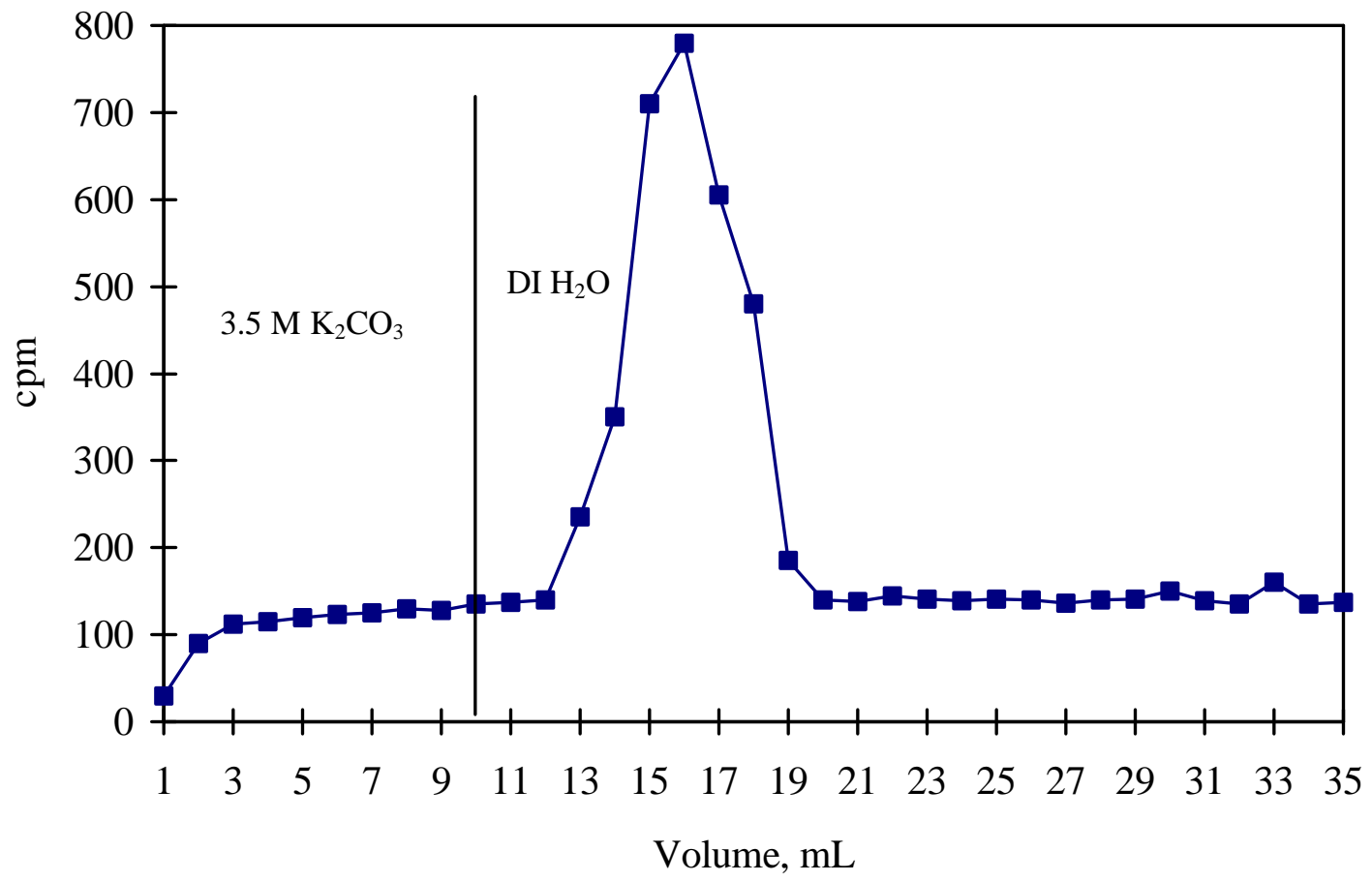

Figure 4. I-131 rinse and elution curve. Melton Valley W-3 tank supernate sample on $\mathrm{Tc} / \mathrm{I}$ selective resin.

In an experiment similar to the I-131 study referenced above, a separation of Tc$99 \mathrm{~m}$ from its parent ion Mo-99 is shown in Figure 5. During the resin loading phase of the experiment, the activity due to Mo-99, which does not load on the resin and reports to the eluent, is plotted on the graph. Mo-99 activity in the column eluent drops rapidly 


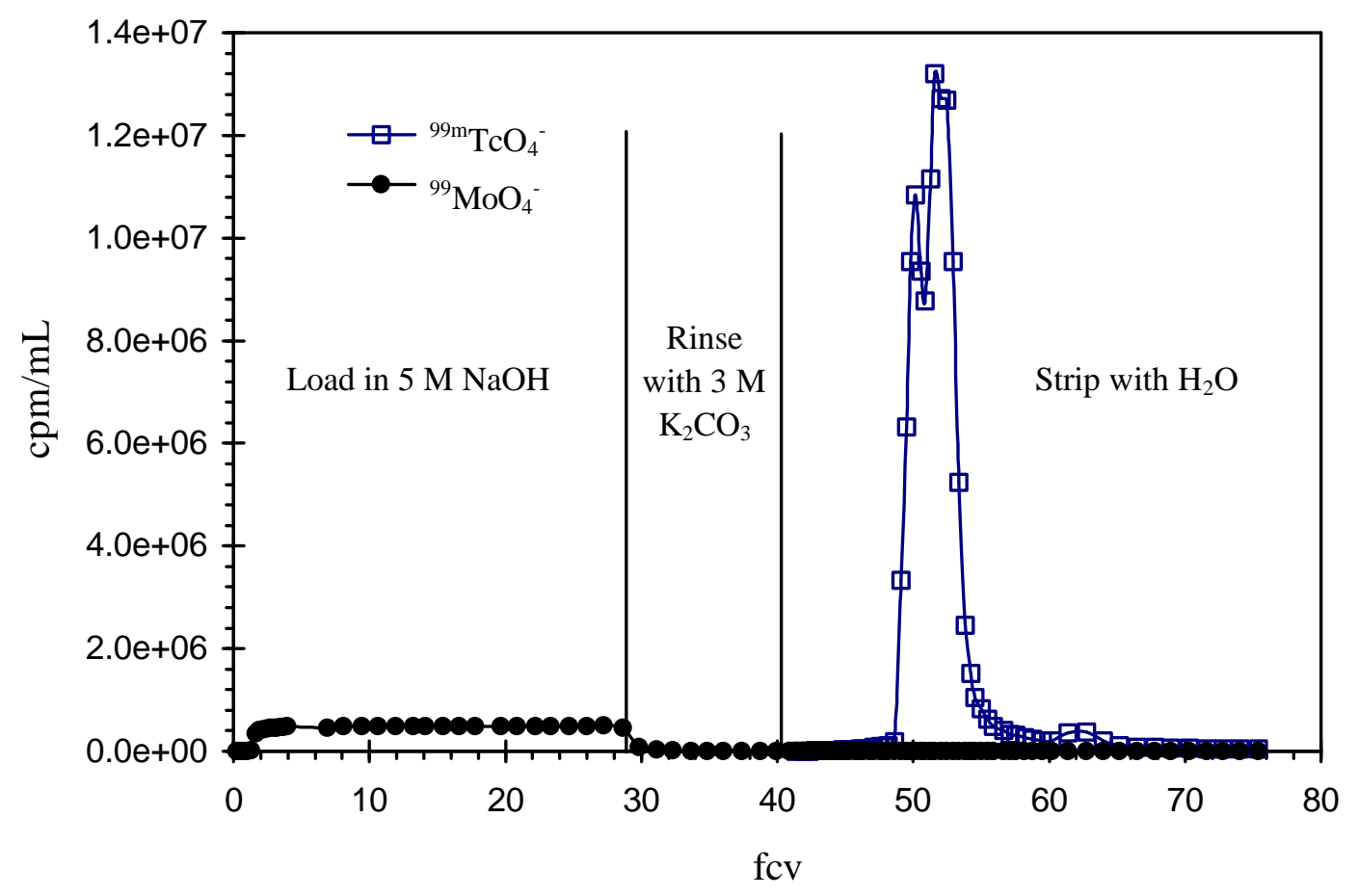

Figure 5. Elution curve for Mo-99, loading Tc-99m. Rinse and elution of Tc-99m from Tc/I selective resin, ABEC-5000.

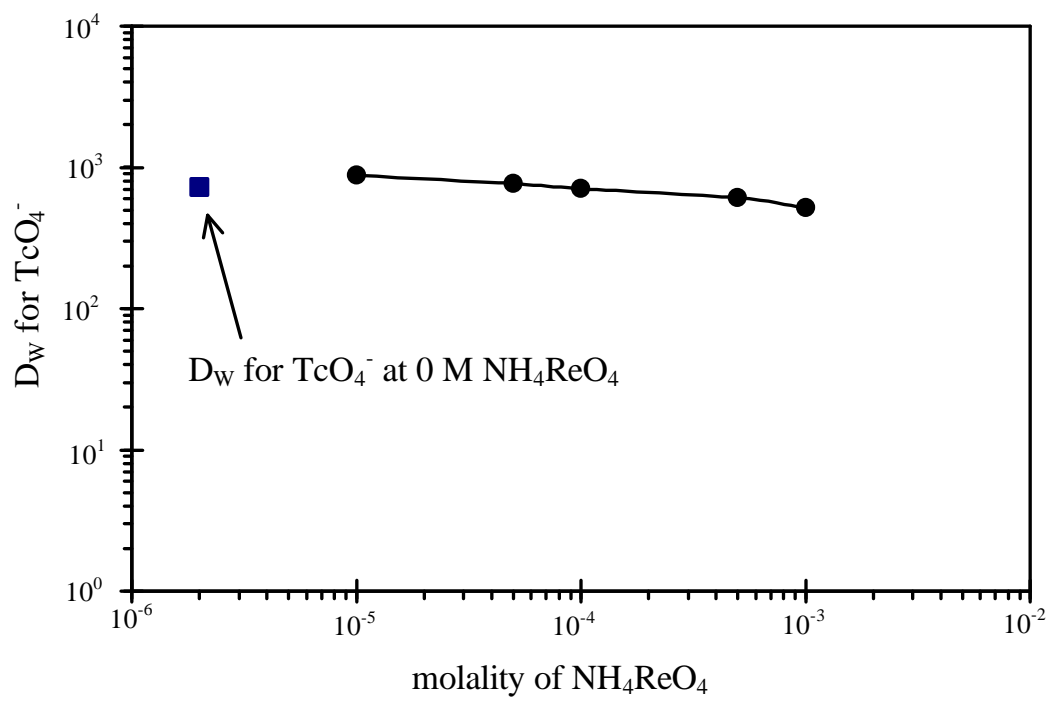

Figure 6. Effect of increasing perrhenate concentration on technetium distribution ratio from $2 \mathrm{M}\left(\mathrm{NH}_{4}\right)_{2} \mathrm{SO}_{4}$ solution on Tc/I selective resin. 
during the carbonate rinse with no observation of Tc-99m breakthrough. The data in Figure 5 again confirm the efficient and complete water elution of activity from the Tc/I selective resin.

\section{Capacity and Concentration Factor of the Tc/I Selective Resin.}

An estimate of the Tc/I selective resin's caceity for iodide of $0.05 \mathrm{mmol} \mathrm{I} / \mathrm{g}$ dry resin was obtained from the A. Meeks' ORNL analytical work referenced above. Loading studies for technetium were performed as part of this research effort. Using perrhenate $\left(\mathrm{ReO}_{4}{ }^{-}\right)$as a cold surrogate for pertechnetate, the effect of increasing perrhenate concentration on distribution ratio for technetium has been determined. The results of this study are shown in Figure 6. Both Figure 6 and the results of the ORNL study indicate that the Tc/I selective resin meets the capacity requirements expected of a commercial separation resin.

The estimated capacity and the efficient and complete water elution of the Tc/I selective resin have been referred to in the previous discussion and charts. These two properties provide a basis for estimating the concentration factor that can be achieved in the first step of the flowsheet shown in Figure 1. We expect an overall concentration factor for Tc/I activity of between 50 and 100 during the resin load and water elution steps.

\section{Sorbing Tc/I onto a Silica Strong-Based Resin.}

The pertechnetate and iodide/iodate species will sorb strongly onto a small quantity of silica strong-based ion exchange resin. The chemistry of the second step of the flowsheet is the well understood exchange of a more strongly bound anion, pertechnetate or iodide/iodate, for another weaker bound anion, chloride $(\mathrm{Cl})$. Exchange of technetium and iodide/iodate for chloride on a strong base anion resin exhibits distribution ratios that increase linearly with increasing $\mathrm{pH}$. Distribution ratios $\$ 510^{4}$ are anticipated, and quantitative pick-up of the technetium and iodine on the silica strong-based resin will be achieved. Use of Eichrom's Tc/I selective resin in the prior separation and concentration step ensures that matrix constituents, e.g., nitrates and nitrates, which otherwise compete for loading on anion resins, will not interfere with technetium and iodine sorption. The flowsheet shown in Figure 1 lists a silica-based strong anion resin named NUCLEOSIL. This particular modified silica gel, particle sizqum, is available commercially and produced in Germany by Macherey-Nagel.. The general form of the resin is $\mathrm{Si}-\mathrm{O}-\left(\mathrm{C}_{3} \mathrm{H}\right.$ $\mathrm{N}^{+}\left(\mathrm{CH}_{3}\right)_{3} \mathrm{Cl}^{-}$. A silica gel based resin was chosen for the flowsheet to address the obvious radiolytic stability concerns.

The capacity of the NUCLEOSIL resin is listed as ca. $1 \mathrm{mmol} / \mathrm{g}$. The prior separation step of loading Tc/I selectively on the resin and eluting with water ensures an additional concentration of activity onto the silica strong-based resin. The combined concentration of Tc/I activity on the first two steps of the flowsheet should be increased by at least a factor of 1,000 . 
A determination of the concentration factor achievable at each of the three steps in the proposed separation, concentration and immobilization flowsheet described in Figure 1 is a task of this project. All of the available data indicate that a significant reduction in waste volume will be achievable, and this will be confirmed in the bench-scale and pilot testing programs as a requirement for an engineering scale-up of the flowsheet.

\section{Encapsulation of the Silica Strong-Based Anion Material Containing Tc/I in a Titania or Zirconia Shell}

In the report No. ORNL/TM-12315 entitled "Development and Testing of Ion Exchangers for Treatment of Liquid Wastes at Oak Ridge National Laboratory" J.L. Collins describes a procedure of encapsulation of inorganic particles that will be included as the final step of Tc/I waste immobilization in the flowsheet described in Figure 1.

In Collins' work, a broth is prepared by addition of silica particles with sorbed technetium and iodine together with hexamethylenetetraamine and either a $\mathrm{Ti}$ Gil $\mathrm{ZrCl}_{4}$ solution. The temperature of the broth is maintained at $0^{\circ} \mathrm{C}$. The fine silica particles, NUCLEOSIL, are available as either 5 or $1 \mu \mathrm{m}$ particles, and precipitated titania or zirconia gels are kept homogeneously suspended using an agitator. Air pressure is used to transfer the suspension out of the container through the end of a flat-tipped 20 gauge needle. Droplets of the suspension are introduced into and sheared by a perpendicular flow of hot silicone oil flowing past the needle tip. To control drop formation, the needle is positioned near the center of the tube. The size of the microsphere is controlled by adjusting the flow through the tube and the air pressure provided as the driving force for expulsion of the suspension broth. Droplets of the aqueous broth begin to gel and entrap the suspended silica particles within seconds of contacting the hot silicone oil. After an aging process, the formed microspheres are filtered from the silicone oil. The silicone oil is recycled. The filtered microspheres are washed to remove traces of silicone oil and urea, and are then dried at $200^{\circ} \mathrm{C}$. The final drying step collapses the outer shell of titania or zirconia onto the silica strong-based resin containing the sorbed technetium and iodine. The reduced porosity of the outer shell makes any leaching of the inner encapsulated particles unlikely.

This approach for preparing a final waste form is not limited to titania or zirconia. Other inorganic coatings, such as zirconium phosphate, are also feasible with the internal gelation technique and may prove to be suitable as encapsulation materials. The basic concept of protecting the primary location of technetium and iodine sorbed on silica particles is the same.

An important part of this research effort will be the evaluation of the stability of the encapsulated silica as a waste form for technetium and iodine to leaching by simulated groundwater and brine solution and the effect of prolonged radiolysis on the particles. Because the final waste form should contain fairly high levels of technetium and iodine 
loading, the detection of a breakdown in the integrity of the encapsulated particles should be relatively simple.

\section{Concentration Factor and Final Waste Volume Estimation}

Earlier it was stated that a concentration factor of at least 1000 is expected from the loading and elution of Tc/I on the resin and from the sorbing of technetium and iodine from the water strip solution onto the silica strong-based resin. The encapsulation step allows a final dilution control of the final waste form. The internal gelation work by J.L. Collins referred to above cites examples of substrate encapsulation such that the weight percent of substrate is between 6 and $32 \%$ in hydrous titanium oxide microspheres.

As an example, consider the treatment of 1,000 liters of alkalisupernate containing $5 \times 10^{5} \mathrm{M}$ technetium and $5 \times 10^{5} \mathrm{M}$ iodine ( $\mathrm{I}$ and $\left.\mathrm{IO}_{3}{ }^{-}\right)$. This solution is loaded onto a Tc/I selective resin column, 20 liters in bed volume. After loading, the column is rinsed with 2 bed volumes of $\mathrm{NGO}_{3}$ and stripped with 50 liters $(5 \mathrm{fcv}$ ) of water. (The A. Meeks work referenced on page 7 indicated a $96 \%$ recovery of activity in $5 \mathrm{fcv}$.) The resulting concentration of technetium and iodine in the strip solution will be $1.0 \times 10^{-3} \mathrm{M}$, or a 20 -fold concentration increase.

The stated capacity of NUCLEOSIL resin, the silica strong-based resin, is $1 \mathrm{mmol} / \mathrm{g}$. If the NUCLEOSIL resin is loaded to stated capacity, 50 grams of resin are required to sorb the technetium and iodine. As a conservative estimate, we assume only a $50 \%$ loading of the NUCLEOSIL and specify 100 grams of resin to load the technetium and iodine. Assuming a density similar to silica gel of $2.0 \mathrm{~g} / \mathrm{c}$, rthe volume of resin with sorbed technetium and iodine will be approximately $50 \mathrm{~cm}$

Using these assumptions, the orignal 1,000 liters of alkaline supernate can be reduced to $50 \mathrm{~cm}^{3}$ of technetium and iodine loaded silica resin, for a reduction factor of 20,000. If one then assumes that an encapsulation of the silica strong-based resin with sorbed technetium and iodine at a level of $10 \%$ in titania or zirconia microspheres will provide a stable final waste form, one can estimate that a 2,000-fold reduction from the initial waste volume can be achieved.

\section{Objectives}

The objective of this work is to synthesize an improved version of the Tc/I selective resin that resolves the performance issues of the original resin known as ABEC-5000. The overall objective is broken into specific items as described below:

The first task is designed to optimize the chemical reactions used to produce the Tc/I selective resin, perform a preliminary cost evaluation, and perform the initial scale-up synthesis of the resin. The specific subtasks are: 
(1) study alternative substrates,

(2) optimize the reaction time of the PEG additiostep,

(3) study alternative molecular weight PEG materials,

(4) study alternatives to using sodium hydride as catalyst in the PEG addition step,

(5) perform scale-up to the 110-liter reactor, and

(6) perform cost evaluation.

The second task is designed to test the newly prepared resin and demonstrate the second and third steps of the flowsheet. These tests involve:

(1) determining the batch uptake properties and column load/strip behavior of technetium/iodine on the resin,

(2) load technetium/iodine from simulated strip solutions onto commercial silicabased anion exchange resins,

(3) encapsulate the technetium/iodine loaded silica-based anion exchange resin by internal gelation, and

(4) perform stability studies on the encapsulated waste form.

\section{Experimental - Laboratory Scale Synthesis}

The general synthetic scheme for ABEC resins consisted of two distinct parts: (1) the suspension copolymerization of styrene, vinylbenzyl chloride (VBC), and divinylbenzene (DVB) monomers using benzoyl peroxide (BPO) as the initiator to give the substrate (the support to which the functional groups are attached), and (2) the attachment of polyethylene glycol monomethyl ether (PEG) to this copolymer substrate via nucleophilic substitiution to yield ABEC resin (Figure 7). The syntheses are discussed in detail in the following sections.

Copolymer Substrate Synthesis: The substrates to which the PEG units were attached during Step 2 of the ABEC resin synthesis were prepared by suspension copolymerization. In this technique there is an aqueous phase (continuous phase), consisting of various stabilizers dispersed in water, and an organic phase (discontinuous phase), consisting of the monomers and a monomer-soluble initiator. During copolymerization the organic phase is suspended in the aqueous phase as droplets of monomer/initiator solution. The suspension is maintained by mechanical agitation and by the presence of the stabilizers, which coat the surface of the monomer droplets and help prevent their agglomeration. 
Styrene, VBC, DVB, BPO

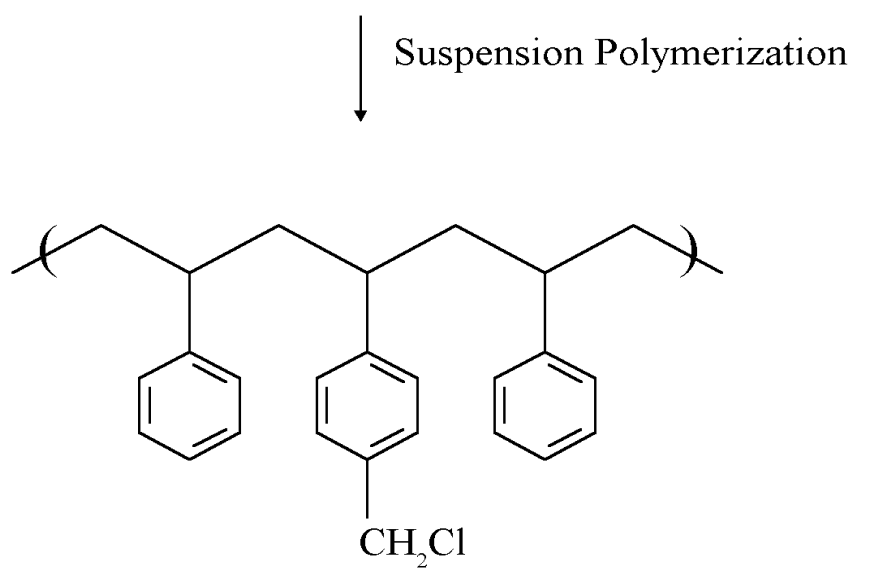

$\downarrow \begin{aligned} & \mathrm{CH}_{3}-(\mathrm{PEG}-2000)-\mathrm{OH}, \mathrm{NaH} \\ & \text { Solvent: Diglyme }\end{aligned}$<smiles>CCCC(CC(CC(CC(C)(C)C)c1ccccc1)c1ccccc1)c1ccccc1</smiles>

VBC: VinylbenzylChloride

DVB: Divinyl Benzene

BPO: Benzoyl Peroxide

PEG: Polyethylene Glycol

Figure 7. Synthetic route to make ABEC resins. 
One of the objectives of this research was to investigate the influence certain copolymer substrate properties had on the physical properties and uptake performance of ABEC resins. These substrate properties included degree of cross-linking, copolymer bead porosity (i.e., gel-type, or microporous, beads vs. xero gel-type beads, a form of macroporous bead), and number of potential sites for attachment of PEG, as determined by the percentage of VBC units in the copolymer substrate. A second objective of this research effort involved the optimization of certain synthetic variables, or parameters, during the functionalization of the substrate with PEG (Step 2 in Figure 7). The parameters investigated included type of solvent; optimum ratio of solvent, $\mathrm{PEG}$, and $\mathrm{NaH}$ to substrate; solvent quantity; reaction temperature; and reaction time.

Two slightly different methods of copolymerization were used for the laboratory scale synthesis of all substrates. The primary differences between the two methods were in the reactor size $(500-\mathrm{mL}$ or $2-\mathrm{L})$, total quantity of organic phase (100 g or $716 \mathrm{~g}$ ), and the aqueous phase composition. During the course of this project, the decision was made to change the composition of the aqueous phase used initially to one which was already in use for larger scale copolymerizations by the potential toll processor to scale up the synthesis in larger scale 1000-gallon reactors. By using an aqueous phase already proven in large scale reactions for the copolymerization of styrene and DVB, it was hoped that the transition from laboratory scale synthesis to production scale synthesis would be made more easily. It should be noted that the change in aqueous phase composition did not have any significant impact on the chemical composition of the copolymer beads nor on the reaction character of the copolymer beads during the subsequent functionalization step.

The details of the two different copolymerization methodare discussed below. As it turns out, all of the copolymers used in the substrate studies were prepared using the initial aqueous phase (Method A), while all of the coploymers used during the functionalization parameter optimization studies were prepared using the aqueous phase formula supplied by the potential toll processor (Method B).

Copolymerization Method A The copolymerizations were carried out in a 500$\mathrm{mL}$ round bottom flask equipped with a teflon stir blade, condenser and thermometer. The organic phase consisted of VBC, styrene, DVB, diluent (for xero gel-type copolymer only), and BPO as initiator. The total quantity of organic phase was 100 grams, and the percentage of each component is described in the results and discussion section. The aqueous phase was prepared by dissolving $0.5 \mathrm{~g}$ of polyvinyl alcohol (PVA) in $100 \mathrm{~mL}$ of water by gentle stirring and heating until the PVA was completely dissolved. Then, $20 \mathrm{~g}$ $\mathrm{CaCl}_{2} \cdot 2 \mathrm{H}_{2} \mathrm{O}$ and $1.0 \mathrm{~g}$ calcium phosphate, tribasic $\left(\mathrm{Ca}(\mathrm{OH})_{2}\left(\mathrm{PO}_{4}\right)_{6}\right)$ were added to the mixture with stirring followed by heating the aqueous phase to 50 . The stir blade was positioned at the aqueous/organic interface, and the stir speed was adjusted to a value designed to give beads of the desired size. The organic phase was then slowly poured into the round bottom flask, and the formation of a suspension was verified by observing the stirring mixture in a flashlight beam. The appearance of sparkling particles in the flashlight beam indicated that organic droplets had been suspended in the aqueous layer. The 
mixture was slowly heated from $50 \mathrm{C}$ to $80^{\circ} \mathrm{C}\left(5^{\circ} \mathrm{C} / 30\right.$ minutes) to initiate the polymerization within the suspended droplets, and the temperature was maintained af 80 for 15 hours. After the polymerization was completed and cooled to room temperature, the product was washed once with 10\% solution of isopropyl alcohol (IPA) in water and twice with deionized (DI) water. If the organic phase contained diluent (as when xero geltype copolymers were prepared), the diluent was removed by azeotropic distillation with methanol before the washing procedures. The resin beads of the desired size fraction were isolated by wet sieving the beads through U.S. Standard screens. After evaporation of water in a hood overnight, the beads were dried in a $\mathbb{C C}^{\circ}$ oven for at least 2 hours before being used for ABEC synthesis. All of the copolymers used for the substrate studies were prepared by this method.

Copolymerization Method B The copolymer beads were synthesized in a 2-liter, three-neck, cylinder-type flask equipped with a metal, double-paddle stir shaft, condenser, and thermometer. The organic phase consisted of $71.60 \mathrm{~g} \mathrm{(10 \% )} \mathrm{VBC,} 616.20 \mathrm{~g}$ styrene, $26.03 \mathrm{~g}(2 \%)$ DVB (technical grade containing 55\% DVB), and $2.15 \mathrm{~g}(0.3 \%) \mathrm{BPO}$. The total quantity of organic phase was $716 \mathrm{~g}$. When a higher level of VBC (such as $15 \%$ and $20 \%$ ) was required in the formula, some styrene was replaced by an equivalent mass of $\mathrm{VBC}$ to maintain a total of $716 \mathrm{~g}$ of organic phase. The formula of the aqueous phase was provided by the potential toll processor to scale up the synthesis in larger scale 1000gallon reactors. The aqueous phase was prepared by dissolving $2.25 g$ gelatin in $735 \mathrm{~mL}$ DI water by heating the solution to $30 \mathrm{C}$ for 30 minutes followed by adding $7.03 \mathrm{~g} \mathrm{NaCl}$, $4.71 \mathrm{~g} \mathrm{Na}_{2} \mathrm{HPO}_{4}, 0.98 \mathrm{~g} \mathrm{Na}_{3} \mathrm{PO}_{4}, 7.03 \mathrm{~g} \mathrm{SA} / \mathrm{RE}$ (a polyacrylate solution provided by the potential toll processor), and $0.55 \mathrm{~mL}$ of $25 \% \mathrm{NaOH}$. The $\mathrm{pH}$ of the final aqueous phase was above 10 . Both the aqueous and organic phases were gently purged with nitrogen for about 3 minutes to remove dissolved oxygen which, because of the small amount of initiator used, could terminate the free radical copolymerization. The organic phase was added to the flask, and the stirring shaft blade positioned at the interface of the two layers. The stir speed was adjusted to a value designed to give beads of the desired size. The formation of a suspension was verified by observing the stirring mixture in a flashlight beam. The appearance of sparkling particles in the flashlight beam indicated that organic droplets had been suspended in the aqueous layer. The reaction mixture was heated from room temperature to $6{ }^{\circ} \mathrm{C}$ over a 2 hour time ramp and held at $6{ }^{\circ} \mathrm{C}$ for 6 hours. The temperature was then raised to $7{ }^{2} \mathrm{C}$ over a one hour time ramp and held at $74^{\circ} \mathrm{C}$ for another 6 hours. To ensure complete polymerization, the polymer was heated at $93^{\circ} \mathrm{C}$ for 3 hours. After cooling to room temperature, the copolymer was washed once with a dilute solution of $\mathrm{HCl}(\mathrm{pH} 3$ to 4), once with $10 \% \mathrm{IP}(\mathrm{A})$ and twice with DI water. The desired bead size fraction was isolated by wet sieving the beads through U.S. Standard screens. After evaporation of water in a hood overnight, the beads were dried in a $60^{\circ} \mathrm{C}$ oven for at least 2 hours before being used for ABEC synthesis. All of the copolymers used for parameter optimization studies were prepared by this method.

ABEC Synthesis: The ABEC resin was prepared in a three-neck, 500-mL round bottom flask equipped with a mechanical stir shaft, condenser (capped with a drying tube through the end of reaction), and thermometer. All of the glassware was oven dried to remove all 
traces of moisture. The copolymer was preswelled in the solvent with stirring for 15 minutes at room temperature. The PEG was then added to the system, followed by a preheat treatment at $50^{\circ} \mathrm{C}$ for 1 hour to aid dissolution of PEG and to allow some penetration of PEG into the copolymer beads. After cooling to $3 \mathbb{C}$, the sodium hydride $(\mathrm{NaH}, 60 \%$ in mineral spirit) was slowly added over a period of approximately 1 hour. The mixture was heated at $70 \mathrm{C}$ for 17 hours, followed by quenching any unreacted $\mathrm{NaH}$ with IPA at room temperature. The functionalized ABEC resin was washed twice with IPA and DI water and finally conditioned with 6 bed volumes (BV) of DI water in a column.

Synthesis of ABEC Resins Using PEG-2000 vs. Peg-5000 ABEC resins containing 2\% crosslinking agent were prepared using both PEG-2000 and PEG-5000 for parallel comparison of synthetic yield and technetium uptake performance.

Synthetic Parameter Optimization ABEC resins prepared by altering various synthetic parameters were evaluated for synthetic yield and uptake performance. In this way the most economical synthetic route for producing ABEC resin having desirable performance characterisitics was determined. The parameters investigated included type of solvent; optimum ratio of solvent, $\mathrm{PEG}$, and $\mathrm{NaH}$ to copolymer; solvent quantity; reaction temperature; reaction time; and percentage of $\mathrm{VBC}$ in the copolymer.

Replacement of Sodium Hydride with Sodium Methoxide Due to the evolution of hydrogen and any potential hazards in the use of sodium hydride, several attempts were made to replace sodium hydride with sodium methoxide as the base in the PEG addition step. To avoid competition between PEG alkoxide and methoxide during this step, a solution of PEG in either toluene or diglyme was pretreated with a 1:1 molar ratio of sodium methoxide. To drive the reaction to completion, the side product methanol was removed by rotary evaporation as the reaction progressed. When no more methanol could be removed, the contents of the flask were added to a reaction vessel containing copolymer suspended in diglyme and the reaction completed as usual.

Evaluation of Resin Properties and Performance Four criteria that are key to the successful implementation oABEC resins for the removal of technetiumand iodine from the DOE's alkaline radioactive wastes are(:1) uptake performance (2) capacity, (3) expansion ofresin bed during stripping and (4) resin density The first two criteria relate to the separation performance of ABEC resins and the last twore importantengineering considerations.

The uptake performance of ABEC resins was evaluated by determining technetium $\mathrm{D}_{\mathrm{W}}$ profiles from $\mathrm{NaOH}$ solution. Volume distribution ratios (D) were also calculated because these may more accurately predict column performance than ${ }_{N} \mathrm{D}$ alues.

Experiments to measure the capacity of ABEC resins for technetium are more complicated due to the quantity of radioactive material being handled and were performed only for selected resins. 
In order to evaluate the performance of ABEC resins more quickly during the optimization of certain synthetic parameters, rhenium was used as a cold surrogate for technetium to help identify desirable resin formulations. This substitution of rhenium for technetium was justified based on the similarites in the aqueous chemisty of pertechnetate and perrhenate (The Chemistry of Technetium and RheniumR.D. Peacock, Elsevier Publishing Co., New York, 1966The Chemistry of Rhenium and TechnetiumR. Colton, Interscience Publishers, New York, 1965) and the fact that initial uptake studies of rhenium from both water and $6 \mathrm{M} \mathrm{NaOH}$ suggested that it would serve as a reliable substitute for macroquantities of technetium. Figure 8 shows the results of radiotracer studies with ${ }^{188} \mathrm{Re}$ in which similar Q values were obtained for technetium and rhenium with ABEC-5000 (PEG-5000 attached to 1\% crosslinked chloromethylated polystyrene of 100 to 200 mesh particle size) from $\mathrm{NaOH}$ solution. Technetium $\mathrm{w}_{\mathrm{D}} \mathrm{Ds}$ in hydroxide solutions were generally higher than those observed for rhenium. For some other salt solutions, however, the measured D's are slightly higher for rhenium than for technetium.

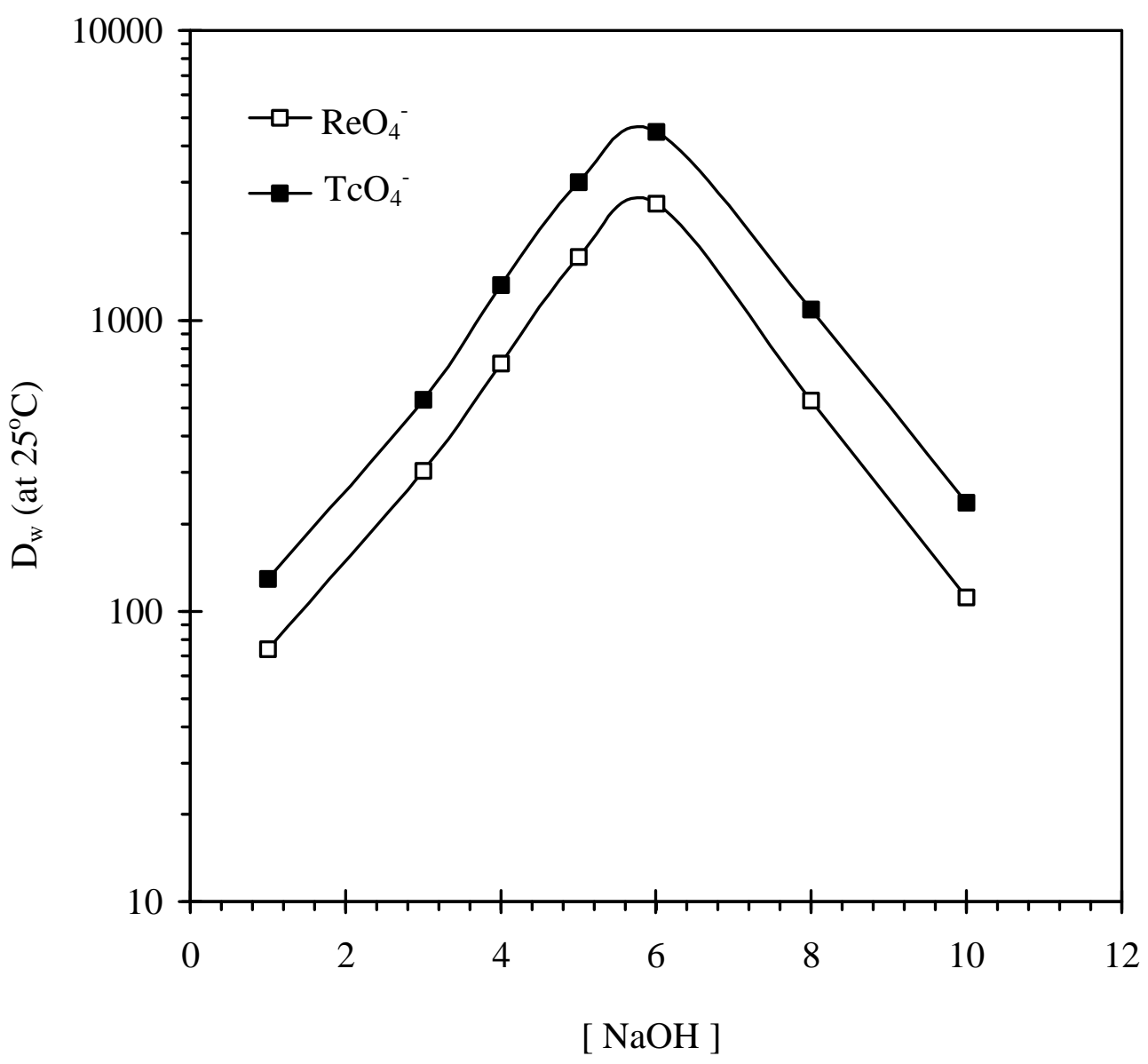

Figure 8. Comparison of ${ }^{188} \mathrm{ReO}_{4}{ }^{-}$and ${ }^{99} \mathrm{TcO}_{4}{ }^{-}$uptake with ABEC-5000 resin from $\mathrm{NaOH}$ solution. 
An additional observation to support substitution of rhenium for technetium in screening studies is the fact that technetium uptake by ABEC-5000 from $2 \mathrm{M}$ and $4 \mathrm{M} \mathrm{NaOH}$ solution decreases as the concentration of $\mathrm{NHReO}_{4}$ increases (Figure 9). This graph indicates that rhenium competes with technetium for resin sites at metal concentrations approaching the loading capacity of the resin.

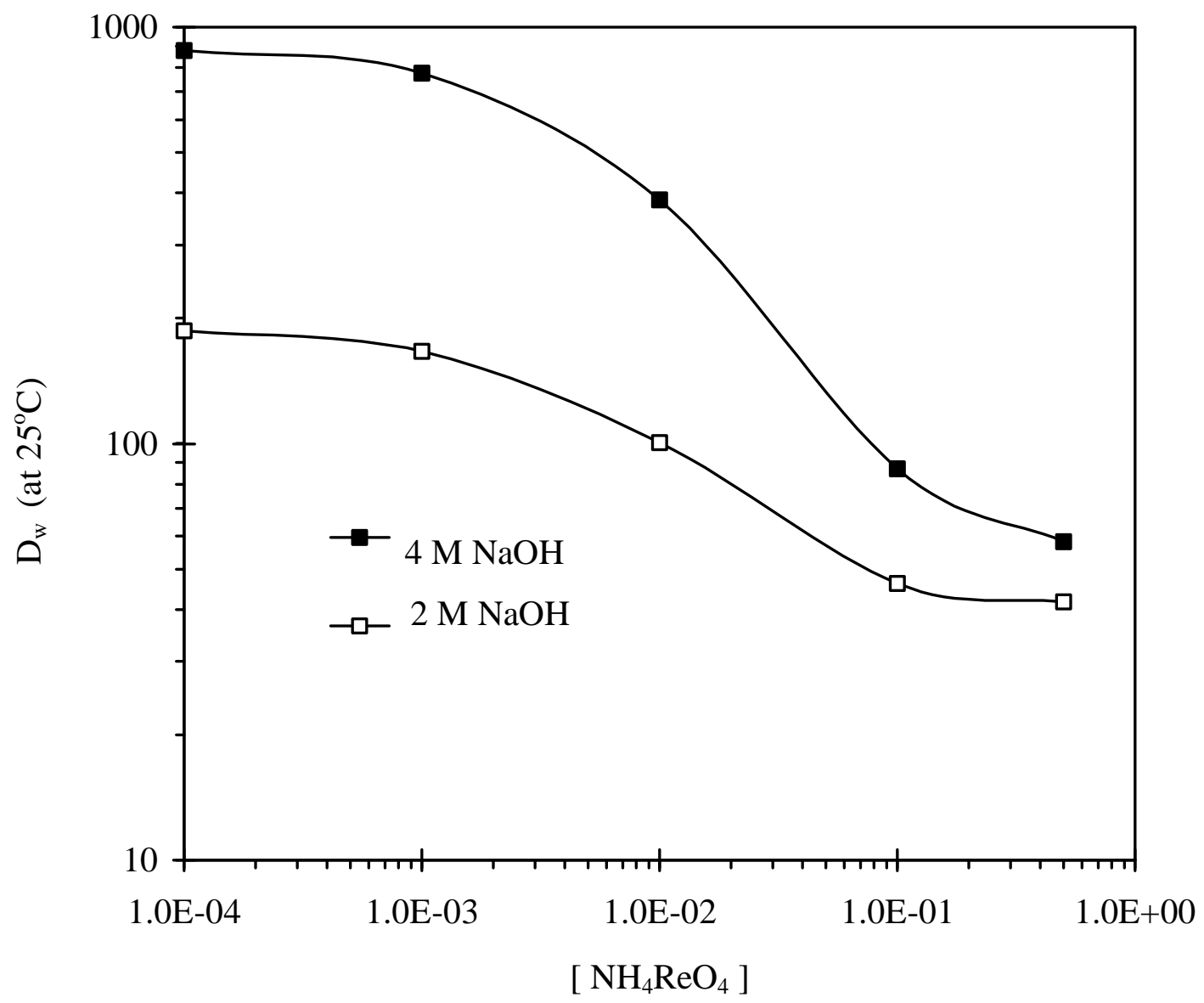

Figure 9. $\mathrm{TcO}_{4}{ }^{-}$uptake with $\mathrm{ABEC}-5000$ resin from $2 \mathrm{M}$ and $4 \mathrm{M} \mathrm{NaOH}$ solution vs. $\mathrm{NH}_{4} \mathrm{ReO}_{4}$ concentration.

For the evaluation of resins during parameter optimization studies, two different rhenium batch uptake studies were conducted for each resin. One involved an excess of resin (in terms of capacity) relative to rhenium and the other an excess of rhenium relative to resin. This approach allowed both the affinity and the capacity of the resin for rhenium to be evaluated in as little as one day so that a number of parameters could be optimized in a short period of time. The most promising resins were then evaluated for technetium uptake and capacity. 
The expansion of theresin bed duringwater stripping was identified early on as potentiallyimportant engineering issue ABEC resins consist of hydrophilic polyethylene glycols (PEGs) grafted to polystyrene-divinylbenzene crosslinked supports and are extensively hydrated. During loadingrom concentrated salt solution, the ABEC resin is dehydrated resulting in a decrease in the size of the resin beads and a concurrent decrease in bed volume. Conversely, on crossover to water strip the resin hydrates and the beads swell. Continuous expansion and contraction of the bed could result in diminished chromatographic performance due to bed fracture and channelingt is also an engineering concernbecause excessive pressure during expansion could damage the chromatographic apparatus Therefore, it was desirable to design and synthesize ABEC resins that did not show significant (i.e., greater than 10\%) changes in bed density during the load/strip cycle.

Resin density is important because previous ABEC resins floated when contacted with dense solutions like the Hanford and Melton Valley Storage Tank wastes. These resin beds may float in the column during loading, and may, therefore, also present an engineering concern. While it is practically and economically feasible to use an upflow load and downflow strip design in this situation, it is more desirable to increase resin density to eliminate the potential of floating resin.

\section{Physical Properties Analysis}

Percent Solids Determination (Moisture Content):The resin was air dried on a Büchner funnel with a coarse filter paper at $660 \mathrm{~mm} \mathrm{Hg}$ for 5 minutes. Resin dried in this manner is referred to as air dried resin. An air dried sample $(0.05 \mathrm{~g}$ to $0.1 \mathrm{~g})$ weighed by analytical balance was heated in a $110^{\circ} \mathrm{C}$ oven until a constant weight was obtained (up to 5 days) and then allowed to cool in a desiccator prior to determination of the dry mass. The relative uncertainty for duplicate percent solids analyses by this technique was typically less than $\pm 5 \%$.

Dry weight conversion factors (dwcf = percent solids/100) for some resins were also determined by thermogravimetric analysis (TGA). In this analysis a small amount of resin was heated under a nitrogen stream from ambient temperature to $500^{\circ} \mathrm{C}$ over a period of approximately 30 minutes while recording any changes in mass over time. The values obtained by TGA analysis were from 1.3 to 2.2 times greater than those obtained by oven analysis (Figure 10). This may indicate that during oven drying some oxidation of resin is occurring such that the weight loss is not entirely due to loss of water. This would be unlikely to occur during the TGA analysis because of the nitrogen atmosphere. At this time it is not completely clear which technique yields more accurate values for dwcf or percent solids. For the time being percent solids have been reported using the data obtained from oven analysis and all weight distribution ratios have been calculated using these values.

Bed Density Determination:The bed density ( $\mathrm{g}$ of dry resin per $\mathrm{mL}$ of resin bed volume) was determined for each resin in both DI water and $4 \mathrm{M} \mathrm{NaOH}$. This was 
accomplished by placing a known mass of resin in a column and marking the bed height when eluted with water and then when eluted with $4 \mathrm{M} \mathrm{NaOH}$. The resin was then removed from the column and the volume of water needed to fill the column to each mark determined by mass difference. The bed densitp(ed) was then calculated as:

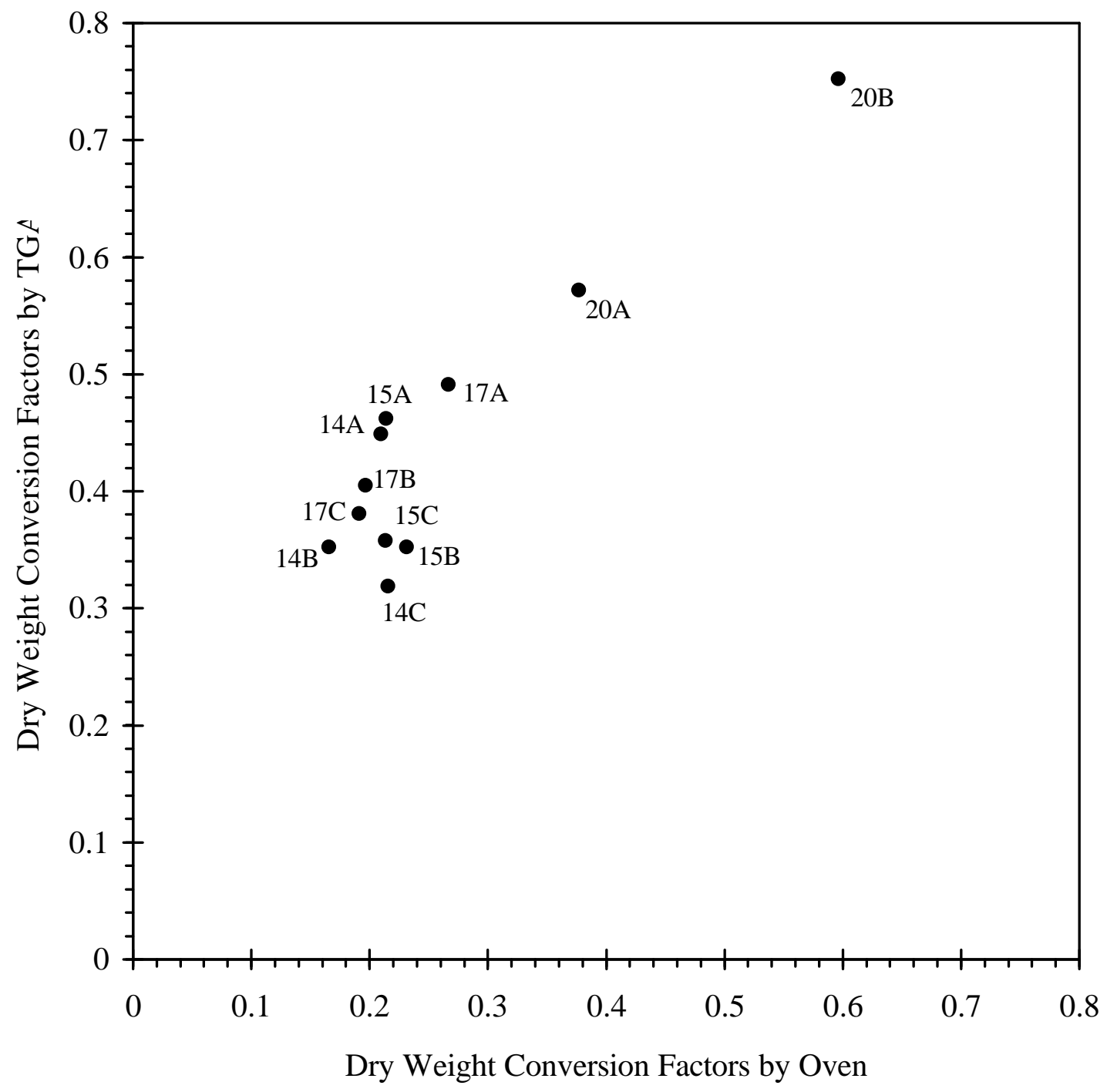

Figure 10. Comparison of dwcf's from oven gravimetric analysis and TGA analysis.

$$
\rho_{\text {bed }}=\frac{\text { g of air dried resin } \times \text { dwcf }}{\text { mL bed in } \mathrm{H}_{2} \mathrm{O} \text { or } \mathrm{NaOH}},
$$

where dwcf is the dry weight conversion factor (\% solids/100).

Evaluation of Percent Resin Swelling During StrippingThe extent of swelling that the resin undergoes upon crossover from a load solution of $4 \mathrm{M} \mathrm{NaOH}$ to a water 
strip was calculated using the bed density data. Owing to the fixed geometric parameters of a chromatographic column, only the bed height changes when the resin swells or contracts. It is then possible to calculate the change in bed height, reported as percent swelling, using the following equation:

$$
\% \text { Swelling }=\left(\frac{\rho_{\text {bed }} \text { in } 4 \mathrm{M} \mathrm{NaOH}-\rho_{\text {bed }} \text { in } \mathrm{H}_{2} \mathrm{O}}{\rho_{\text {bed }} \text { in } 4 \mathrm{M} \mathrm{NaOH}}\right) \bullet 100 \text {. }
$$

All of the percent swelling values reported in this work were calculated according to the above equation.

It was also observed following elution of the resin with $\mathrm{NaOH}$ that the resin did not swell to its original volume upon elution with water. In this case percent swelling values were calculated as

$$
\% \text { Swelling }=\left(\frac{\left|\mathrm{V}_{\mathrm{NaOH}}-\mathrm{V}_{2} \mathrm{O}\right|}{\mathrm{V}_{\mathrm{NaOH}}}\right) \bullet 100,
$$

where $\mathrm{V}_{\mathrm{NaOH}}$ is the resin volume after elution with $5 \mathrm{BV}$ of $4 \mathrm{M} \mathrm{NaOH}$ and $\mathrm{H}_{2} \mathrm{O}_{\mathrm{O}}$ is the rehydrated resin volume after elution with 5 BV of DI water. Percent swelling values calculated in this way were usually about half the value of those calculated from the bed density data. This indicates that the percent swelling values calculated from the bed density data are a conservative estimate of the degree of expansion the resins will undergo upon crossover from load solution to strip solution.

\section{Resin Uptake Performance}

$\underline{D}_{\mathrm{w}}$ Measurement of Pertechnetate Uptake Pertechnetate $\mathrm{D}_{\mathrm{w}}$ values $(\mathrm{mL} / \mathrm{g})$ for ABEC resins were measured as a function of $\mathrm{NaOH}$ concentration by contacting 30 to 50 $\mathrm{mg}$ of air dried resin with $1.0 \mathrm{~mL}$ of $\mathrm{NaOH}$ solution containing $\mathrm{N}_{4} \mathrm{TcO}_{4}$. A portion of the solution was counted by liquid scintillation before and after contact. The dry weight distribution ratios were calculated as

$$
D_{W}=\left(\frac{A_{0}-A_{f}}{A_{f}}\right)\left(\frac{V(m L)}{W(g) \times d w c f}\right),
$$

where $A_{0}$ is the aqueous phase activity before equilibration, ${ }_{\mathrm{f}} \mathrm{A}$ is the aqueous phase activity after equilibration, $\mathrm{W}$ is the weight of air dried resin in grams, and $\mathrm{V}$ is the aqueous phase volume in $\mathrm{mL}$. Based on agreement between values obtained for duplicate samples, a conservative estimate of the relative uncertainty associated with this measurement is $\pm 15 \%$. 
The resins prepared in this project had dwcf values ranging from less than 0.15 to greater than 0.85 . These values can have a significant impact on the value of losee equation above and Figure 11). Therefore, it may be misleading to compare $\mathbb{D}$ alues for resins having very different levels of percent solids. For column applications it may be more meaningful to compare volume distribution ratios (Din order to predict resin performance per unit volume rather than per $g$ of dry resin. Dvalues $(\mathrm{mL} / \mathrm{g})$ from $4 \mathrm{M}$ $\mathrm{NaOH}$ solution can be converted to $\mathrm{Q}$ values $(\mathrm{mL} / \mathrm{mL})$ from $4 \mathrm{M} \mathrm{NaOH}$ solution according to the following equation:

$$
\mathrm{D}_{\mathrm{v}}=\mathrm{D}_{\mathrm{w}} \times \rho_{\text {bed }} \text { in } 4 \mathrm{M} \mathrm{NaOH} \text {. }
$$

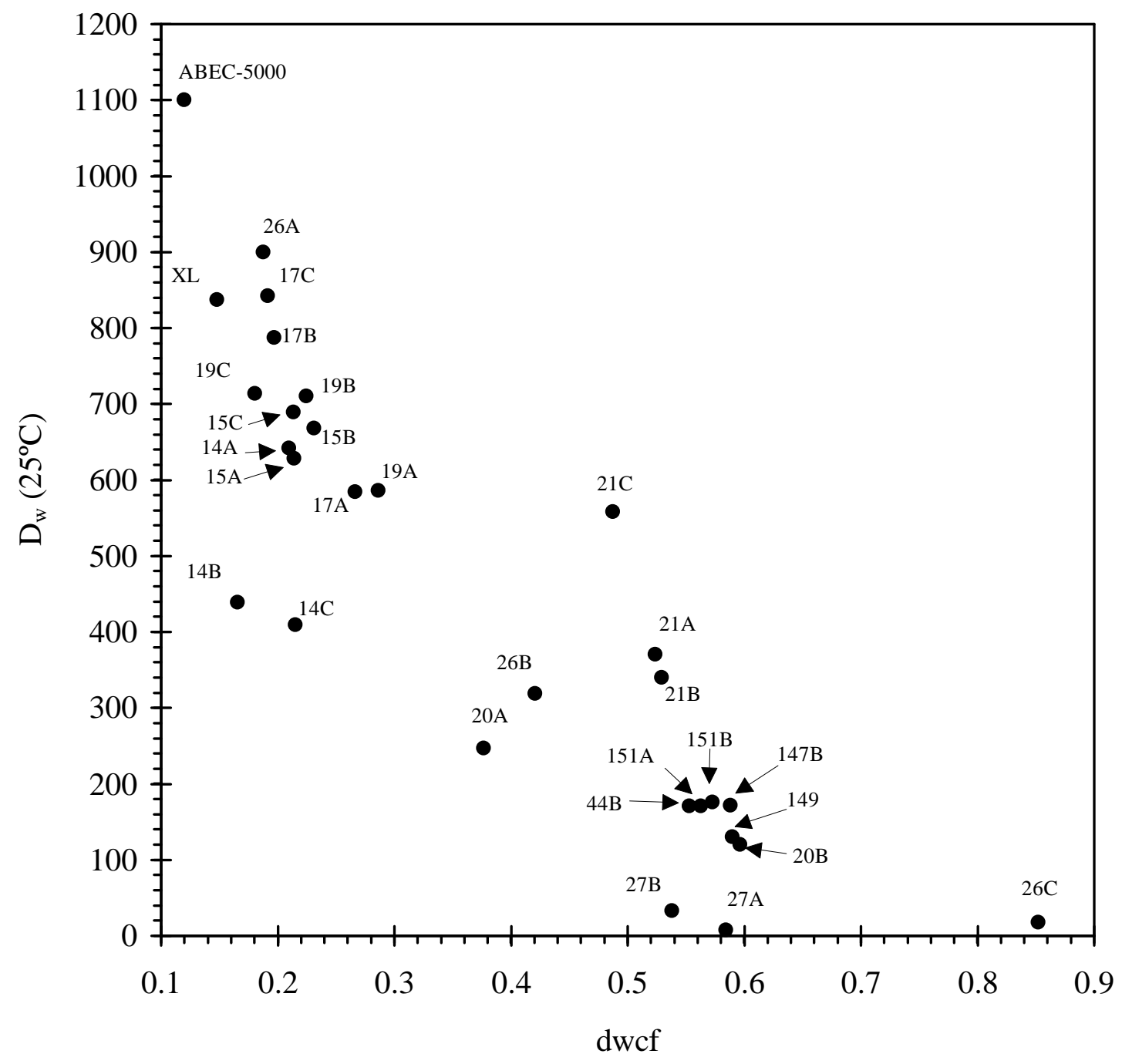

Figure 11. $\mathrm{TcO}_{4}{ }^{-} \mathrm{D}_{\mathrm{W}}$ in $4 \mathrm{M} \mathrm{NaOH}$ solution vs. dwcf by oven gravimetric analysis.

The fact that bed densities are usually proportional to dwcf values results in much less difference between $\mathrm{Q}$ values than between $\mathrm{Q}$ values. This is illustrated by the graph in 
Figure 12 which depicts a much narrower range of Dvalues $\left(3<\mathrm{D}_{\mathrm{V}}<200\right)$ than the range of $\mathrm{D}_{\mathrm{w}}$ values in Figure $11\left(8<\mathrm{Q}_{\mathrm{w}}<1100\right)$.

Technetium Capacity and Column Loading/Stripping BehavioABEC resin capacity for pertechnetate was determined for the ABEC resin produced in the 110-liter reactor. The capacity, in units of $\mathrm{mol} / \mathrm{mL}$ bed in water (can be converted t $\phi \mathrm{mol} / \mathrm{g}$ dry resin by dividing by the bed density in water), was calculated from the column breakthrough curve where rhenium served as a bulk nonradioactive surrogate for technetium in a spiked solution. A load solution containing ${ }^{59} \mathrm{TcO}_{4}{ }^{-}$and $0.01 \mathrm{M} \mathrm{ReO}_{4}^{-}$in $4 \mathrm{M} \mathrm{NaOH}$ was passed throuh a column containing approximately $3 \mathrm{~mL}$ of ABEC resin, and $0.5 \mathrm{~mL}$ fractions of eluant were collected in preweighed gamma counting tubes. The column was rinsed with 3 or 4 bed volumes of $4 \mathrm{M} \mathrm{NaOH}$ solution and then technetium and rhenium were stripped from the column by elution with DI water. The collection tubes were weighed again to determine the exact amount of each fraction. A plot of loading/stripping behavior was constructed from the data obtained by gamma counting individual fractions of the load and strip solutions. The capacity of the resin at $10 \%$ breakthrough was then calculated using the volume and composition of the load solution. The loading/elution curve and capacity value are shown in Figure 23, p. 49.

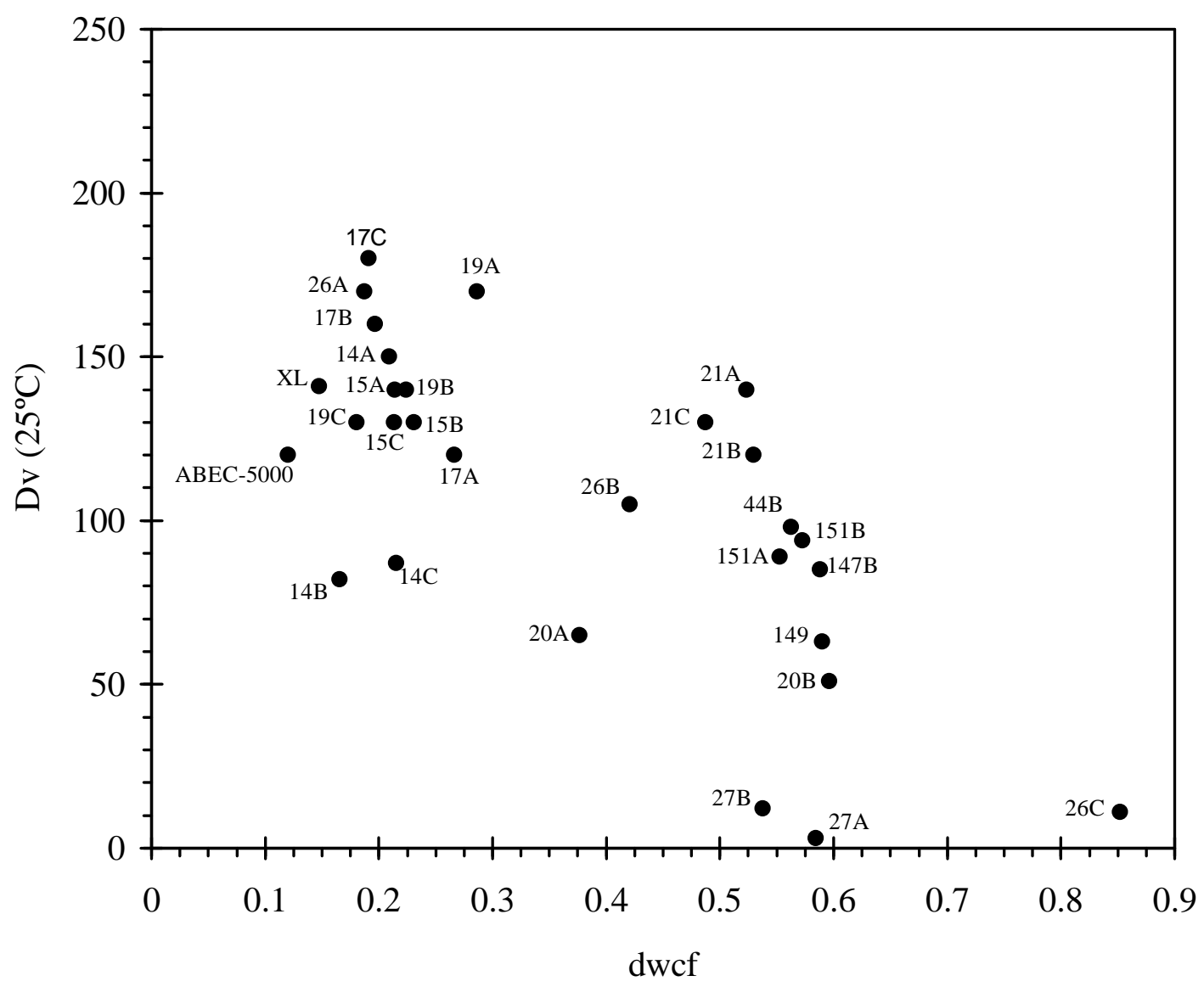

Figure 12. $\mathrm{TcO}_{4}{ }^{-} \mathrm{D}_{\mathrm{v}}$ in $4 \mathrm{M} \mathrm{NaOH}$ solution vs. dwcf by oven gravimetric analysis. 
Rhenium Uptake Performance The sorption of rhenium by ABEC resins during optimization studies was monitored using flame atomic absorption (FAA). Due to flame interference from the high levels of sodium in $4 \mathrm{M} \mathrm{NaOH}$ load solutions, uptake studies for rhenium were conducted in $2 \mathrm{M}\left(\mathrm{NH}_{2} \mathrm{SO}_{4}\right.$ solution. Two different batch uptake experiments were conducted for each resin. The first consisted of contacting $0.40 \mathrm{~g}$ of air dried resin with $10.00 \mathrm{~mL}$ of solution containing $250 \mathrm{mg} / \mathrm{L}$ rhenium $\left(1 \times 314^{-3} \mathrm{M} \mathrm{ReO}_{4}^{-}\right)$. The contact time was one hour (previous kinetic studies indicated no difference in uptake for contact times ranging from 30 minutes to 8 hours). In this experiment the amount of rhenium was small relative to the amount that could actually be loaded onto the resin. The uptake of rhenium, reported inumol of rhenium per $\mathrm{mL}$ of resin in water, was used to evaluate the resins' relative affinity for rhenium and, therefore, for technetium.

The second experiment involved contacting $0.10 \mathrm{~g}$ of air dried resin with $5.00 \mathrm{~mL}$ of solution containing $4 \mathrm{~g} / \mathrm{L}$ rhenium $\left(2 . \$ 510^{-2} \mathrm{M} \mathrm{ReO}_{4}{ }^{-}\right)$. Again, a contact time of 1 hour was found to be sufficient to achieve equilibrium. The purpose of this experiment was to load as much rhenium as possible onto the resins so that the rhenium uptake, reported in $\mu \mathrm{mol}$ of rhenium per $\mathrm{mL}$ of resin in water, was an estimate of the rhenium saturation capacity. Based on repeated analyses of the same resin the relative uncertainty associated with both the relative affinity and saturation capacity measurements was conservatively estimated to be $\pm 15 \%$.

Column Loading/Elution Behavior of RheniumColumn studies were performed with two resins in which $\mathrm{NaReQ}$ was loaded onto ABEC resin from $4 \mathrm{M}\left(\mathrm{NH}_{2} \mathrm{SO}_{4}\right.$ solution. The resin was rinsed with $4 \mathrm{M}\left(\mathrm{NH}_{2} \mathrm{SO}_{4}\right.$ and then stripped with DI water. All three solutions-load, rinse, and strip - were collected in appropriate sized fractions in preweighed plastic centrifuge tubes. The tubes were weighed a second time and the net weights divided by the appropriate density term to determine the exact volume of each fraction. The concentration of rhenium in each fraction was determined by FAA. From this data the amount of rhenium loaded on the resin and stripped from the resin was determined. Plots of column loading/elution behavior were also constructed from this data.

Technetium Uptake from Simulant Waste SolutionsDuring the course of this project British Nuclear Fuels (BNFL) in Great Britain expressed a keen interest in testing ABEC resins for removal of technetium from waste streams at both their Sellafield and Capenhurst locations. This was an extremely important development in that they may be willing to provide a demonstration site for technetium removal from real waste streams with $\mathrm{ABEC}$ resin at their Capenhurst facility.

In an effort to assist them in applying this technology to their applications for removal of technetium, the uptake of technetium from two different simulant waste solutions was investigated. One simulant waste solution, referred to as BNFL Sellafield waste simulant, contained $200 \mathrm{~g} / \mathrm{L} \mathrm{NaNQ}(2.4 \mathrm{M})$ and $3 \mathrm{~g} / \mathrm{L} \mathrm{Na}_{2} \mathrm{CO}_{3}(0.03 \mathrm{M})$. A second 
waste simulant, referred to as BNFL Capenhurst waste simulant, contained $20 \mathrm{~g} / \mathrm{L}$ $\mathrm{FeSO}_{4} \bullet 7 \mathrm{H}_{2} \mathrm{O}(0.072 \mathrm{M}), 62 \mathrm{~g} / \mathrm{L} \mathrm{A}\left(\mathrm{SO}_{4}\right)_{3} \bullet 18 \mathrm{H}_{2} \mathrm{O}(0.093 \mathrm{M})$, and $284 \mathrm{~g} / \mathrm{L} \mathrm{NaSO}_{4}(2.0$ $\mathrm{M})$. The total sulfate concentration was approximately $2.4 \mathrm{M}$. The column loading and elution behavior of technetium from the BNFL Capenhurst waste simulant was also investigated. The data are presented in the Results and Discussion Section (pp. 39-43).

\section{Results and Discussion of Laboratory Scale Synthesis}

Study of Substrates The study of substrates was initially focused on ABEC resins prepared using a set of copolymers classified as xero gel resins. Xero gel resins are a form of macroporous resin produced by suspension polymerization when an organic solvent, or diluent, which is a solvent for both the monomers and the copolymer is present in the organic phase. The presence of the diluent during coplymerization results in a more porous bead structure than that obtained for copolymer beads prepared when a diluent is not present (regular gel-type beads). Xero gel substrates were the initial focus of this work because it was thought that, due to their more porous structure, more complete and homogeneous functionalization of the beads with the bulky PEG molecules would be obtained.

A series of copolymer beads was synthesized using varying levels of divinylbenzene ( $1 \%$ and $2 \%$ ), vinylbenzyl chloride $(10 \%, 15 \%$ and $20 \%)$, and toluene $(0 \%, 10 \%, 20 \%$ and $30 \%)$. The rest of the formula was composed of styrene and a low level of initiator, BPO. Divinylbenzene is the crosslinking agent which usually provides the primary control of the swelling property for the copolymer beads. Vinylbenzyl chloride is the unit which reacts with PEG in the subsequent functionalization reaction. Using varying amounts of toluene as the diluent in the substrate synthesis yields copolymer beads with different porosities. The presence of diluent in the copolymer synthesis also influences the swelling property of the copolymer beads. The yield of copolymerization and the swelling ratio of these copolymer beads in THF are summarized in Table 1. In general, all of the copolymerization yields are higher than $90 \%$, while the quantity of the copolymer prepared from the same size reactor decreases as the amount of diluent increases. Moreover, the copolymers prepared with more diluent show higher swelling ratios than the copolymers prepared with less diluent.

All of the substrates studied at this stage were functionalid to ABEC-2000 resins using THF as the solvent with scalable amounts of PEG-2000 and sodium hydride depending on the percentage of $\mathrm{VBC}$ in the copolymer. The reagent quantities are summarized as follows:

Solvent: $\quad 20 \mathrm{~mL} / \mathrm{g}$ of copolymer,

PEG-2000 1.5 mole / mole of theoretical VBC unit,

$\mathrm{NaH} \quad 5$ mole / mole of theoretical VBC unit. 
Table 1. Copolymerization Yield and Swelling Ratios for Copolymer Beads Prepared in Substrate Studies

\begin{tabular}{|c|c|c|c|c|c|c|}
\hline $\begin{array}{c}\text { Lot\# } \\
\text { Copolymer } \\
\text { (Substrate) }\end{array}$ & Resin Type & $\begin{array}{l}\% \text { Diluent } \\
\text { (Toluene) }\end{array}$ & $\begin{array}{c}\% \text { DVB } \\
\text { (Crosslinking) }\end{array}$ & $\% \mathrm{VBC}$ & $\begin{array}{c}\text { Yield of } \\
\text { Copolymerization }\end{array}$ & $\begin{array}{c}\text { Copolymer } \\
\text { Swelling Ratio in } \\
\text { THF }\end{array}$ \\
\hline FC-54-009-A & Xero-gel & $30 \%$ & $1 \%$ & $10 \%$ & $90.0 \%$ & $7.3 X$ \\
\hline FC-54-009-B & Xero-gel & $30 \%$ & $1 \%$ & $15 \%$ & $90.2 \%$ & $7.3 \mathrm{X}$ \\
\hline FC-54-009-C & Xero-gel & $30 \%$ & $1 \%$ & $20 \%$ & $92.3 \%$ & $6.9 \mathrm{X}$ \\
\hline FC-54-011-A & Xero-gel & $20 \%$ & $1 \%$ & $10 \%$ & $94.0 \%$ & $5.9 \mathrm{X}$ \\
\hline FC-54-011-B & Xero-gel & $20 \%$ & $1 \%$ & $15 \%$ & $97.5 \%$ & $5.9 \mathrm{X}$ \\
\hline FC-54-011-C & Xero-gel & $20 \%$ & $1 \%$ & $20 \%$ & $90.3 \%$ & $6.0 \mathrm{X}$ \\
\hline FC-54-012-A & Xero-gel & $10 \%$ & $1 \%$ & $10 \%$ & $93.8 \%$ & $4.6 \mathrm{X}$ \\
\hline FC-54-012-B & Xero-gel & $10 \%$ & $1 \%$ & $15 \%$ & $97.1 \%$ & $5.1 \mathrm{X}$ \\
\hline FC-54-012-C & Xero-gel & $10 \%$ & $1 \%$ & $20 \%$ & $95.4 \%$ & $4.7 \mathrm{X}$ \\
\hline FC-54-013-A & Gel & $0 \%$ & $1 \%$ & $10 \%$ & $94.3 \%$ & $5.2 \mathrm{X}$ \\
\hline FC-54-013-B & Gel & $0 \%$ & $1 \%$ & $15 \%$ & $94.6 \%$ & $4.8 \mathrm{X}$ \\
\hline FC-54-013-C & Gel & $0 \%$ & $1 \%$ & $20 \%$ & $93.8 \%$ & $5.1 X$ \\
\hline FC-54-018-A & Xero-gel & $30 \%$ & $2 \%$ & $15 \%$ & $98.9 \%$ & $4.4 \mathrm{X}$ \\
\hline FC-54-018-B & Xero-gel & $10 \%$ & $2 \%$ & $15 \%$ & $99.4 \%$ & $3.4 \mathrm{X}$ \\
\hline FC-54-016-A & Xero-gel & $20 \%$ & $2 \%$ & $10 \%$ & $99.3 \%$ & $3.7 \mathrm{X}$ \\
\hline FC-54-016-B & Xero-gel & $20 \%$ & $2 \%$ & $15 \%$ & $98.9 \%$ & $3.6 \mathrm{X}$ \\
\hline FC-54-016-C & Xero-gel & $20 \%$ & $2 \%$ & $20 \%$ & $95.8 \%$ & $3.7 \mathrm{X}$ \\
\hline
\end{tabular}

The functionalization yields were measured both by weight and by volume and are listed in Table 2. The data indicate that the yield of functionalization increases with the content of VBC units on the copolymer. This is because there are more sites for PEG-2000 to attach to the substrate. Moreover, the yield also increases with the quantity of diluent used in copolymerization. Because the substrate prepared with a higher level of diluent can swell more during functionalization, there is a better chance for PEG molecules to penetrate deeper into the polymer network and to give more homogeneously functionalized ABEC resin.

The physical properties and technetiumptake data from $4 \mathrm{M} \mathrm{NaOH}$ are also summarized in Table 2, and technetium profiles from $\mathrm{NaOH}$ solution are given in Figure 13. All of these resins show a high affinity for technetium as indicated by their D and $\mathrm{D}_{\mathrm{V}}$ values. The ABEC-2000 resins prepared from $1 \%$ crosslinked xero gel substrates generally showed a very high percent swelling during stripping compared to the $2 \%$ 
Table 2. Formulations and Yields of ABEC-2000 Resins Prepared for Substrate Studies

\begin{tabular}{|c|c|c|c|c|c|c|c|c|}
\hline $\begin{array}{c}\text { Lot\# } \\
\text { (ABEC-2000) }\end{array}$ & $\begin{array}{l}\text { Lot\# } \\
\text { for } \\
\text { Copolymer } \\
\text { (Substrate) }\end{array}$ & $\begin{array}{c}\text { Yield* } \\
\text { of } \\
\text { PEG } \\
\text { Addition } \\
\text { g(mL) }\end{array}$ & $\begin{array}{l}\text { \% Swelling } \\
\text { During } \\
\text { Stripping }\end{array}$ & $\%$ Solids & $\begin{array}{c}\text { Bed Density } \\
\text { in } \\
\mathrm{H}_{2} \mathrm{O} \\
\text { (g.mL) }\end{array}$ & $\begin{array}{c}\text { Bed Density } \\
\text { in } \\
4 \mathrm{M} \mathrm{NaOH} \\
\text { (g.mL) }\end{array}$ & $\begin{array}{c}\text { Dw of } \mathrm{Tc} \\
\text { in } \\
4 \mathrm{M} \mathrm{NaOH} \\
(\mathrm{mL} / \mathrm{g})\end{array}$ & $\begin{array}{c}\text { Dv of } \mathrm{Tc} \\
\text { in } \\
4 \mathrm{M} \mathrm{NaOH} \\
(\mathrm{mL} / \mathrm{mL})\end{array}$ \\
\hline FC-54-014-A & FC-54-009-A & $\begin{array}{l}52.2 \\
(71)\end{array}$ & $40.6 \%$ & $21.0 \%$ & 0.139 & 0.234 & 640 & 150 \\
\hline FC-54-014-B & FC-54-009-B & $\begin{array}{c}77.6 \\
(110)\end{array}$ & $43.1 \%$ & $15.5 \%$ & 0.107 & 0.187 & 440 & 82 \\
\hline FC-54-014-C & FC-54-009-C & $\begin{array}{l}106.8 \\
(154)\end{array}$ & $55.1 \%$ & $14.2 \%$ & 0.095 & 0.211 & 410 & 87 \\
\hline FC-54-015-A & FC-54-011-A & $\begin{array}{l}49.2 \\
(76) \\
\end{array}$ & $32.6 \%$ & $22.5 \%$ & 0.153 & 0.227 & 630 & 140 \\
\hline FC-54-015-B & FC-54-011-B & $\begin{array}{c}70.1 \\
(116) \\
\end{array}$ & $38.7 \%$ & $14.2 \%$ & 0.119 & 0.194 & 670 & 130 \\
\hline FC-54-015-C & FC-54-011-C & $\begin{array}{l}93.8 \\
(146)\end{array}$ & $48.2 \%$ & $13.7 \%$ & 0.098 & 0.189 & 690 & 130 \\
\hline FC-54-017-A & FC-54-012-A & $\begin{array}{l}43.7 \\
(68)\end{array}$ & $29.2 \%$ & $24.5 \%$ & 0.153 & 0.216 & 550 & 120 \\
\hline FC-54-017-B & FC-54-012-B & $\begin{array}{c}64.1 \\
(102) \\
\end{array}$ & $42.3 \%$ & $17.9 \%$ & 0.118 & 0.205 & 790 & 160 \\
\hline FC-54-017-C & FC-54-012-C & $\begin{array}{c}78.0 \\
(120)\end{array}$ & $45.8 \%$ & $17.0 \%$ & 0.115 & 0.212 & 840 & 180 \\
\hline FC-54-019-A & FC-54-013-A & $\begin{array}{l}44.9 \\
(70)\end{array}$ & $29.7 \%$ & $24.4 \%$ & 0.205 & 0.292 & 590 & 170 \\
\hline FC-54-019-B & FC-54-013-B & $\begin{array}{l}57.3 \\
(88) \\
\end{array}$ & $27.8 \%$ & $20.7 \%$ & 0.140 & 0.193 & 710 & 140 \\
\hline FC-54-019-C & FC-54-013-C & $\begin{array}{c}70.8 \\
(108) \\
\end{array}$ & $36.8 \%$ & $18.8 \%$ & 0.116 & 0.186 & 710 & 130 \\
\hline FC-54-020-A & FC-54-018-A & $\begin{array}{l}29.0 \\
(43) \\
\end{array}$ & $7.5 \%$ & $36.9 \%$ & 0.240 & 0.26 & 250 & 65 \\
\hline FC-54-020-B & FC-54-018-B & $\begin{array}{l}16.4 \\
(27) \\
\end{array}$ & $11.7 \%$ & $64.3 \%$ & 0.376 & 0.426 & 120 & 51 \\
\hline FC-54-021-A & FC-54-016-A & $\begin{array}{l}18.1 \\
(27)\end{array}$ & $0 \%$ & $55.8 \%$ & 0.384 & 0.384 & 370 & 140 \\
\hline FC-54-021-B & FC-54-016-B & $\begin{array}{l}18.0 \\
(29)\end{array}$ & $0 \%$ & $60.2 \%$ & 0.366 & 0.366 & 340 & 120 \\
\hline FC-54-021-C & FC-54-016-C & $\begin{array}{l}23.2 \\
(34)\end{array}$ & $3.0 \%$ & $35.2 \%$ & 0.226 & 0.226 & 560 & 130 \\
\hline
\end{tabular}

*All of ABEC-2000 resins are prepared from 10 grams of copolymer beads and the yields are measured after the ABEC-2000 resins are dried on a Buchner funnel for 5 minutes.

crosslinked resins. The $2 \%$ crosslinked resins show somewhat lowerk $\mathrm{D}$ alues than the $1 \%$ crosslinked resins, but the D values are very similar (Table 2). Due to the fact that it can be more difficult to work with the resins if they undergo dramatic volume changes during loading and stripping, the substrate study was continued focusing on the $2 \%$ crosslinked xero gel and regular gel copolymers. 


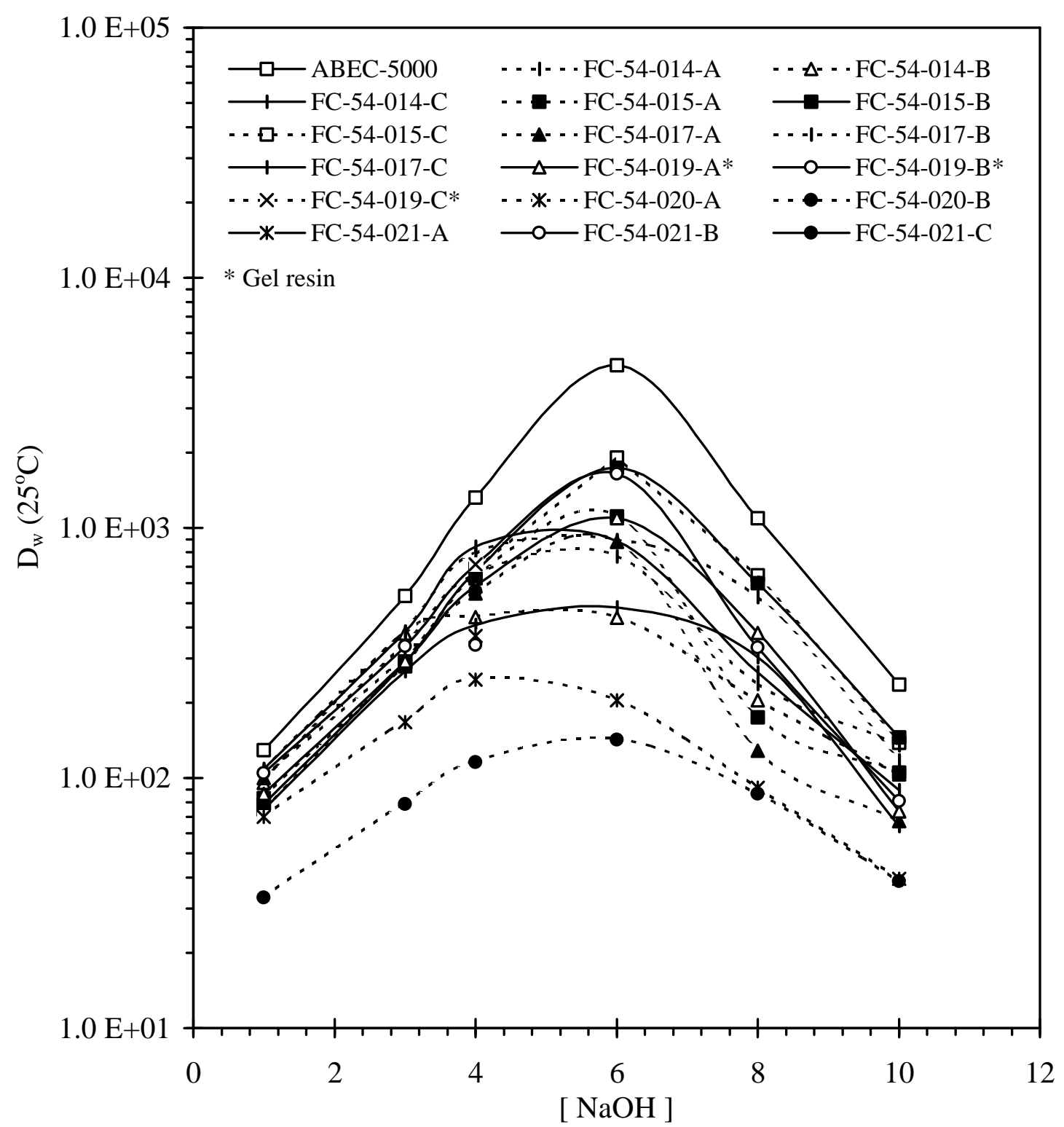

Figure 13. $\mathrm{TcO}_{4}^{-} \mathrm{D}_{\mathrm{W}} \mathrm{vs}$. $[\mathrm{NaOH}]$ for $\mathrm{ABEC}$ resins prepared for substrate studies.

The characterization results of $2 \%$ crosslinked xero gel and regular gel ABEC2000 resins are summarized in Table 3 and technetium ${ }_{\Downarrow} D p r o f i l e s$ for these resins are included in Figure 14. Both products exhibit much lower percentage swelling during stripping - approximately 10\% compared to between $25 \%$ and $50 \%$ for $1 \%$ crosslinked resins. Additionally, the distribution ratios measured for these $2 \%$ crosslinked resins compare very favorably with those measured for $1 \%$ crosslinked resins (see Figure 13). The xero gel resins show a slightly better weight distribution ratio, however, the observed difference in $\mathrm{D}_{\mathrm{W}}$ values is mainly due to the fact that the xero gel resins have lower percent solid values than the regular gel resins. The Dvalues are much closer, indicating that column behavior should be quite similar. Because the diluent used for making xero 
gel resins needs to be removed by an azeotrope distillation, which can make a significant cost difference between xero gel and regular gel resins, the $2 \%$ crosslinked regular gel copolymer was chosen for further parameter studies.

Table 3. Comparison of Xero Gel and Regular Gel ABEC-2000 Resins.

\begin{tabular}{|c|c|c|c|c|c|c|c|c|c|}
\hline $\begin{array}{c}\text { ABEC } \\
\text { Lot\# }\end{array}$ & Resin Type & $\begin{array}{c}\text { DVB } \\
\text { Content }\end{array}$ & $\begin{array}{c}\text { VBC } \\
\text { Content }\end{array}$ & $\%$ Solids & $\begin{array}{c}\text { Bed Density in } \\
\text { Water }(\mathrm{g} / \mathrm{mL})\end{array}$ & $\begin{array}{c}\text { Bed Density in } \\
\text { 4M NaOH } \\
(\mathrm{g} / \mathrm{mL})\end{array}$ & $\begin{array}{c}\text { Dw of TcO4 in } \\
4 \mathrm{M} \mathrm{NaOH} \\
\mathrm{mL} / \mathrm{g}\end{array}$ & $\begin{array}{c}\text { Dv of TcO4 in } \\
4 \mathrm{M} \text { NaOH } \\
\mathrm{mL} / \mathrm{mL}\end{array}$ & $\begin{array}{c}\% \text { Swelling } \\
\text { During } \\
\text { Stripping }\end{array}$ \\
\hline FC-54-021-C & xero gel & $2 \%$ & $20 \%$ & $35.2 \%$ & 0.224 & 0.231 & 560 & 130 & $3.0 \%$ \\
\hline FC-54-044-A & xero gel* & $2 \%$ & $10 \%$ & $34.2 \%$ & 0.213 & 0.245 & 517 & 126 & $12.0 \%$ \\
\hline FC-54-026-B & gel & $2 \%$ & $20 \%$ & $41.4 \%$ & 0.296 & 0.328 & 320 & 105 & $9.8 \%$ \\
\hline FC-54-044-B & gel & $2 \%$ & $20 \%$ & $44.2 \%$ & 0.301 & 0.333 & 310 & 103 & $9.4 \%$ \\
\hline
\end{tabular}

* Prepared with $20 \%$ toluene as the diluent in copolymer synthesis.

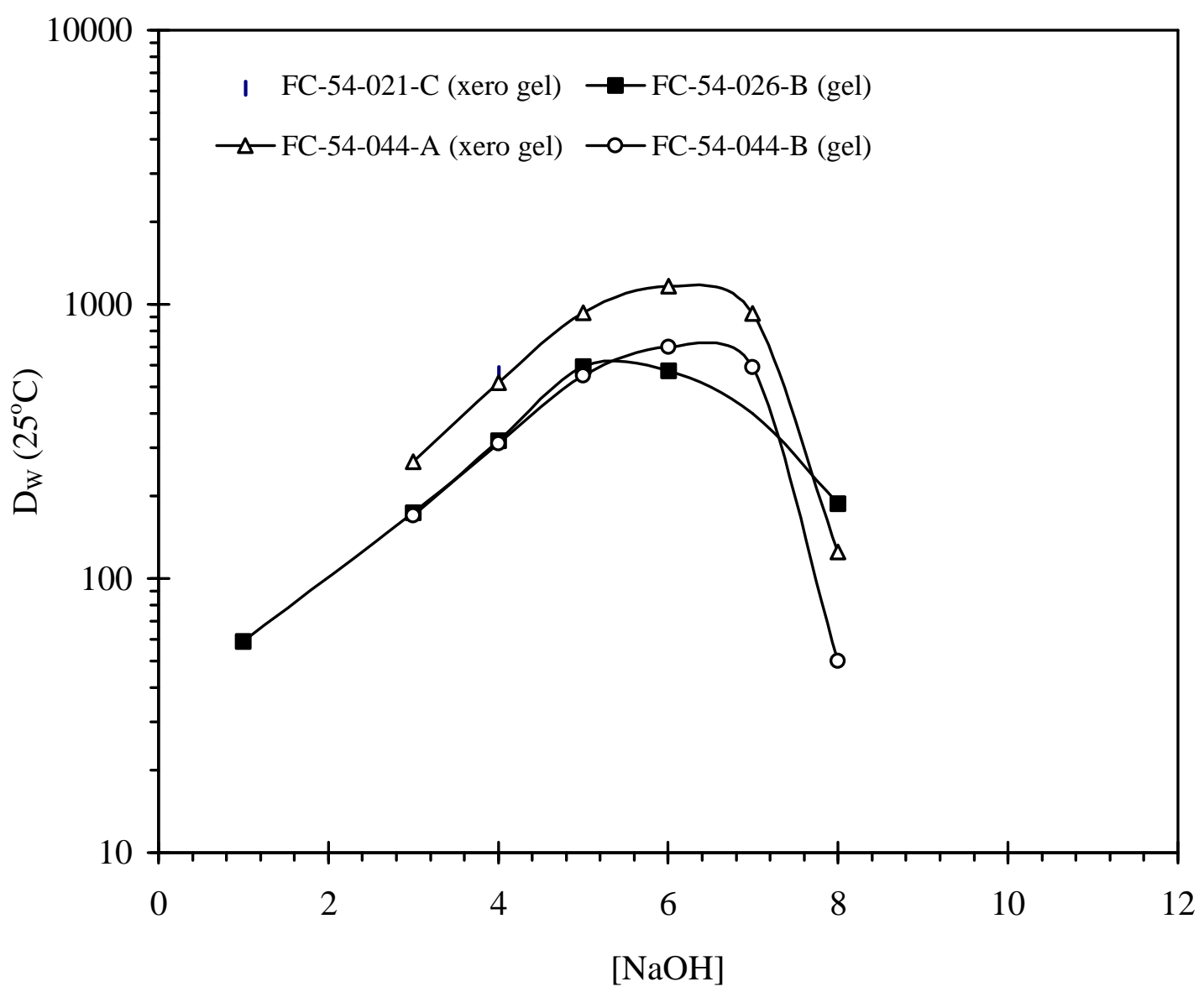

Figure 14. $\mathrm{TcO}_{4}{ }^{-} \mathrm{D}_{\mathrm{W}}$ vs. $[\mathrm{NaOH}]$ for xero gel and regular gel ABEC-2000 resins. 
Study of PEG Molecular Weight: The PEG used for ABEC synthesis was studied at two molecular weight ranges, PEG-2000 and PEG-5000. The copolymer containing $2 \%$ crosslinking agent and 20\% VBC was functionalized to ABEC-2000 and ABEC-5000 respectively in experiments FC-54-038-C and FC-54-038-D. The results shown in Table 4 indicate that both the yield of ABEC-2000 synthesis and the uptake performance of ABEC-2000 resin are better than that of the $2 \%$ crosslinked ABEC-5000. This could be due to the fact that the activated alkoxide group on the less bulky PEG-2000 molecule has better opportunity to react with the VBC unit on the substrate. Additionally, the synthesis of ABEC-5000 requires more solvent to dissolve the PEG-5000. The use of PEG-2000 for the synthesis of $2 \%$ crosslinked ABEC resin proved to be more economical and yielded a resin with higher Q's for technetium. Therefore, further parameter studies were based upon the synthesis of ABEC resin functionalized with PEG-2000.

Table 4. Comparison of ABEC-2000 and -5000 Resins Prepared from 2\% Crosslinked, $20 \%$ VBC Substrate.

\begin{tabular}{|c|c|c|c|c|c|c|c|c|}
\hline $\begin{array}{c}\text { ABEC } \\
\text { Lot \# }\end{array}$ & $\begin{array}{c}\text { M.W. of } \\
\text { PEG }\end{array}$ & $\begin{array}{c}\text { Yield of PEG } \\
\text { addition } \\
\mathrm{g}(\mathrm{mL})\end{array}$ & \%Solids & $\begin{array}{c}\text { Bed Density } \\
\text { in Water } \\
(\mathrm{g} / \mathrm{mL})\end{array}$ & $\begin{array}{c}\text { Bed Density } \\
\text { i 4M NaOH } \\
(\mathrm{g} / \mathrm{mL})\end{array}$ & $\begin{array}{c}\text { Dw of TcO4- in } \\
\text { 4 M NaOH } \\
\mathrm{g} / \mathrm{mL}\end{array}$ & $\begin{array}{c}\text { Dv of TcO4- in } \\
\text { M NaOH } \\
\mathrm{mL} / \mathrm{mL}\end{array}$ & $\begin{array}{c}\text { \% Swelling } \\
\text { During } \\
\text { Stripping }\end{array}$ \\
\hline FC-54-038-C & 2000 & $49.1(72)$ & $48.8 \%$ & 0.21 & 0.255 & 579 & 148 & $17.7 \%$ \\
\hline FC-54-038-D & 5000 & $32.2(50)$ & $62.5 \%$ & 0.372 & 0.372 & 111 & 48 & $0 \%$ \\
\hline
\end{tabular}

Study of the Alternate Solvent, Diglyme:Due to the potential safety concern of peroxide accumulation in the system when running the reaction in THF, the PEG addition reaction was studied side-by-side using THF and diglyme as the reaction solvents (JW-53065-A and B). The reaction conditions and results shown in Table 5 indicate that diglyme gives a product with better yield and comparable rhenium uptake character. Since diglyme is a safer solvent in production scale operations, the reaction solvent was changed from THF to diglyme for further studies.

Effect of Reducing Solvent/PEG/NaH: In this set of experiments, the quantities of solvent, PEG and $\mathrm{NaH}$ were studied in the same ratio with respect to each other but at different levels relative to the amount of copolymer (JW-53-085-A, B, C). Both the synthesis yield and rhenium uptake character (Table 6) decrease when a lower level of solvent/PEG/NaH combination is used. Because the reaction conditions used for JW-53085-B gave ABEC-2000 with the best compromise of yield, affinity for rhenium, percent swelling, and process quantity in reaction vessel, the parameters chosen for experiment JW-53-085-B were used for further studies.

Effect of Solvent Quantity: In order to increase the concentration of PEG in the reaction mixture and thus the production yield, the synthesis was further explored with decreasing quantities of solvent (JW-53-085-B, JW-53-106-A and B). In Table 7, the results indicate that the distribution of rhenium to the resin phase under conditions not 
Table 5. Effect of Solvent on PEG Addition Reaction

Part A: Synthesis Parameter and Yield

\begin{tabular}{|c|c|c|c|c|c|c|c|c|c|c|}
\hline & $\begin{array}{l}\text { \% DVB } \\
\text { in } \\
\text { Copolymer }\end{array}$ & $\begin{array}{c}\% \text { VBC } \\
\text { in } \\
\text { Copolymer }\end{array}$ & Solvent & $\begin{array}{c}\mathrm{mL} \text { of Solvent } \\
\text { per } \\
\mathrm{g} \text { of Copolymer }\end{array}$ & $\begin{array}{c}\mathrm{g} \text { of PEG-CHB } \\
\text { per } \\
\mathrm{g} \text { of copolymer }\end{array}$ & $\begin{array}{c}\mathrm{g} \text { of } 60 \% \mathrm{NaH} \\
\text { per } \\
\mathrm{g} \text { of copolymer }\end{array}$ & $\begin{array}{c}\mathrm{mg} \text { of } 60 \% \mathrm{NaH} \\
\text { per } \\
\mathrm{g} \text { of } \mathrm{PEG}-\mathrm{CH} 3\end{array}$ & $\begin{array}{c}\text { Reaction Temp } \\
\text { and } \\
\text { Reaction Time }\end{array}$ & $\begin{array}{c}\text { Yield of ABEC } \\
\text { wet in } g \\
\text { per g of copolymer }\end{array}$ & $\begin{array}{c}\text { Yield of ABEC } \\
\text { wet in mL } \\
\text { per g of copolymer }\end{array}$ \\
\hline JW-53-065-A & $2 \%$ & $20 \%$ & THF & $20 \mathrm{~mL}$ & $3.83 \mathrm{~g}$ & $260 \mathrm{mg}$ & $67.8 \mathrm{mg}$ & reflux / 17 hrs & 2.45 & 3.53 \\
\hline JW-53-065-B* & $2 \%$ & $20 \%$ & Diglyme & $20 \mathrm{~mL}$ & $3.83 \mathrm{~g}$ & $260 \mathrm{mg}$ & $67.8 \mathrm{mg}$ & $7^{\circ} \mathrm{C} / 17 \mathrm{hrs}$ & 2.98 & 4.40 \\
\hline
\end{tabular}

Part B: Characterization and Uptake Property

\begin{tabular}{|c|c|c|c|c|c|c|}
\hline & $\begin{array}{c}\text { Bed Density in } \\
\mathrm{H}_{2} \mathrm{O} \\
(\mathrm{g} / \mathrm{mL})\end{array}$ & $\begin{array}{c}\text { Bed Density in } \\
4 \mathrm{M} \mathrm{NaOH} \\
(\mathrm{g} / \mathrm{mL})\end{array}$ & \%Solid & $\begin{array}{c}\text { \% Swelling } \\
\text { During } \\
\text { Stripping }\end{array}$ & $\begin{array}{c}\text { Re Capacity } \\
\mu \text { mole of Re } \\
\text { per ml of wet resin }\end{array}$ & $\begin{array}{c}\text { Re Affinity } \\
\mu \text { mole of Re } \\
\text { per ml of wet resin }\end{array}$ \\
\hline JW-53-065-A & 0.300 & 0.330 & $43.1 \%$ & $9.1 \%$ & 129 & 15.0 \\
\hline JW-53-065-B* & $\mathbf{0 . 2 4 2}$ & $\mathbf{0 . 3 1 3}$ & $\mathbf{3 5 . 5 \%}$ & $\mathbf{2 2 . 5 \%}$ & $\mathbf{1 3 7}$ & $\mathbf{1 5 . 2}$ \\
\hline
\end{tabular}

*Bold type indicates the experiment selected for further optimization studies. 
Table 6. Effect of Reducing Solvent/PEG/NaH on PEG Addition Reaction

Part A: Synthesis Parameters and Yield

\begin{tabular}{|c|c|c|c|c|c|c|c|c|c|c|}
\hline & $\begin{array}{c}\% \text { DVB } \\
\text { in } \\
\text { Copolymer }\end{array}$ & $\begin{array}{c}\% \text { VBC } \\
\text { in } \\
\text { Copolymer }\end{array}$ & Solvent & $\begin{array}{c}\mathrm{mL} \text { of Solvent } \\
\text { per } \\
\mathrm{g} \text { of Copolymer }\end{array}$ & $\begin{array}{c}\mathrm{g} \text { of PEG-CHB } \\
\text { per } \\
\mathrm{g} \text { of copolymer }\end{array}$ & $\begin{array}{c}\mathrm{mg} \text { of } 60 \% \mathrm{NaH} \\
\text { per } \\
\mathrm{g} \text { of copolymer }\end{array}$ & $\begin{array}{c}\mathrm{mg} \text { of } 60 \% \mathrm{NaH} \\
\text { per } \\
\mathrm{g} \text { of PEG-CH3 }\end{array}$ & $\begin{array}{c}\text { Reaction Temp } \\
\text { and } \\
\text { Reaction Time }\end{array}$ & $\begin{array}{c}\text { Yield of ABEC } \\
\text { wet in } g \\
\text { per g of copolymer }\end{array}$ & $\begin{array}{c}\text { Yield of ABEC } \\
\text { wet in } \mathrm{mL} \\
\text { per } \mathrm{g} \text { of copolymer }\end{array}$ \\
\hline JW-53-065-A & $2 \%$ & $20 \%$ & THF & $20 \mathrm{~mL}$ & $3.83 \mathrm{~g}$ & $260 \mathrm{mg}$ & $67.8 \mathrm{mg}$ & reflux / $17 \mathrm{hrs}$ & 2.45 & 3.53 \\
\hline JW-53-085-A & $2 \%$ & $20 \%$ & Diglyme & $20 \mathrm{~mL}$ & $2.60 \mathrm{~g}$ & $104 \mathrm{mg}$ & $40.0 \mathrm{mg}$ & $70^{\circ} \mathrm{C} / 17 \mathrm{hrs}$ & 1.91 & 2.80 \\
\hline JW-53-085-B* & $2 \%$ & $20 \%$ & Diglyme & $10 \mathrm{~mL}$ & $1.30 \mathrm{~g}$ & $52 \mathrm{mg}$ & $40.0 \mathrm{mg}$ & $70^{\circ} \mathrm{C} / 17 \mathrm{hrs}$ & 1.58 & 2.33 \\
\hline JW-53-085-C & $2 \%$ & $20 \%$ & Diglyme & $5 \mathrm{~mL}$ & $0.65 \mathrm{~g}$ & $26 \mathrm{mg}$ & $40.0 \mathrm{mg}$ & $70^{\circ} \mathrm{C} / 17 \mathrm{hrs}$ & 1.42 & 2.07 \\
\hline
\end{tabular}

Part B: Characterization and Uptake Property

\begin{tabular}{|c|c|c|c|c|c|c|}
\hline & $\begin{array}{c}\text { Bed Density in } \\
\mathrm{H}_{2} \mathrm{O} \\
(\mathrm{g} / \mathrm{mL})\end{array}$ & $\begin{array}{c}\text { Bed Density in } \\
4 \mathrm{M} \mathrm{NaOH} \\
(\mathrm{g} / \mathrm{mL})\end{array}$ & \%Solid & $\begin{array}{c}\text { \% Swelling } \\
\text { During } \\
\text { Stripping }\end{array}$ & $\begin{array}{c}\text { Re Capacity } \\
\mu \text { mole of Re } \\
\text { per ml of wet resir }\end{array}$ & $\begin{array}{c}\text { Re Affinity } \\
\mu \text { mole of Re } \\
\text { per ml of wet resin }\end{array}$ \\
\hline JW-53-065-A & 0.300 & 0.330 & $43.1 \%$ & $9.1 \%$ & 129 & 15.0 \\
\hline JW-53-085-A & 0.372 & 0.439 & $54.5 \%$ & $15.2 \%$ & 125 & 13.0 \\
\hline JW-53-085-B & $\mathbf{0 . 4 3 7}$ & $\mathbf{0 . 4 8 9}$ & $\mathbf{6 4 . 4 \%}$ & $\mathbf{1 0 . 7 \%}$ & $\mathbf{7 1}$ & $\mathbf{1 1 . 1}$ \\
\hline JW-53-085-C & 0.484 & 0.494 & $70.0 \%$ & $2.0 \%$ & 84 & 9.6 \\
\hline
\end{tabular}

*Bold type indicates the experiment selected for further optimization studies. 
Table 7. Effect of Solvent Quantity on PEG Addition Reaction

Part A: Synthesis Parameters and Yield

\begin{tabular}{|c|c|c|c|c|c|c|c|c|c|c|}
\hline & $\begin{array}{c}\% \text { DVB } \\
\text { in } \\
\text { Copolymer }\end{array}$ & $\begin{array}{c}\% \text { VBC } \\
\text { in } \\
\text { Copolymer }\end{array}$ & Solvent & $\begin{array}{c}\mathrm{mL} \text { of Solvent } \\
\text { per } \\
\mathrm{g} \text { of Copolymer }\end{array}$ & $\begin{array}{c}\mathrm{g} \text { of PEG-CH3 } \\
\text { per } \\
\mathrm{g} \text { of copolymer }\end{array}$ & $\begin{array}{c}\mathrm{mg} \text { of } 60 \% \mathrm{NaH} \\
\text { per } \\
\mathrm{g} \text { of copolymer }\end{array}$ & $\begin{array}{c}\mathrm{mg} \text { of } 60 \% \mathrm{NaH} \\
\text { per } \\
\mathrm{g} \text { of PEG-CH3 }\end{array}$ & $\begin{array}{c}\text { Reaction Temp } \\
\text { and } \\
\text { Reaction Time }\end{array}$ & $\begin{array}{c}\text { Yield of ABEC } \\
\text { wet in } g \\
\text { per g of copolymer }\end{array}$ & $\begin{array}{c}\text { Yield of ABEC } \\
\text { wet in } \mathrm{mL} \\
\text { per } \mathrm{g} \text { of copolymer }\end{array}$ \\
\hline JW-53-065-A & $2 \%$ & $20 \%$ & THF & $20 \mathrm{~mL}$ & $3.83 \mathrm{~g}$ & $260 \mathrm{mg}$ & $67.8 \mathrm{mg}$ & reflux / $17 \mathrm{hrs}$ & 2.45 & 3.53 \\
\hline JW-53-085-B & $2 \%$ & $20 \%$ & Diglyme & $10 \mathrm{~mL}$ & $1.30 \mathrm{~g}$ & $52 \mathrm{mg}$ & $40.0 \mathrm{mg}$ & $70^{\circ} \mathrm{C} / 17 \mathrm{hrs}$ & 1.58 & 2.33 \\
\hline JW-53-106-A* & $2 \%$ & $20 \%$ & Diglyme & $6.7 \mathrm{~mL}$ & $1.30 \mathrm{~g}$ & $52 \mathrm{mg}$ & $40.0 \mathrm{mg}$ & $70^{\circ} \mathrm{C} / 17 \mathrm{hrs}$ & 1.76 & 2.60 \\
\hline JW-53-106-B & $2 \%$ & $20 \%$ & Diglyme & $5.0 \mathrm{~mL}$ & $1.30 \mathrm{~g}$ & $52 \mathrm{mg}$ & $40.0 \mathrm{mg}$ & $70^{\circ} \mathrm{C} / 17 \mathrm{hrs}$ & 1.60 & 2.40 \\
\hline
\end{tabular}

Part B: Characterization and Uptake Property

\begin{tabular}{|c|c|c|c|c|c|c|}
\hline & $\begin{array}{c}\text { Bed Density in } \\
\mathrm{H}_{2} \mathrm{O} \\
(\mathrm{g} / \mathrm{mL})\end{array}$ & $\begin{array}{c}\text { Bed Density in } \\
4 \mathrm{M} \mathrm{NaOH} \\
(\mathrm{g} / \mathrm{mL})\end{array}$ & \%Solid & $\begin{array}{c}\text { \% Swelling } \\
\text { During } \\
\text { Stripping }\end{array}$ & $\begin{array}{c}\text { Re Capacity } \\
\mu \text { mole of Re } \\
\text { per ml of wet } \\
\text { resin }\end{array}$ & $\begin{array}{c}\text { Re Affinity } \\
\mu \text { mole of Re } \\
\text { per ml of wet resin }\end{array}$ \\
\hline JW-53-065-A & 0.300 & 0.330 & $43.1 \%$ & $9.1 \%$ & 129 & 15.0 \\
\hline JW-53-085-B & 0.437 & 0.489 & $64.4 \%$ & $10.7 \%$ & 71 & 11.1 \\
\hline JW-53-106-A & $\mathbf{0 . 4 0 3}$ & $\mathbf{0 . 4 6 4}$ & $\mathbf{5 8 . 0 \%}$ & $\mathbf{1 3 . 0 \%}$ & $\mathbf{1 1 8}$ & $\mathbf{1 1 . 7}$ \\
\hline JW-53-106-B & 0.441 & 0.480 & $63.4 \%$ & $8.3 \%$ & 85 & 11.3 \\
\hline
\end{tabular}

*Bold type indicates the experiment selected for further optimization studies. 
approaching the loading capacity of the resin is similar for the three resins $(11.1,11.7$, and $11.3 \mu \mathrm{mol} / \mathrm{mL}$ of resin, respectively), but JW-53-106-A exhibits a greater capacity for rhenium $(118 \mu \mathrm{mol} / \mathrm{mL}$ of resin vs. 71 and $85 \mu \mathrm{mol} / \mathrm{mL})$. The reaction yield was slightly improved in experiment JW-53-106-A. This was attributed to a greater concentration of PEG in the reaction vessel. However, the yield decreased when the solvent was further reduced in experiment $\mathrm{JW}-53-106-\mathrm{B}$. Because the fluidity of the mixture was reduced to an unacceptable level in experiment JW-53-106-B, the quantity of diglyme solvent used for experiment JW-53-106-A $(6.7 \mathrm{~mL} / \mathrm{g}$ copolymer) was chosen as the standard level for further parameter studies.

Effect of Reaction Temperature: The reaction temperature was studied at $78 \mathrm{C}, 85^{\circ} \mathrm{C}$ and $100^{\circ} \mathrm{C}$ (Table 8 ). The changes of reaction temperature between 70 and $100^{\circ} \mathrm{C}$ did not have any significant impact on either the reaction yield or the rhenium uptake of the resulting product. Therefore, a reaction temperature of $7 \mathfrak{C}$ was used in subsequent studies.

Effect of Reaction Time: The impact of reaction time was studied with three reaction periods: 17 hours (JW-53-106-A), 12 hours (JW-53-139-A) and 6 hours (JW-53-139-B). The analysis results shown in Table 9 indicate that the resins prepared with shorter reaction period have similar affinity for rhenium but the loading capacities for rhenium decreased significantly. Also, more floating beads were observed during the transfer with water for the resins prepared with lower reaction time. Since PEG-2000, though not as bulky as PEG-5000, is still a relatively large molecule, more time may be required for the activated alkoxide to contact the methylene chloride group on the substrate, and a longer reaction time for PEG addition should yield resin with better uptake properties. Therefore, a reaction time of 17 hours (experiment JW-53-106-A) was chosen for subsequent copolymer functionalizations.

Study of Substrates with Various levels of VBC:Up to this point, the $2 \%$ crosslinked substrate used for the parameter studies contained $20 \% \mathrm{VBC}$, the functional group for attaching the PEG molecule in the addition reaction. Since the PEG-2000 is moderately bulky, it is very important to leave enough space between the VBC units on the substrate for attaching the PEG molecules. A series of ABEC resins was prepared using copolymers prepared with lower VBC levels(15\% and $10 \%)$. The data summarized in Table 10 show that reducing the VBC content in the substrate from $20 \%$ down to $10 \%$ does not compromise the rhenium uptake performance of ABEC-2000 resin. The resin synthesized with the substrate containing $10 \%$ VBC shows similar affinity character and loading capacity for rhenium compared to the resin made from the substrate with $20 \%$ VBC. Due to the relatively high cost of VBC monomer $(\$ 110 / \mathrm{kg})$ compared to the cost of the styrene and DVB monomers $(\$ 6.57 / \mathrm{kg}$ and $\$ 8.52 / \mathrm{kg}$, respectively), it is advantageous from an economic perspective to reduce the amount of VBC used in the copolymerization. Therefore, a VBC level of 10\% (experiment JW-53-140-C) was chosen for future work. 
Table 8. Effect of Reaction Temperature on PEG Addition Reaction

Part A: Synthesis Parameters and Yield

\begin{tabular}{|c|c|c|c|c|c|c|c|c|c|c|}
\hline & $\begin{array}{c}\% \text { DVB } \\
\text { in } \\
\text { Copolymer }\end{array}$ & $\begin{array}{c}\% \text { VBC } \\
\text { in } \\
\text { Copolymer }\end{array}$ & Solvent & $\begin{array}{c}\mathrm{mL} \text { of Solvent } \\
\text { per } \\
\mathrm{g} \text { of Copolymer }\end{array}$ & $\begin{array}{c}\mathrm{g} \text { of PEG-CH3 } \\
\text { per } \\
\mathrm{g} \text { of copolymer }\end{array}$ & $\begin{array}{c}\mathrm{mg} \text { of } 60 \% \mathrm{NaH} \\
\text { per } \\
\mathrm{g} \text { of copolymer }\end{array}$ & $\begin{array}{c}\mathrm{mg} \text { of } 60 \% \mathrm{NaH} \\
\text { per } \\
\mathrm{g} \text { of PEG-CH3 }\end{array}$ & $\begin{array}{c}\text { Reaction Temp } \\
\text { and } \\
\text { Reaction Time }\end{array}$ & \begin{tabular}{|c|} 
Yield of ABEC \\
wet in $g$ \\
per g of copolymer
\end{tabular} & $\begin{array}{c}\text { Yield of ABEC } \\
\text { wet in } \mathrm{mL} \\
\text { per } \mathrm{g} \text { of copolymer }\end{array}$ \\
\hline JW-53-065-A & $2 \%$ & $20 \%$ & THF & $20 \mathrm{~mL}$ & $3.83 \mathrm{~g}$ & $260 \mathrm{mg}$ & $67.8 \mathrm{mg}$ & reflux / $17 \mathrm{hrs}$ & 2.45 & 3.53 \\
\hline JW-53-106-A* & $2 \%$ & $20 \%$ & Diglyme & $6.7 \mathrm{~mL}$ & $1.30 \mathrm{~g}$ & $52 \mathrm{mg}$ & $40.0 \mathrm{mg}$ & $70^{\circ} \mathrm{C} / 17 \mathrm{hrs}$ & 1.76 & 2.60 \\
\hline JW-53-133-A & $2 \%$ & $20 \%$ & Diglyme & $6.7 \mathrm{~mL}$ & $1.30 \mathrm{~g}$ & $52 \mathrm{mg}$ & $40.0 \mathrm{mg}$ & $85^{\circ} \mathrm{C} / 17 \mathrm{hrs}$ & 1.81 & 2.53 \\
\hline JW-53-133-B & $2 \%$ & $20 \%$ & Diglyme & $6.7 \mathrm{~mL}$ & $1.30 \mathrm{~g}$ & $52 \mathrm{mg}$ & $40.0 \mathrm{mg}$ & $100^{\circ} \mathrm{C} / 17 \mathrm{hrs}$ & 1.77 & 2.53 \\
\hline
\end{tabular}

Part B: Characterization and Uptake Property

\begin{tabular}{|c|c|c|c|c|c|c|}
\hline & $\begin{array}{c}\text { Bed Density in } \\
\mathrm{H}_{2} \mathrm{O} \\
(\mathrm{g} / \mathrm{mL})\end{array}$ & $\begin{array}{c}\text { Bed Density in } \\
4 \mathrm{M} \mathrm{NaOH} \\
(\mathrm{g} / \mathrm{mL})\end{array}$ & \%Solid & $\begin{array}{c}\text { \% Swelling } \\
\text { During } \\
\text { Stripping }\end{array}$ & $\begin{array}{c}\text { Re Capacity } \\
\mu \text { mole of Re } \\
\text { per ml of wet resin }\end{array}$ & $\begin{array}{c}\text { Re Affinity } \\
\mu \text { mole of Re } \\
\text { per ml of wet resin }\end{array}$ \\
\hline JW-53-065-A & 0.300 & 0.330 & $43.1 \%$ & $9.1 \%$ & 129 & 15.0 \\
\hline JW-53-106-A & $\mathbf{0 . 4 0 3}$ & $\mathbf{0 . 4 6 4}$ & $\mathbf{5 8 . 0 \%}$ & $\mathbf{1 3 . 0 \%}$ & $\mathbf{1 1 8}$ & 11.7 \\
\hline JW-53-133-A & 0.404 & 0.436 & $57.4 \%$ & $7.4 \%$ & 110 & 12.0 \\
\hline JW-53-133-B & 0.399 & 0.435 & $58.8 \%$ & $8.3 \%$ & 96 & 11.7 \\
\hline
\end{tabular}

*Bold type indicates the experiment selected for further optimization studies. 
Table 9. Effect of Reaction Time on PEG Addition Reaction

Part A: Synthesis Parameters and Yield

\begin{tabular}{|c|c|c|c|c|c|c|c|c|c|c|}
\hline & $\begin{array}{l}\text { \% DVB } \\
\text { in } \\
\text { Copolymer }\end{array}$ & $\begin{array}{c}\% \text { VBC } \\
\text { in } \\
\text { Copolymer }\end{array}$ & Solvent & $\begin{array}{c}\mathrm{mL} \text { of Solvent } \\
\text { per } \\
\mathrm{g} \text { of Copolymer }\end{array}$ & $\begin{array}{c}\mathrm{g} \text { of PEG-CH3 } \\
\text { per } \\
\mathrm{g} \text { of copolymer }\end{array}$ & $\begin{array}{c}\mathrm{mg} \text { of } 60 \% \mathrm{NaH} \\
\text { per } \\
\mathrm{g} \text { of copolymer }\end{array}$ & $\begin{array}{c}\mathrm{mg} \text { of } 60 \% \mathrm{NaH} \\
\text { per } \\
\mathrm{g} \text { of PEG-CH3 }\end{array}$ & $\begin{array}{c}\text { Reaction Temp } \\
\text { and } \\
\text { Reaction Time }\end{array}$ & $\begin{array}{c}\text { Yield of ABEC } \\
\text { wet in } g \\
\text { per } \mathrm{g} \text { of copolymer }\end{array}$ & $\begin{array}{c}\text { Yield of ABEC } \\
\text { wet in mL } \\
\text { per g of copolymer }\end{array}$ \\
\hline JW-53-065-A & $2 \%$ & $20 \%$ & THF & $20 \mathrm{~mL}$ & $3.83 \mathrm{~g}$ & $260 \mathrm{mg}$ & $67.8 \mathrm{mg}$ & reflux / $17 \mathrm{hrs}$ & 2.45 & 3.53 \\
\hline JW-53-106-A* & $2 \%$ & $20 \%$ & Diglyme & $6.7 \mathrm{~mL}$ & $1.30 \mathrm{~g}$ & $52 \mathrm{mg}$ & $40.0 \mathrm{mg}$ & $70^{\circ} \mathrm{C} / 17 \mathrm{hrs}$ & $\overline{1.76}$ & 2.60 \\
\hline JW-53-139-A & $2 \%$ & $20 \%$ & Diglyme & $6.7 \mathrm{~mL}$ & $1.30 \mathrm{~g}$ & $52 \mathrm{mg}$ & $40.0 \mathrm{mg}$ & $70^{\circ} \mathrm{C} / 12 \mathrm{hrs}$ & 1.81 & 2.40 \\
\hline JW-53-139-B & $2 \%$ & $20 \%$ & Diglyme & $6.7 \mathrm{~mL}$ & $1.30 \mathrm{~g}$ & $52 \mathrm{mg}$ & $40.0 \mathrm{mg}$ & $70^{\circ} \mathrm{C} / 6 \mathrm{hrs}$ & 1.77 & 2.47 \\
\hline
\end{tabular}

Part B: Characterization and Uptake Property

\begin{tabular}{|c|c|c|c|c|c|c|}
\hline & $\begin{array}{c}\text { Bed Density in } \\
\mathrm{H}_{2} \mathrm{O} \\
(\mathrm{g} / \mathrm{mL})\end{array}$ & $\begin{array}{c}\text { Bed Density in } \\
4 \mathrm{M} \mathrm{NaOH} \\
(\mathrm{g} / \mathrm{mL})\end{array}$ & \%Solid & $\begin{array}{c}\text { \% Swelling } \\
\text { During } \\
\text { Stripping }\end{array}$ & $\begin{array}{c}\text { Re Capacity } \\
\mu \text { mole of Re } \\
\text { per ml of wet resin }\end{array}$ & $\begin{array}{c}\text { Re Affinity } \\
\mu \mathrm{mole} \text { of Re } \\
\text { per ml of wet resin }\end{array}$ \\
\hline JW-53-065-A & 0.300 & 0.330 & $43.1 \%$ & $9.1 \%$ & 129 & 15.0 \\
\hline JW-53-106-A & $\mathbf{0 . 4 0 3}$ & $\mathbf{0 . 4 6 4}$ & $\mathbf{5 8 . 0 \%}$ & $\mathbf{1 3 . 0 \%}$ & $\mathbf{1 1 8}$ & 1.7 \\
\hline JW-53-139-A & 0.434 & 0.460 & $61.7 \%$ & $5.7 \%$ & 89 & 11.8 \\
\hline JW-53-139-B & 0.431 & 0.461 & $61.6 \%$ & $6.5 \%$ & 52 & 11.5 \\
\hline
\end{tabular}

*Bold type indicates the experiment selected for further optimization studies. 
Table 10. Study of PEG Addition Reaction Using Copolymers with Various Levels of VBC

Part A: Synthesis Parameters and Yield

\begin{tabular}{|c|c|c|c|c|c|c|c|c|c|c|}
\hline & $\begin{array}{c}\% \text { DVB } \\
\text { in } \\
\text { Copolymer }\end{array}$ & $\begin{array}{c}\% \text { VBC } \\
\text { in } \\
\text { Copolymer }\end{array}$ & Solvent & $\begin{array}{c}\mathrm{mL} \text { of Solvent } \\
\text { per } \\
\mathrm{g} \text { of Copolymer }\end{array}$ & $\begin{array}{c}\mathrm{g} \text { of PEG-CH3 } \\
\text { per } \\
\mathrm{g} \text { of copolymer }\end{array}$ & $\begin{array}{c}\mathrm{g} \text { of } 60 \% \mathrm{NaH} \\
\text { per } \\
\mathrm{g} \text { of copolymer }\end{array}$ & $\begin{array}{c}\mathrm{mg} \text { of } 60 \% \mathrm{NaH} \\
\text { per } \\
\mathrm{g} \text { of PEG-CH3 }\end{array}$ & $\begin{array}{c}\text { Reaction Temp } \\
\text { and } \\
\text { Reaction Time }\end{array}$ & \begin{tabular}{|c|} 
Yield of ABEC \\
wet in $g$ \\
per g of copolymer
\end{tabular} & \begin{tabular}{|c|} 
Yield of ABEC \\
wet in $\mathrm{mL}$ \\
per g of copolymer
\end{tabular} \\
\hline JW-53-065-A & $2 \%$ & $20 \%$ & THF & $20 \mathrm{~mL}$ & $3.83 \mathrm{~g}$ & $260 \mathrm{mg}$ & $67.8 \mathrm{mg}$ & reflux / $17 \mathrm{hrs}$ & 2.45 & 3.53 \\
\hline JW-53-106-A & $2 \%$ & $20 \%$ & Diglyme & $6.7 \mathrm{~mL}$ & $1.30 \mathrm{~g}$ & $52 \mathrm{mg}$ & $40.0 \mathrm{mg}$ & $70^{\circ} \mathrm{C} / 17 \mathrm{hrs}$ & 1.76 & 2.60 \\
\hline JW-53-140-A & $2 \%$ & $20 \%$ & Diglyme & $6.7 \mathrm{~mL}$ & $1.30 \mathrm{~g}$ & $52 \mathrm{mg}$ & $40.0 \mathrm{mg}$ & $70^{\circ} \mathrm{C} / 17 \mathrm{hrs}$ & 1.91 & 2.70 \\
\hline JW-53-140-B & $2 \%$ & $15 \%$ & Diglyme & $6.7 \mathrm{~mL}$ & $1.30 \mathrm{~g}$ & $52 \mathrm{mg}$ & $40.0 \mathrm{mg}$ & $70^{\circ} \mathrm{C} / 17 \mathrm{hrs}$ & 2.25 & 2.83 \\
\hline JW-53-140-C* & $2 \%$ & $10 \%$ & Diglyme & $6.7 \mathrm{~mL}$ & $1.30 \mathrm{~g}$ & $52 \mathrm{mg}$ & $40.0 \mathrm{mg}$ & $70^{\circ} \mathrm{C} / 17 \mathrm{hrs}$ & 1.77 & 2.67 \\
\hline
\end{tabular}

Part B: Characterization and Uptake Property

\begin{tabular}{|c|c|c|c|c|c|c|}
\hline & $\begin{array}{c}\text { Bed Density in } \\
\mathrm{H}_{2} \mathrm{O} \\
(\mathrm{g} / \mathrm{mL})\end{array}$ & $\begin{array}{c}\text { Bed Density in } \\
4 \mathrm{M} \mathrm{NaOH} \\
(\mathrm{g} / \mathrm{mL})\end{array}$ & \%Solid & $\begin{array}{c}\text { \% Swelling } \\
\text { During } \\
\text { Stripping }\end{array}$ & $\begin{array}{c}\text { Re Capacity } \\
\mu \text { mole of Re } \\
\text { per ml of wet resin }\end{array}$ & $\begin{array}{c}\text { Re Affinity } \\
\mu \mathrm{mole} \text { of Re } \\
\text { per ml of wet resin }\end{array}$ \\
\hline JW-53-065-A & 0.300 & 0.330 & $43.1 \%$ & 9.1 & 129 & 15.0 \\
\hline JW-53-106-A & 0.403 & 0.464 & $58.0 \%$ & $13.0 \%$ & 118 & 11.7 \\
\hline JW-53-140-A & 0.401 & 0.449 & $56.5 \%$ & $10.7 \%$ & 97 & 13.5 \\
\hline JW-53-140-B & 0.346 & 0.436 & $48.3 \%$ & $20.6 \%$ & 132 & 13.8 \\
\hline JW-53-140-C & $\mathbf{0 . 4 1 6}$ & $\mathbf{0 . 4 5 4}$ & $\mathbf{5 8 . 0 \%}$ & $\mathbf{8 . 3 \%}$ & $\mathbf{1 2 7}$ & $\mathbf{1 3 . 3}$ \\
\hline
\end{tabular}

*Bold type indicates the experiment selected for further optimization studies. 
Sodium Methoxide as a Substitute for Sodium Hydride:Several batches of ABEC2000 resin were prepared from $2 \%$ crosslinked substrate using sodium methoxide to activate the PEG. However, in each case the resin percent solids was higher and the synthetic yield and rhenium uptake performance lower than for resin JW-53-140-C, which was prepared using sodium hydride to activate the PEG (Table 11). All of these factors indicate that a lower level of substrate functionalization was obtained when sodium methoxide was used instead of sodium hydride. Additional work is needed in order to improve the level of functionalization obtained when sodium methoxide is used to replace sodium hydride as the activating agent.

Table 11. Results of Replacing Sodium Hydride with Sodium Methoxide

\begin{tabular}{|c|c|c|c|c|c|c|c|}
\hline Lot \# & $\begin{array}{l}\text { Yield of } \\
\text { ABEC } \\
\text { wet in g } \\
\text { per g of } \\
\text { copolymer }\end{array}$ & $\begin{array}{l}\text { Yield of } \\
\text { ABEC } \\
\text { wet in mL } \\
\text { per g of } \\
\text { copolymer }\end{array}$ & $\begin{array}{c}\text { Bed } \\
\text { Density in } \\
\mathrm{H}_{2} \mathrm{O} \\
(\mathrm{g} / \mathrm{mL})\end{array}$ & $\mid \begin{array}{c}\text { Bed } \\
\text { Density in } \\
4 \mathrm{M} \\
\mathrm{NaOH} \\
(\mathrm{g} / \mathrm{mL})\end{array}$ & $\%$ Solid & $\begin{array}{c}\mathrm{Re} \\
\text { Capacity } \\
\mu \mathrm{mol} \text { of } \\
\mathrm{Re} \\
\text { per mL of } \\
\text { wet resin }\end{array}$ & $\begin{array}{c}\text { Re } \\
\text { Affinity } \\
\mu \text { mol of } \\
\text { Re } \\
\text { per ml of } \\
\text { wet resin }\end{array}$ \\
\hline $\mathrm{JW}-53-140-\mathrm{C}^{\mathrm{n}}$ & 1.77 & 2.67 & 0.416 & 0.454 & $58.0 \%$ & 127 & 13.3 \\
\hline $\mathrm{JW}-53-118^{\mathrm{b}}$ & 1.27 & 1.87 & 0.522 & 0.564 & $76.6 \%$ & -- & 3.4 \\
\hline JW-53-146 & 1.58 & 2.37 & 0.444 & 0.466 & $64.0 \%$ & 21 & 8.9 \\
\hline$J W-53-148^{b}$ & 1.33 & 1.97 & 0.499 & 0.529 & $73.7 \%$ & 68 & 4.2 \\
\hline CD-73-005 & 1.46 & 2.00 & 0.484 & 0.498 & $70.7 \%$ & 78 & 2.7 \\
\hline
\end{tabular}

a. Sodium hydride used to activate PEG.

b. Sodium methoxide used to activate PEG.

Synthesis Summary: The substrate synthesis and composition and the parameters of the PEG addition reaction have been optimized in this project. Based on compromises between physical characteristics, uptake performance, and production safety and cost considerations, the ABEC-2000 resin produced in experiment JW-53-140-C was selected as the model for the scale up syntheses. The substrate characteristics and reaction conditions follow:

Substrate: regular gel-type copolymer with $2 \%$ DVB and $10 \%$ VBC,

Particle Size: 30 to 60 mesh,

Solvent: $6.7 \mathrm{~mL}$ of Diglyme / $\mathrm{g}$ of copolymer,

PEG-2000: $1.30 \mathrm{~g} / \mathrm{g}$ of copolymer, $\mathrm{NaH}(60 \%): \quad 52 \mathrm{mg} / \mathrm{g}$ of copolymer, Reaction Temp.: $\quad 70^{\circ} \mathrm{C}$, Reaction Time: 17 hours. 


\section{Uptake and Column Loading/Elution Studies of Technetium-Spiked Waste Simulants}

Uptake studies for removal of ${ }^{99} \mathrm{TcO}_{4}^{-}$from waste simulant solutions (see discussion on p. 21) were conducted to demonstrate removal of technetium from simulants of actual waste streams generated at two BNFL sites. The solution referred to as BNFL Sellafield waste simulant contained only a very low concentration of biphase forming anion ( $0.03 \mathrm{M}$ carbonate ion) and a high concentration of nitrate ion $(2.4 \mathrm{M})$. The uptake of technetium by ABEC-5000 (100 to 200 mesh, 1\% crosslinked chloromethylated polystyrene beads functionalized with PEG-5000) from the BNFL Sellafield waste simulant was determined as the $\mathrm{N}_{2} \mathrm{OO}_{3}$ concentration was increased from the initial concentration of $0.03 \mathrm{M}$ to $1.0 \mathrm{M}$ (Figure 15). The technetium distribution was found to increase with increasing $\mathrm{N}_{2} \mathrm{CO}_{3}$ concentration, but in every case the values were less than 100 .

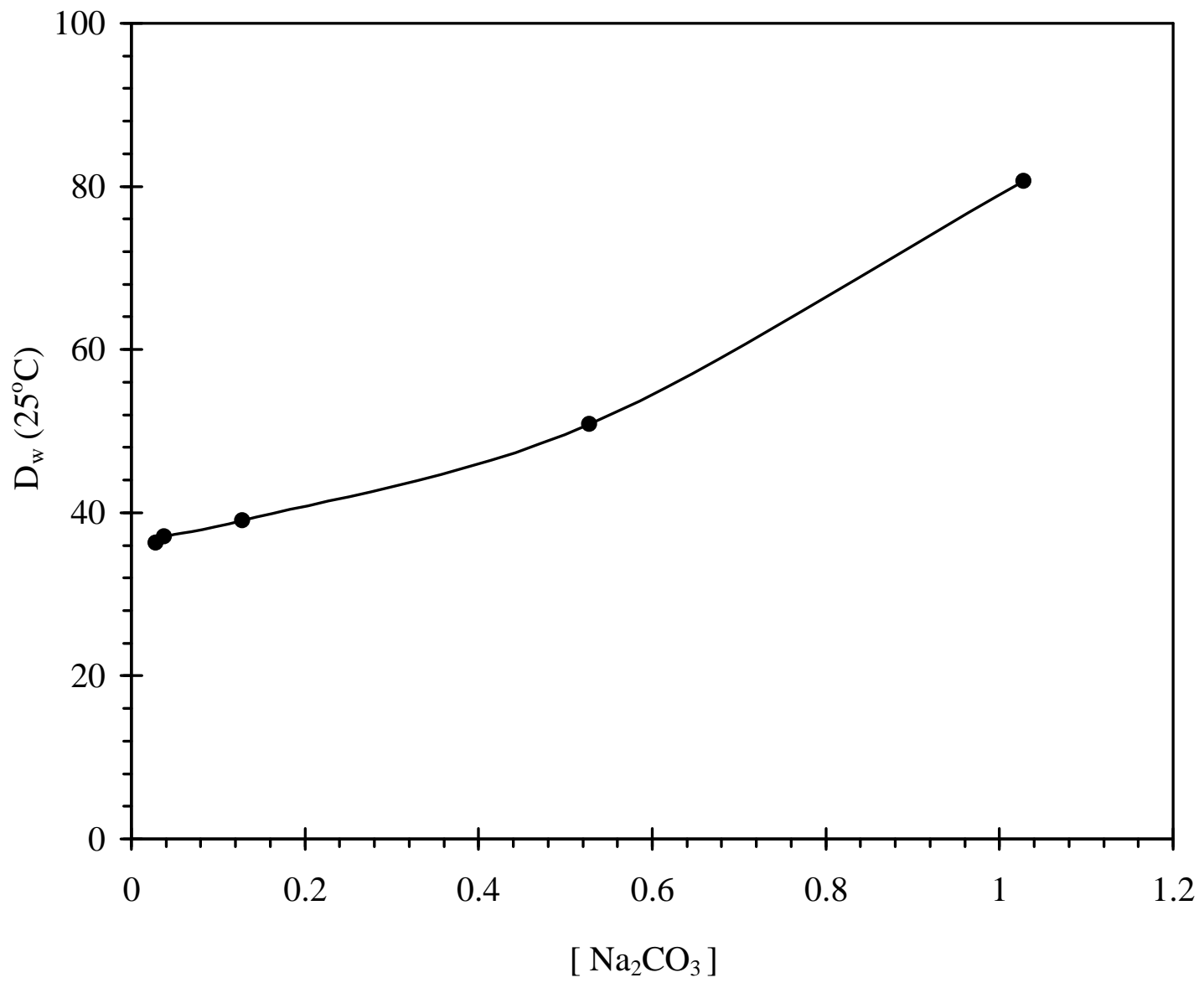

Figure 15. $\mathrm{TcO}_{4}{ }^{-} \mathrm{D}_{\mathrm{w}}$ with $\mathrm{ABEC}-5000$ vs. total $\left[\mathrm{NaCO}_{3}\right]$ in BNFL Sellafield waste simulant solution. 
Next, higher concentrations of biphase-forming salts $\left(1.3 \mathrm{M}_{2} \mathbf{K O}_{3}, 1.4 \mathrm{M}\right.$ $\mathrm{Na}_{2} \mathrm{CO}_{3}$, and $\left.1.7 \mathrm{M}\left(\mathrm{NH}_{4}\right)_{2} \mathrm{SO}_{4}\right)$ were added to the waste simulant and $\mathrm{Q}$ values greater

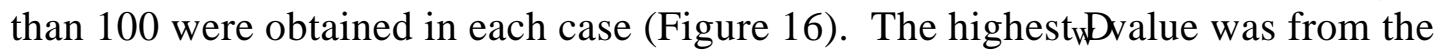
simulant to which $1.3 \mathrm{M} \mathrm{KCO}_{3}$ had been added. The technetium uptake will likely increase as the $\mathrm{KCO}_{3}$ concentration is increased even further (see Figure 2). The addition of carbonate salts to the waste stream to enhance the uptake of technetium by ABEC resins is acceptable to BNFL because the treated waste will be released to the ocean, which already contains high concentrations of carbonate species.

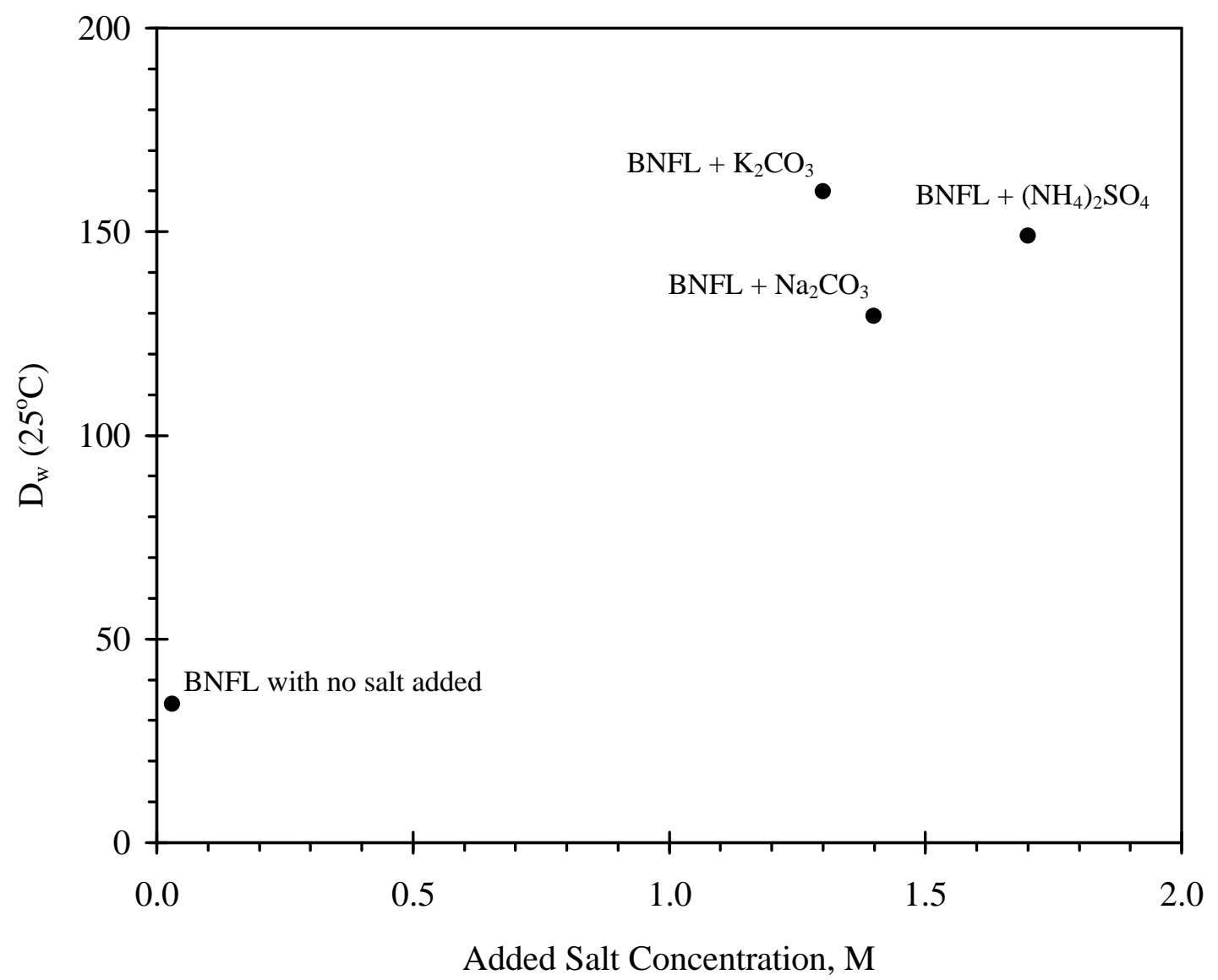

Figure 16. $\mathrm{TcO}_{4}{ }^{-} \mathrm{D}_{\mathrm{W}}$ with $\mathrm{ABEC}-5000$ vs. molarities of different biphase-forming salts added to BNFL Sellafield waste simulant solution.

The technetium distribution ratio for the BNFL Sellafield simulant iwh had been made 1.3 $\mathrm{M}$ in $\mathrm{K}_{2} \mathrm{CO}_{3}$ was also measured for the ABEC-2000 resin FC-54-026-B, the most promising ABEC-2000 resin which had been produced at the time this work was performed. An average $\mathrm{D}_{\mathrm{W}}$ value of 67 was obtained. While this is less than the $\mathrm{Dvalue}$ of 180 measured for ABEC-5000 resin, the difference is largely due to the the fact that ABEC-5000 resin has a dwcf value of 0.12 compared to a dwcf of 0.42 for resin FC-54026-B. Based on the differences in the bed densities in $4 \mathrm{M} \mathrm{NaOH}$ (see Figure 11) for these resins, the $\mathrm{D}_{\mathrm{w}}$ 's for ABEC-5000 resin and resin FC-54-026-B would convert to 
Dv's of approximately 20 and 22, respectively. This indicates that on a volume basis, the resins were equally effective in removing technetium from this waste solution.

Technetium $\mathrm{D}_{\mathrm{v}}$ values from the BNFL Capenhurst waste simulant solution were also measured for ABEC-5000 resin and resin FC-54-026-B. This simulant solution contained relatively high concentrations of the biphase-forming anion sulfate. The solution also contained moderate concentrations of aluminum and iron(II) cations, both of which were shown to enhance the uptake of technetium. The averagenDralue for ABEC-5000 resin was 3552 while resin FC-54-026-B gave an averagewDf 728. Again, using the bed densities in $4 \mathrm{M} \mathrm{NaOH}$, these values convert to approximate Dalues of 391 for ABEC-5000 resin and 239 for resin FC-54-026-B. Based on these results, both resins exhibit very good uptake of technetium from the Capenhurst waste simulant.

The loadingand elution behavior of ${ }^{99} \mathrm{TcO}_{4}{ }^{-}$on ABEC-5000 resin (100 to 200 mesh) and resin FC-54-026-B (50 to 100 mesh) for the BNFL Capenhurst waste simulant solution were also investigated (Figures 17 and 18, respectively).

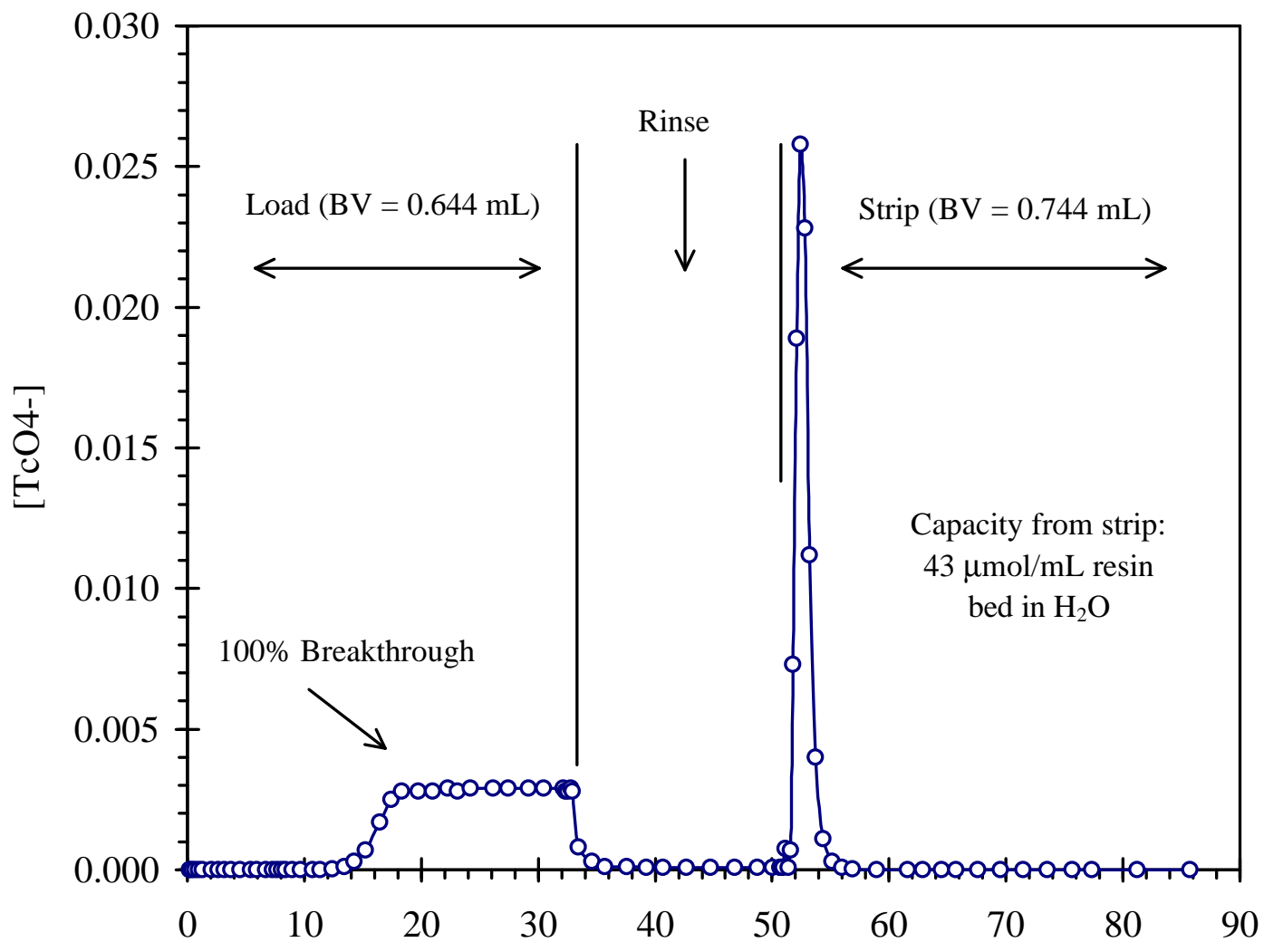

Geometric Bed Volumes

Figure 17. Column loading and elution of TcQ in BNFL Capenhurst waste simulant with ABEC-5000 resin. 
The initial concentration of pertechnetate in the ABEC-5000 resin load solution was 2.92 $\mathrm{mM}$, and $100 \%$ breakthrough was reached at 18 bed volumes $(0.644 \mathrm{~mL} / \mathrm{BV})$ of load solution (Figure 17). The loading capacity, based on the amount of technetium stripped from the column was $43 \mu \mathrm{mol} / \mathrm{mL}$ of resin bed in water $(4.3 \mathrm{~g}$ technetium per liter of resin). Essentially all of the technetium was stripped in 5 bed volumes.

The initial concentration of pertechnetate in the load solution for resin FC-54-026B was $6.99 \mathrm{mM}$, and $100 \%$ breakthrough was reached at 17 bed volumes $(0.729 \mathrm{~mL} / \mathrm{BV})$ of load solution (Figure 18). Greater than $95 \%$ of the technetium was stripped in the first 8 bed volumes. The technetium loading capacity based on the total amount of technetium stripped from the resin was $81 \mu \mathrm{mol} / \mathrm{mL}$ ( $8.0 \mathrm{~g}$ technetium per liter of resin). The capacity values for both resins are of the same order of magnitude as typical rhenium saturation capacities measured for the ABEC resins discussed in previous sections.

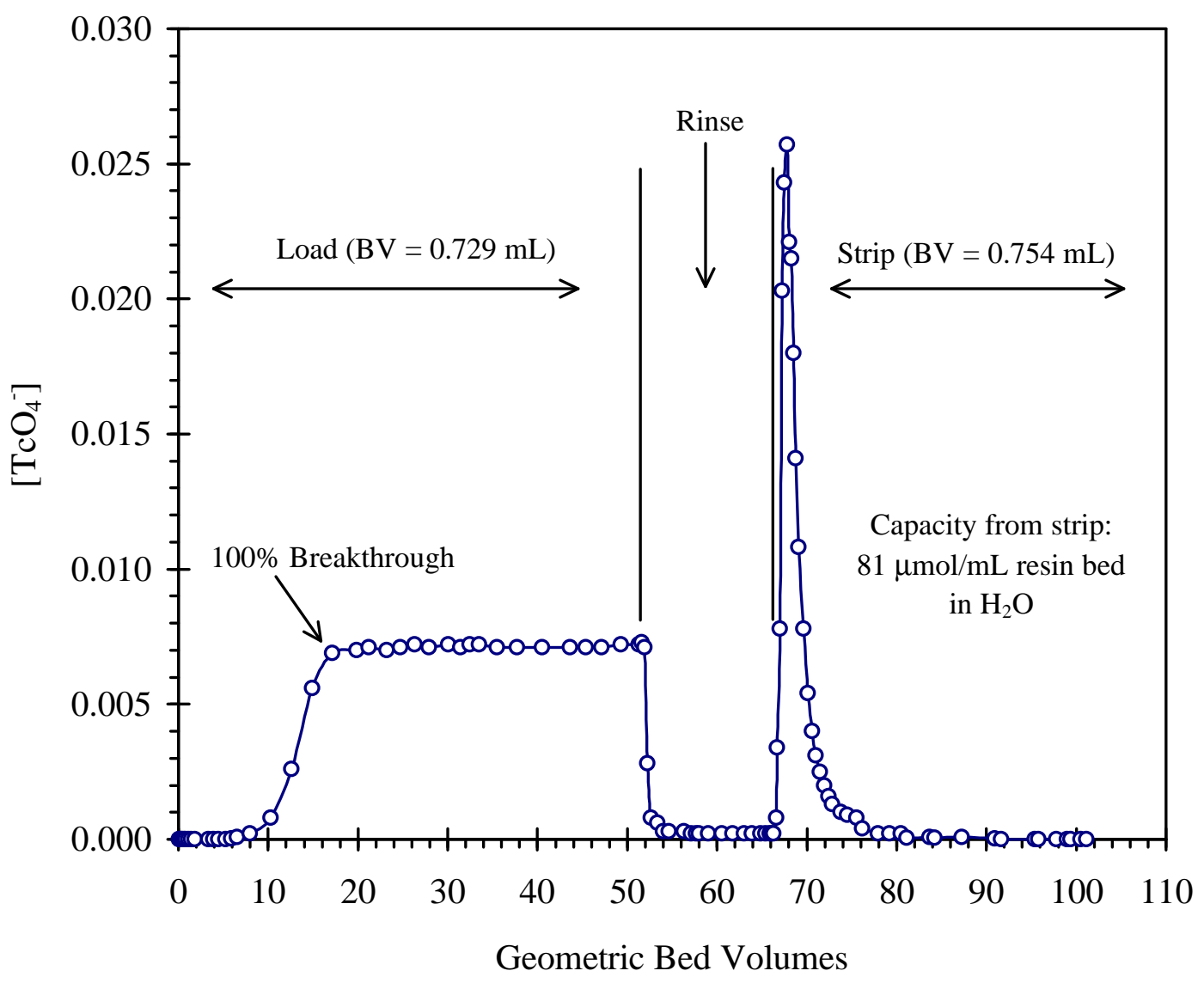

Figure 18. Column loading and elution of $T c \emptyset$ in BNFL Capenhurst waste simulant with resin FC-54-026-B. 


\section{Scale-Up}

The formula summarized from the laboratory synthesis was scaled-up inifent (synthesis of substrate), 5-liter (addition of PEG), and 110-liter (both synthesis of substrate and addition of PEG) reactors. The complete production flowsheets for the process used in the 110-liter reactor are presented in Appendix C. The processes and results of each step of scale-up are discussed in the following sections.

Synthesis of Substrate (Copolymerization):The quantity of monomers used for each size of reactor and the yield of copolymerization from each size of reactor are summarized in Table 12. The chlorine contents of the substrates (representative of the VBC incorporation into the polymer) prepared in both 2-liter and 110-liter reactors were determined (Table 12) and the values are very close to the theoretically calculated chlorine content of $0.65 \mathrm{meq} / \mathrm{g}$. The stirring speed chosen for the 110 -liter reactor was $150 \mathrm{rpm}$ which gave a product containing $85 \%$ of the copolymer beads within the expected particle size range (30 to 60 mesh). The reaction showed a very minor exothermic phenomenon (Figure 19 and Appendix B) but the exotherm was well controlled by the reactor's cooling system. This exotherm could be avoided or minimized by decreasing the rate at which the temperature is raised from $6 \% \mathrm{C}$ to $74^{\circ} \mathrm{C}$.

Table 12. Reactant Quantities and Synthesis Yields for Scale-Up of Copolymer Synthesis

\begin{tabular}{|c|c|c|}
\hline Lot \# & FC-54-055 & JW-53-152 \\
\hline Reactor Size & 2 -Liter & $110-$ Liter \\
\hline Styrene & $616.25 \mathrm{~g}$ & $18.486 \mathrm{Kg}$ \\
\hline VBC $(10 \%)$ & $71.65 \mathrm{~g}$ & $2.148 \mathrm{Kg}$ \\
\hline DVB(2\%) & $26.03 \mathrm{~g}$ & $0.781 \mathrm{Kg}$ \\
\hline BPO(0.3\%) & $2.15 \mathrm{~g}$ & $64.5 \mathrm{~g}$ \\
\hline & & $92.7 \%$ \\
\hline Yield & $93.0 \%$ & $0.61 \mathrm{meq} / \mathrm{g}$ \\
\hline Chlorine content & $0.63 \mathrm{meq} / \mathrm{g}$ & $84.1 \%$ \\
\hline -30+60 Mesh & $86.20 \%$ & \\
\hline
\end{tabular}

Addition of PEG-2000: The PEG addition reaction was scaled-up in 5-liter and 110-liter reactors. The quantity of chemicals used for both size reactors and the yields of functionalizations are summarized in Table 13A. The rhenium and technetium uptake performance of these ABEC-2000 resins prepared from different size reactors are compared in Table 13B, and technetium profiles in $\mathrm{NaOH}$ solution are shown in Figure 20. These data indicate that the products are comparable, with JW-53-151-A and JW-53-155 exhibiting slightly higher affinity for rhenium and technetium than JW-53-140C. This difference may be due to a slight modification of the process for JW-53-155. 


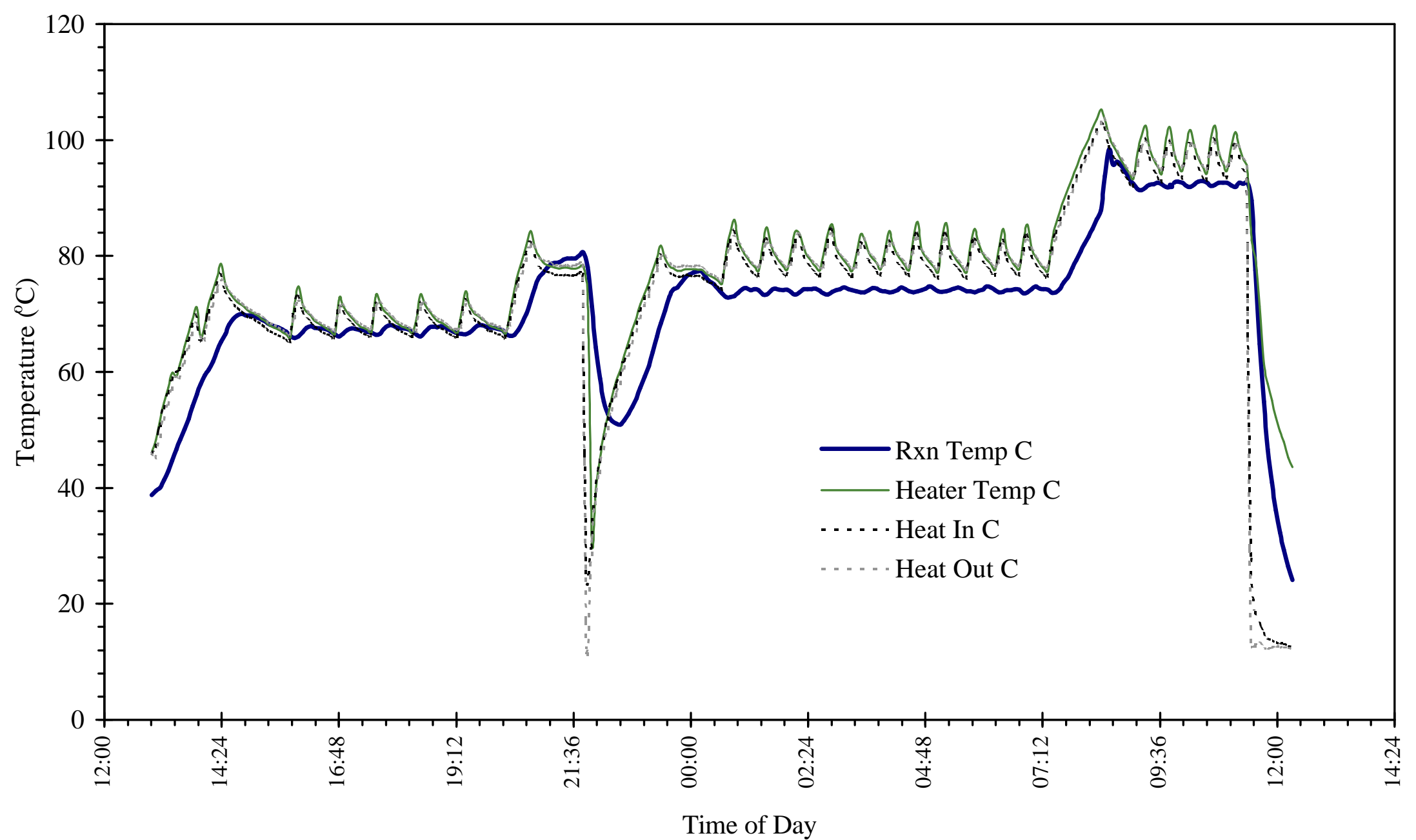

Figure 19. Temperature record of copolymerization reaction in 110-liter reactor. 
Table 13. Comparison of ABEC-2000 Resins from Different Size Reactors

Part A. Synthesis Parameters and Yields

\begin{tabular}{|c|c|c|c|c|c|c|c|}
\hline Lot \# & Reactor Size & Copolymer & Diglyme & CH3-PEG-2000-OH & NaH(60\%) & Yield, Buchner dried & Yield, Volume \\
\hline JW-53-140-C & $500-\mathrm{mL}$ & $30 \mathrm{~g}$ & $200 \mathrm{~mL}$ & $39.00 \mathrm{~g}$ & $1.56 \mathrm{~g}$ & $53.2 \mathrm{~g}$ & $80 \mathrm{~mL}$ \\
\hline JW-54-151-A & 5 -liter & $300 \mathrm{~g}$ & $2000 \mathrm{~mL}$ & $390 \mathrm{~g}$ & $15.6 \mathrm{~g}$ & $622.0 \mathrm{~g}$ & $905 \mathrm{~mL}$ \\
\hline JW-53-155 & 110 -liter & $6.60 \mathrm{~kg}$ & $44 \mathrm{~L}$ & $8.58 \mathrm{~kg}$ & $343.2 \mathrm{~g}$ & $14.7 \mathrm{~kg}$ & $19.9 \mathrm{~L}$ \\
\hline
\end{tabular}

Part B. Characterization and Uptake Property

\begin{tabular}{|c|c|c|c|c|c|c|c|c|}
\hline Lot \# & $\begin{array}{c}\text { Bed Density in } \\
\mathrm{H}_{2} \mathrm{O} \\
(\mathrm{g} / \mathrm{mL})\end{array}$ & $\begin{array}{c}\text { Bed Density in } \\
4 \mathrm{M} \mathrm{NaOH} \\
(\mathrm{g} / \mathrm{mL})\end{array}$ & $\%$ Solid & $\begin{array}{c}\text { \% Swelling } \\
\text { During } \\
\text { Stripping }\end{array}$ & $\begin{array}{c}\text { Re Capacity } \\
\mu \text { mol of Re } \\
\text { per mL of wet } \\
\text { resin }\end{array}$ & $\begin{array}{c}\text { Re } \mathrm{Affinity}_{\mu \mathrm{mol} \text { of } \mathrm{Re}} \\
\text { per mL of wet } \\
\text { resin }\end{array}$ & $\begin{array}{c}\mathrm{TcO}_{4}{ }^{-} \mathrm{D}_{\mathrm{w}} \\
\text { in } \\
4 \mathrm{M} \mathrm{NaOH}\end{array}$ & $\begin{array}{c}\mathrm{TcO}_{4}{ }^{-} \mathrm{D}_{\mathrm{v}} \\
\text { in } \\
4 \mathrm{M} \mathrm{NaOH}\end{array}$ \\
\hline JW-53-140-C & 0.416 & 0.454 & $58.0 \%$ & $8.3 \%$ & 127 & 13.1 & 122 & 55.4 \\
\hline JW-54-151-A & 0.359 & 0.370 & $52.1 \%$ & $2.9 \%$ & 158 & 13.7 & 176 & 65.1 \\
\hline JW-53-155 & 0.382 & 0.428 & $53.0 \%$ & $10.7 \%$ & 166 & 15.3 & 192 & 82.2 \\
\hline
\end{tabular}




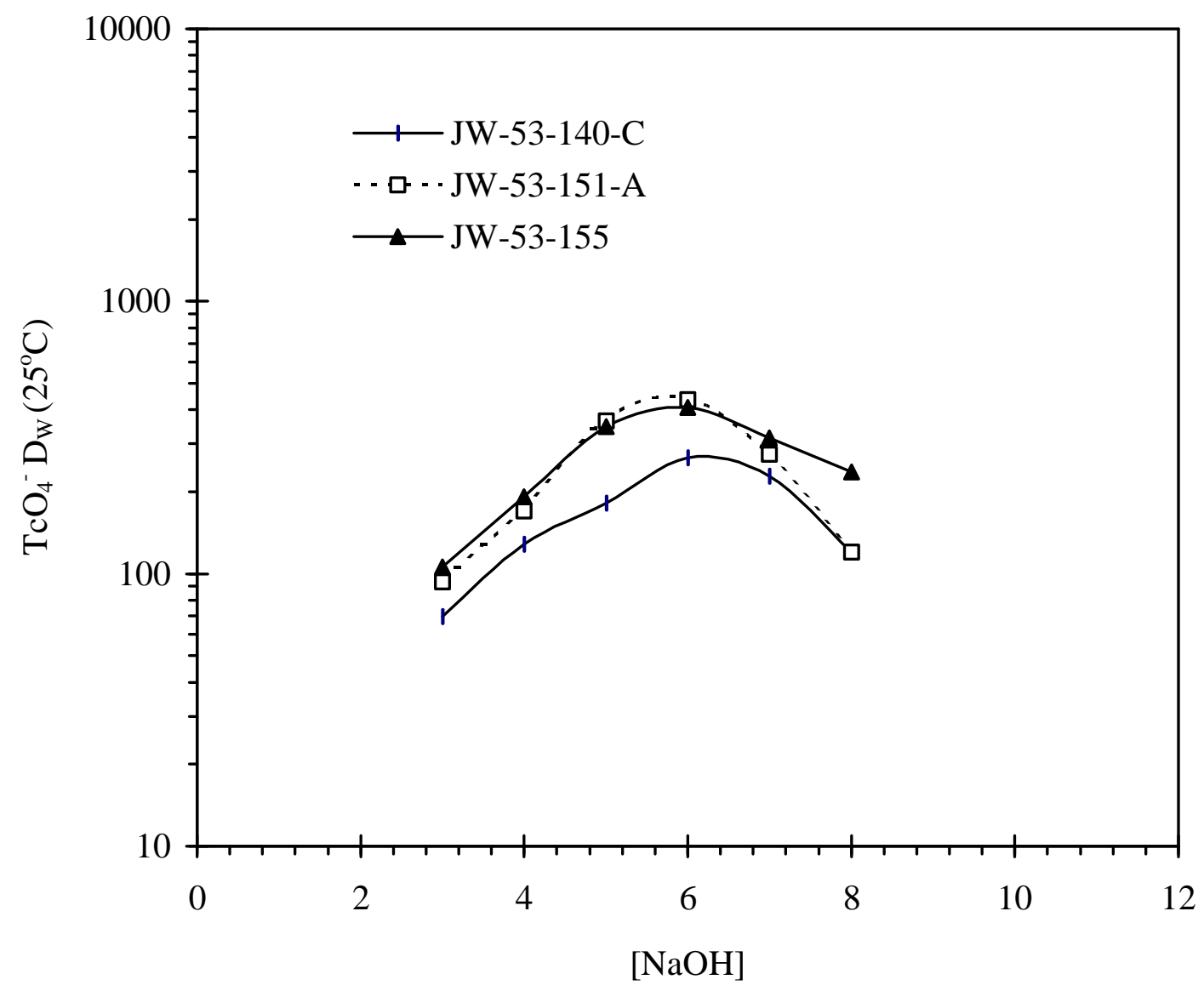

Figure 20. $\mathrm{TcO}_{4}{ }^{-} \mathrm{D}_{\mathrm{W}}$ vs. $[\mathrm{NaOH}]$ for $\mathrm{ABEC}-2000$ resins produced from larger scale reactions.

Because the PEG addition reaction step involves hydrogen evolution, the synthesis in the 110-liter reactor was processed with a nitrogen flow to dilute the concentration of hydrogen produced during the reaction and sweep it from the reactor headspace. Also, the sodium hydride was added over a longer, 8 hour period in order to control the rate of hydrogen gas evolution.

The column loading and elution behavior of Re-Owith resin JW-53-155 was investigated in two different experiments. In the first experiment (Figure 21) 26.4 BV's $(161 \mathrm{~mL})$ of load solution, consisting of $1.1 \mathrm{mg} / \mathrm{mL}$ rhenium $\left(6 \times 010^{-3} \mathrm{M}\right)$ in $4 \mathrm{M}$ $\left(\mathrm{NH}_{4}\right)_{2} \mathrm{SO}_{4}$ solution, was passed through the column at a rate of $1.4 \mathrm{~mL} / \mathrm{min}$. The column was rinsed with approximately $14.0 \mathrm{BV}$ 's $(85.1 \mathrm{~mL})$ of $4 \mathrm{M}\left(\mathrm{NH}_{1} \mathrm{SO}_{4}\right.$ solution and then stripped with 11.4 BV's (71.3 mL) of DI water. Greater than $95 \%$ of the rhenium was stripped in the first 3 BV's $(\mathrm{mL})$ resulting in a concentration factor from load to strip of 10.2. The resin capacity for rhenium determined from this study was $1 \beta \mathrm{mol} / \mathrm{mL}$ resin ( $24 \mathrm{~g}$ rhenium per liter of resin). 
In the second experiment (Figure 22) $256 \mathrm{BV}$ 's (1557 mL) of load solution, consisting of $0.10 \mathrm{mg} / \mathrm{mL}$ rhenium $\left(5 . * 10^{-4} \mathrm{M}\right)$ in $4 \mathrm{M}\left(\mathrm{NH}_{4}\right)_{2} \mathrm{SO}_{4}$ solution, were passed through the column at a flow rate of $5.6 \mathrm{~mL} / \mathrm{min}$. The column was rinsed with $4.1 \mathrm{BV}$ 's $(25 \mathrm{~mL})$ of $4 \mathrm{M}\left(\mathrm{NH}_{4}\right)_{2} \mathrm{SO}_{4}$ solution and then stripped with $18.4 \mathrm{BV}$ 's (115 mL) of DI water at a flow rate of $3.4 \mathrm{~mL} / \mathrm{min}$. A total of $101 \mathrm{mg}$ of rhenium was removed from the column for a capacity of $87 \mathrm{mmol}$ rhenium per $\mathrm{mL}$ of resin bed in water $(16 \mathrm{~g}$ rhenium per liter of resin). Approximately $95 \%$ of the rhenium was stripped in the first 6.0 BV's (38 $\mathrm{mL}$ ) for a final concentration factor from load to strip of approximately 25 . Given that the concentation of rhenium used in this experiment was approximately 10 times greater than the expected average concentration of technetium in actual wastes, it is reasonable to assume that concentration factors of at least 100 can be attained for technetium from tank waste streams.

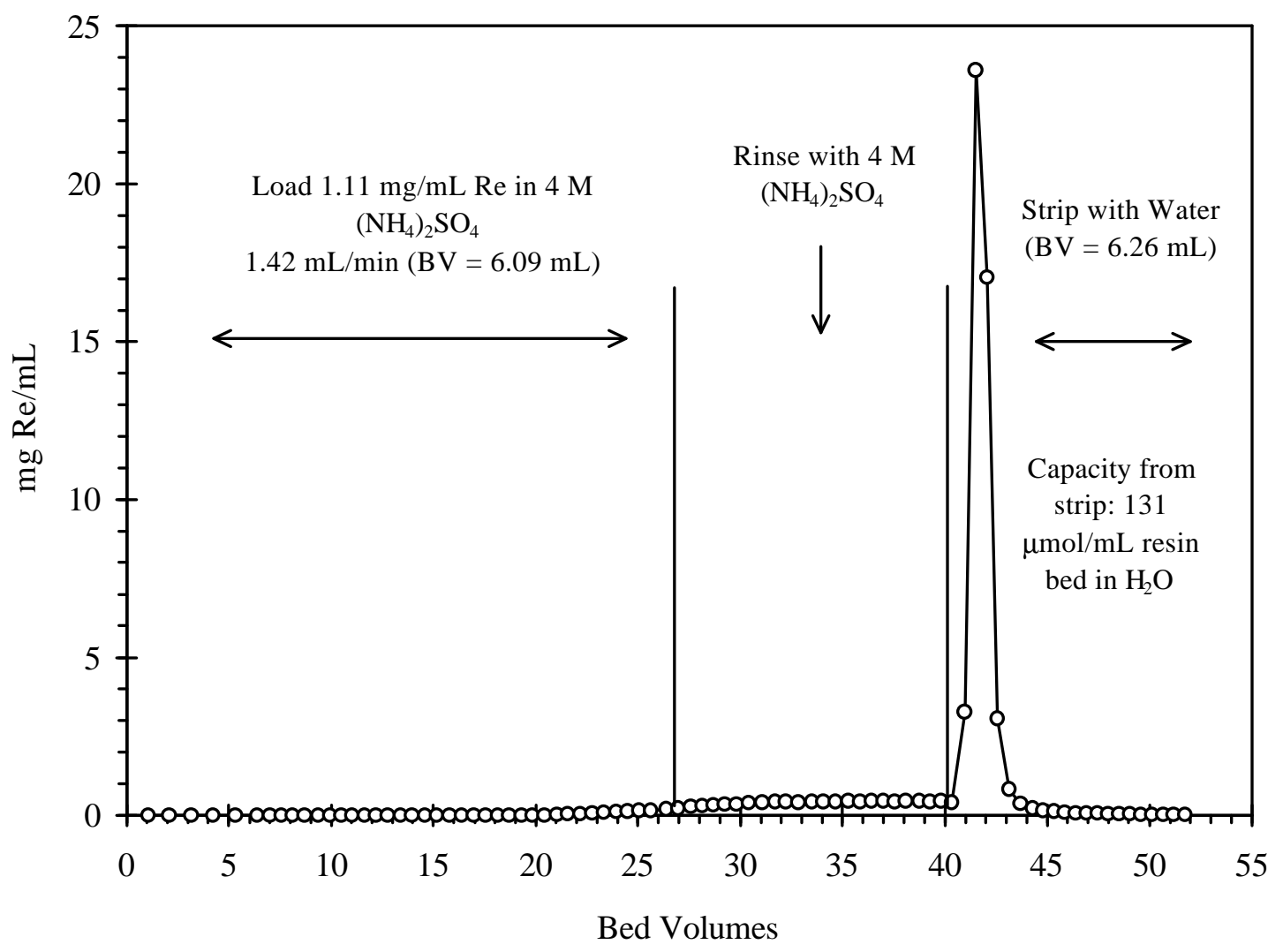

Figure 21. Column loading/elution curve for $1.1 \mathrm{~g} / \mathrm{L}$ rhenium as $\mathrm{NaRe}(\mathrm{n} 4 \mathrm{M}$ $\left(\mathrm{NH}_{4}\right)_{2} \mathrm{SO}_{4}$ with resin JW-53-155. 


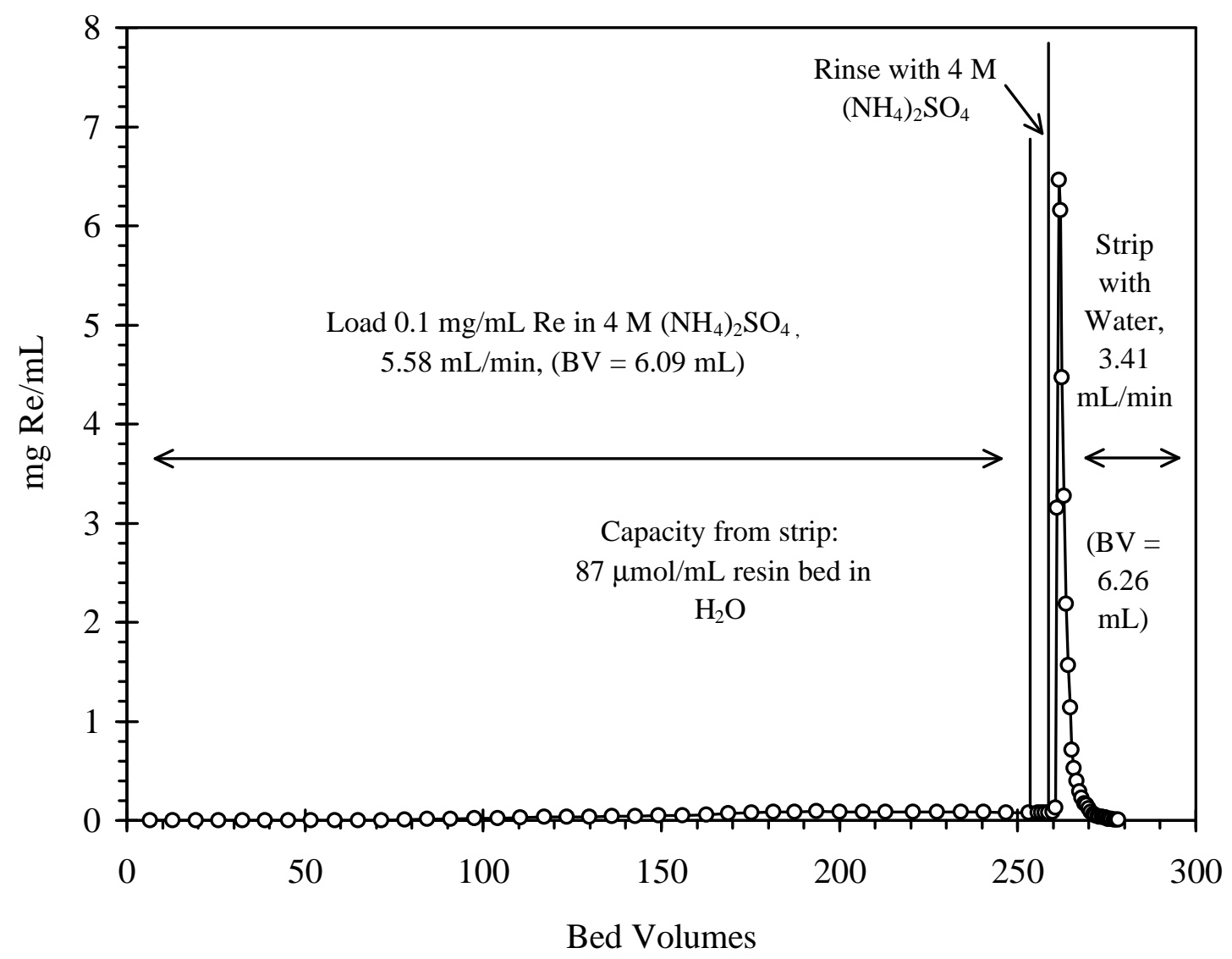

Figure 22. Column loading/elution curve for $0.10 \mathrm{~g} / \mathrm{L}$ rhenium as $\mathrm{NaRe} 0 \mathrm{Cn} 4 \mathrm{M}$ $\left(\mathrm{NH}_{4}\right)_{2} \mathrm{SO}_{4}$ with resin JW-53-155.

A column study with ${ }^{95 \mathrm{~m}} \mathrm{TcO}_{4}{ }^{-} / 0.01 \mathrm{M} \mathrm{NH}_{4} \mathrm{ReO}_{4}$ was also conducted and the loading/elution curve is shown in Figure 23. The capacity measured in this study was 76 $\mu \mathrm{mol} / \mathrm{mL}$ resin bed in water ( $7.5 \mathrm{~g}$ technetium per liter of resin) based on loading to $10 \%$ breakthrough. The Tc/Re uptake performance and resin capacity of the 110-liter reactor product are comparable to those observed for resin produced in smaller reactors, therefore indicating a successful reaction scale-up.

\section{Economic Evaluation}

The economic evaluation of ABEC-2000 resin is based upon the data collected from running the synthesis in Eichrom's 110-liter reactor. The detailed cost calculations for ABEC resin synthesis presented in Table 14 provide an approximate breakdown of costs between labor and materials. In general, all of the chemicals were purchased in 


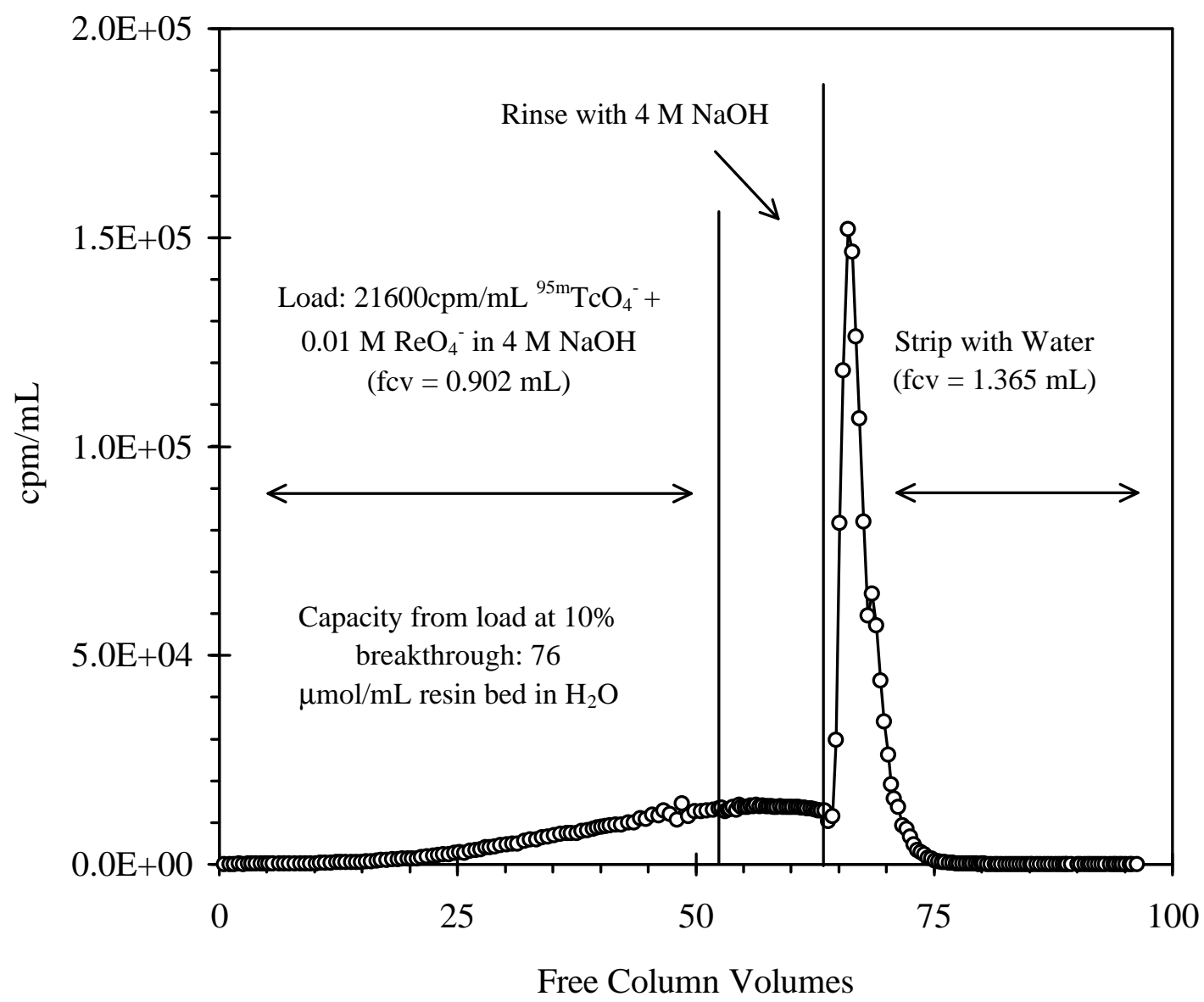

Figure 23. Column loading/elution curve for ${ }^{95 \mathrm{~m}} \mathrm{TcO}_{4}{ }^{-} / 0.01 \mathrm{M} \mathrm{ReO}_{4}^{-}$in $4 \mathrm{M} \mathrm{NaOH}$ with resin JW-53-155.

1-liter bottle to 5-gallon drum sizes. Further scale up will allow for dramatic cost reductions when it is possible to obtain certain chemicals in 55-gallon drum, or larger, quantities. For example, both diglyme and PEG-2000 can be directly purchased from the original manufactures, Grant Chemicals and Union Carbide, respectively, at much lower prices. Other components such as styrene and vinylbenzyl chloride can also be purchased at reduced costs, further lowering the overall cost, when the synthesis is scaled to a production reactor. Based upon previous scale up experience, the price summarized in Table 14 for ABEC resin is comparable with the cost for making other specialty resins at the 110-liter scale. 
Table 14: Manufacturing Costs for ABEC Resin in 110-Liter Reactor Using Actual Quantities Purchased.

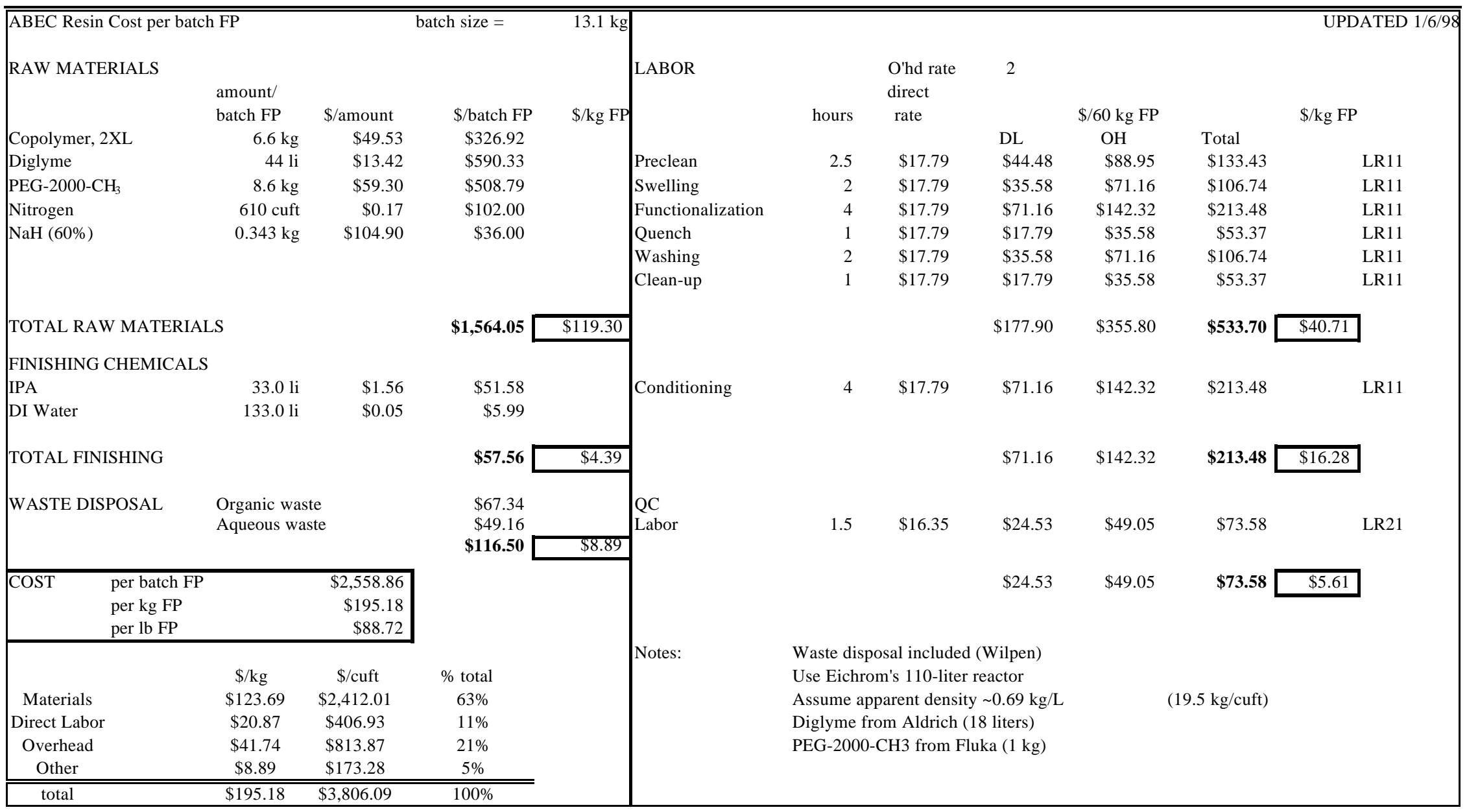




\section{Sorption of Technetium Onto Silica-Based Anion Exchange Resin}

Step two in the flowsheet for the separation, concentration and immobilization of $\mathrm{Tc} / \mathrm{I}$ from alkaline supernate wastes involves stripping Tc/I from ABEC resin with water followed by loading onto a commercial silica-based anion exchange resin (NUCLEOSIL) from the strip solution. We have established (see Figures 18 and 21-23 above) that the ABEC-2000 resins are readily stripped with water. The $\mathrm{pH}$ of the water strip solution is expected to be near neutral or slightly basic. Experiments were conducted to determine the $\mathrm{D}_{\mathrm{w}}$ values for technetium sorption by NUCLEOSIL in the $\mathrm{pH}$ range of 1 to 12 (Figure 24). Aniline was used to buffer the solution $\mathrm{pH}$ from 3 to 6 and ethylenediamine was used to buffer the solution $\mathrm{pH}$ from 7 to 12 . The measured $\$$ values increased from about

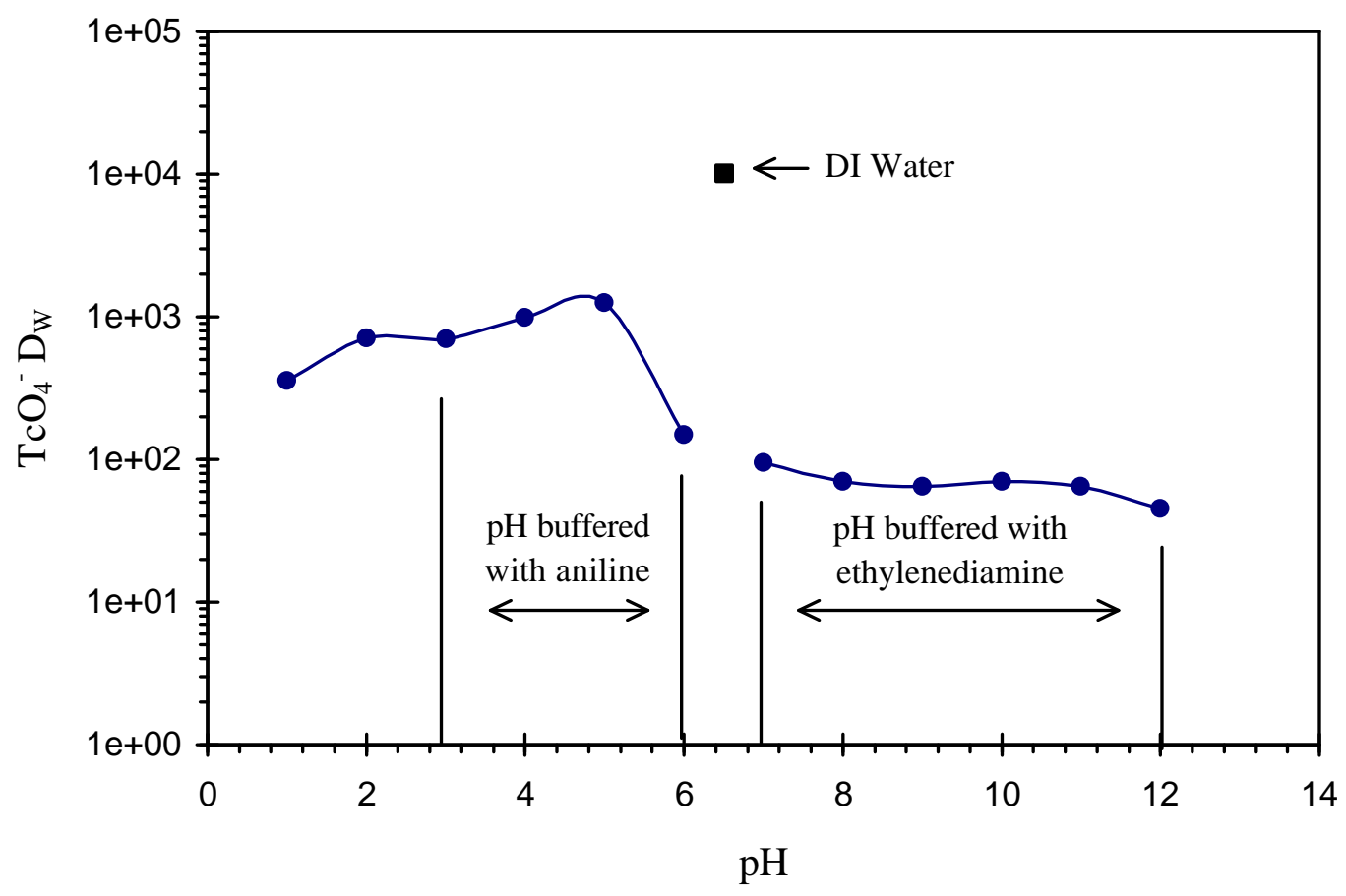

Figure 24. Technetium uptake by NUCLEOSIL as a function of solution $\mathrm{pH}$.

350 at $\mathrm{pH} 1$ to almost 1300 at $\mathrm{pH} 5$ and then decreased to less than 50 at $\mathrm{pH} 12$. Due to inconsistencies in some of the $\mathrm{D}$ values measured using the buffered solutions, it was decided to measure the technetium uptake from unbuffered DI water at $\mathrm{pH} 6.5$ for comparison (Table 15). The $\mathrm{D}$ values obtained were from 10 to 100 times greater than for the buffered solutions. The concentration of pertechnetate in the NUCLEOSIL uptake experiments was approximately $\& 10^{-4} \mathrm{M}$, and all measurements were made in the same manner as technetium $\mathrm{D}$ measurements with ABEC resins. The average was $1.0 \mathrm{x}$ $10^{4}$ at the $95 \%$ confidence level, with greater than $99.5 \%$ uptake of technetium by NUCLEOSIL resin under these conditions. This represents an additional concentration 
factor for technetium of approximately 70; a factor of 20-25 concentration is already demonstrated for the first flowsheet step ABEC treatment of the original waste.

Table 15. Uptake of Technetium by NUCLEOSIL from DI Water

\begin{tabular}{|c|c|c|c|c|c|c|}
\hline & $\begin{array}{c}\text { DI Water } \\
(\mathrm{mL})\end{array}$ & $\begin{array}{c}\text { NUCLEOSIL } \\
(\mathrm{g})\end{array}$ & $\begin{array}{c}\text { Tc Added } \\
(\mathrm{mg})\end{array}$ & $\begin{array}{c}\mathrm{D}_{\mathrm{w}} \\
(\mathrm{mL} / \mathrm{g})\end{array}$ & $\begin{array}{c}\text { Tc Loaded } \\
(\mu \mathrm{mol} / \mathrm{g})\end{array}$ \\
\hline 1 & 1.00 & 0.0269 & 0.0215 & 99.5 & 8232 & 8.03 \\
\hline 2 & & 0.0271 & 0.0224 & 99.5 & 7496 & 8.31 \\
\hline 3 & & 0.0285 & 0.0224 & 99.7 & 10710 & 7.92 \\
\hline 4 & & 0.0235 & 0.0220 & 99.6 & 10591 & 9.42 \\
\hline 5 & & 0.0294 & 0.0214 & 99.7 & 11652 & 7.33 \\
\hline 6 & & 0.0242 & 0.0224 & 99.7 & 12437 & 9.32 \\
\hline
\end{tabular}

Additional NUCLEOSIL loading data was gathered in preparation for encapsulation studies designed to demonstrate the third step in the flowsheet. In these experiments technetium was loaded onto three separate samples of NUCLEOSIL resin from DI water solution (Table 16). In preparations 1 and 2 the NUCLEOSIL resin alone was contacted for $48 \mathrm{~h}$ with DI water ( $\mathrm{pH} 4$ to 5) containing $9 \mathrm{Tc}$ traced with ${ }^{95 \mathrm{~m}} \mathrm{Tc}$. In preparation 3 the NUCLEOSIL resin was encapsulated within the hydrous titanium oxide microspheres $(40 \%$ resin $/ 60 \% \mathrm{HTiO})$ prior to contacting the wet microspheres with the technetium solution for $48 \mathrm{~h}$. The data in Table 16 indicate that technetium was strongly sorbed by NUCLEOSIL under both of these conditions. The maximum amount of technetium loaded per $g$ of resin in these studies was approximately $70 \%$ of the stated resin capacity of $1 \mathrm{mmol} / \mathrm{g}$ and at least $99 \%$ of technetium in the load solution was sorbed on the resin in two out of the three experiments.

Table 16. Uptake of Technetium by NUCLEOSIL from DI Water Under Conditions Approaching Resin Loading Capacity

\begin{tabular}{|c|c|c|c|c|c|c|}
\hline Preparation & $\begin{array}{c}\text { DI Water } \\
(\mathrm{mL})\end{array}$ & $\begin{array}{c}\text { NUCLEOSIL } \\
(\mathrm{g})\end{array}$ & $\begin{array}{c}\text { Tc Added } \\
(\mathrm{mg})\end{array}$ & $\begin{array}{c}\mathrm{D}_{(48 \mathrm{~h})} \\
(\mathrm{mL} / \mathrm{g})\end{array}$ & $\begin{array}{c}\text { Tc Loaded } \\
(\mathrm{mmol} / \mathrm{g})\end{array}$ \\
\hline A & 8.57 & 1.161 & 77.8 & 94.1 & 117 & 0.64 \\
\hline B & 19.19 & 3.1037 & 214 & 99.6 & 1360 & 0.693 \\
\hline C & 26.3 & 1.05 & 47.5 & 99.0 & 958 & 0.452 \\
\hline
\end{tabular}

\section{Encapsulation of Silica-Based Anion Exchange Resin}

Step three in the flowsheet for the separation, concentration and immobilization of Tc/I from alkaline supernate waste involves the encapsulation of Tc/I-loaded, silica-based anion exchange resin in hydrous titanium oxide (HTiO) microspheres. To demonstrate 
this portion of the process, microspheres were prepared by suspending either Tc-loaded or non-loaded NUCLEOSIL resin in a predetermined formulation of broth containing hexamethylene-tetramine (HMTA), urea, and titanium salt. The exact composition of the broth was varied to yield air-dried microspheres with a composition of either $20 \%$ NUCLEOSIL resin/80\% HTiO (Preparation A) or 40\% NUCLEOSIL resin/60\% HTiO (Preparation B) by weight. After forming and aging the microspheres in hot silicone oil $\left(90^{\circ} \mathrm{C}\right)$ in the Internal Gelation Process apparatus, the microspheres were washed four times with trichloroethylene (TCE) to remove the silicone oil from the surface. To remove the reaction products (HMTA, urea, and ammonium chloride), the microspheres were washed four times with $0.05 \mathrm{M} \mathrm{NHOH}$ and once with DI water. All rinse fractions from preparations A and B made using Tc-loaded NUCLEOSIL resin beads were gamma counted to determine the amount of technetium desorbed by each rinse fraction. The data in Table 17 show that a total of approximately $5 \%$ of the loaded technetium was removed by all washes and rinses combined. The majority of technetium released was found in the first two $\mathrm{NH}_{4} \mathrm{OH}$ wash fractions. Removal of a small amount of technetium at this stage

Table 17. Technetium Desorbed During Microsphere Preparations and Washing Steps.

\begin{tabular}{|c|c|c|c|c|}
\hline \multicolumn{5}{|c|}{ 99 Tc Removed } \\
\hline & \multicolumn{2}{|c|}{ Preparation $\mathrm{A}^{b}$} & \multicolumn{2}{|c|}{ Preparation $\mathrm{B}^{c}$} \\
\hline Component & $\mu \mathrm{Ci}$ & $\%$ & $\mu \mathrm{Ci}$ & $\%$ \\
\hline $\mathrm{TCE}$ & BDL & BDL & $\mathrm{BDL}$ & BDL \\
\hline Silicone Oil & BDL & BDL & $\mathrm{BDL}$ & BDL \\
\hline (1) $\mathrm{NH}_{4} \mathrm{OH} \mathrm{Wash}{ }^{a}$ & 42 & 3.33 & 91 & 2.52 \\
\hline (2) $\mathrm{NH}_{4} \mathrm{OH} \mathrm{Wash}{ }^{a}$ & 10 & 0.79 & 40 & 1.12 \\
\hline (3) $\mathrm{NH}_{4} \mathrm{OH} \mathrm{Wash}{ }^{a}$ & 7 & 0.55 & 16 & 0.45 \\
\hline (4) $\mathrm{NH}_{4} \mathrm{OH} \mathrm{Wash}{ }^{a}$ & 7 & 0.55 & 17 & 0.46 \\
\hline $\mathrm{H}_{2} \mathrm{O}$ Rinse & 2 & 0.16 & 7 & 0.19 \\
\hline Total Removed & 68 & 5.38 & 171 & 4.73 \\
\hline
\end{tabular}

a. $0.05 \mathrm{M} \mathrm{NH}_{4} \mathrm{OH}$ washes

b. $20 \%$ Nucleosil resin $/ 80 \% \mathrm{HTiO}$ microspheres ${ }^{9}$ (Tc sorbed on resin at start of preparation $=1244 \mathrm{mCi}$ )

c. $40 \%$ Nucleosil resin $/ 60 \% \mathrm{HTiO}$ microspheres ${ }^{99}$ Tc sorbed on resin at start of preparation $=3619 \mathrm{mCi}$ )

does not present a problem because the aqueous wash solutions can be fed back into alkaline waste supernate solution where technetium will be removed by passing through the Tc/I selective resin. Following the washing steps the microspheres were placed in a drying container and dried at ambient temperature for 3 days. The microspheres were then divided into three fairly equal portions, and two of the portions were dried at higher temperatures, one at $105^{\circ} \mathrm{C}$ for $5.3 \mathrm{~h}$ and the other at $170^{\circ} \mathrm{C}$ for $5.3 \mathrm{~h}$. Drying of the 
microspheres was not attempted at higher temperatures because previous thermogravimetric studies with NUCLEOSIL resin indicated that the organic functional groups began to decompose at temperatures of 190 to $200^{\circ} \mathrm{C}$.

This study included three different HTiO miosphere preparations of encapsulated NUCLEOSIL resin. The original test plan called for the encapsulation of Tc-loaded NUCLEOSIL resin beads within the HTiO microshperes. Therefore, the first two preparations contained $20 \%$ Tc-loaded NUCLEOSIL resin/80\% $\mathrm{HTiO}$ and $40 \% \mathrm{Tc}-$ loaded NUCLEOSIL resin/60\% HTiO, respectively. These correspond to Preparations A and $\mathrm{B}$ in Tables 16 and 17 above. Drying the microspheres from Preparation $\mathrm{A}$ at $105^{\circ} \mathrm{C}$ and $170^{\circ} \mathrm{C}$ resulted in water losses of 17.4 and $35.9 \%$, respectively while drying the microspheres of Preparation B resulted in water losses of 4.7 and $22.8 \%$, respectively.

During the course of this work it was suggested by researchers at Oak Ridge National Laboratory that the process could be simplified greatly if the NUCLEOSIL resin could be encapsulated prior to loading with technetium. This approach has the added advantage of avoiding radioactive contamination of the Internal Gelation Apparatus and eliminating exposure hazards during the encapsulation process. Therefore, in the third experiment microspheres containing 40\% NUCLEOSIL resin/60\% HTiO were prepared, and then the wet microspheres were loaded with technetium prior to drying to collapse the microspheres (Preparation $C$ in Table 16). It can be seen from the data in Table 16 that technetium is sorbed just as well by microspheres prepared in this way as when the NUCLEOSIL resin is loaded prior to encapsulation. Drying of these microspheres at $170^{\circ} \mathrm{C}$ resulted in a water loss of about $25 \%$. Successful encapsulation of the Tc-loaded NUCLEOSIL resin was achieved in all three instances.

\section{Stability Studies of the Encapsulated Waste Form}

Leaching Tests The final task in testing the proposed flowsheet involved performing stability studies on the encapsulated waste form. Parallel leaching experiments were conducted with microsphere samples that were dried at ambient temperature, 105 and $170^{\circ} \mathrm{C}$. One set of experiments was conducted with toxicity characterisitic leaching procedure (TCLP) leachant (Table 18) and the other set with a simulated Waste Isolation Pilot Plant (WIPP) brine solution (Table 19). The TCLP leachant stock was prepared by adding $11.4 \mathrm{~mL}$ glacial acetic acid to $1 \mathrm{~L}$ of DI water, adding $128.6 \mathrm{~mL}$ of $1.0 \mathrm{M} \mathrm{NaOH}$, and diluting to a volume of $2 \mathrm{~L}$. The $\mathrm{pH}$ of the solution was about 4.9. Two liters of brine solution was prepared that contained $1.83 \mathrm{M} \mathrm{NaCl}, 0.77 \mathrm{M} \mathrm{KCl}$, and $2.87 \mathrm{M} \mathrm{Mg.Cl}$ The $\mathrm{pH}$ of this solution was about 6.6.

The samples of microspheres were gently mixed with the indicated volumes of leachants, as given in Tables 18 and 19. Samples were removed and counted after $24 \mathrm{~h}$, $96 \mathrm{~h}$, and $168 \mathrm{~h}$ and the activity of $\mathrm{Tc}$ removed with time and the percentages of the initial ${ }^{99}$ Tc removed were determined (Tables 20 and 21). Afterwards, these leachants 
Table 18. Test Conditions at the Start of the TCLP Leaching Tests.

\begin{tabular}{|l|c|c|c|c|}
\hline Type Microspheres & $\begin{array}{c}\text { Sample } \\
\text { Wt. } \\
(\mathrm{g})\end{array}$ & $\begin{array}{c}\text { NUCLEOSIL } \\
\text { resin } \\
(\mathrm{g})\end{array}$ & $\begin{array}{c}\text { Sorbed }{ }^{99} \mathrm{Tc} \\
\text { at the start } \\
(\mu \mathrm{Ci})\end{array}$ & $\begin{array}{c}\text { Amount } \\
\text { of Leachant } \\
(\mathrm{g})\end{array}$ \\
\hline $20 \%(\text { air-dried })^{a}$ & 0.7377 & 0.148 & 155 & 250 \\
\hline $20 \%\left(105^{\circ} \mathrm{C}\right)^{a}$ & 0.5401 & 0.135 & 141 & 250 \\
\hline $20 \%\left(170^{\circ} \mathrm{C}\right)^{a}$ & 0.5465 & 0.169 & 176 & 250 \\
\hline $40 \%(\text { air-dried })^{b}$ & 0.6425 & 0.257 & 285 & 250 \\
\hline $40 \%\left(105^{\circ} \mathrm{C}\right)^{b}$ & 0.7104 & 0.298 & 331 & 250 \\
\hline $40 \%\left(170^{\circ} \mathrm{C}\right)^{b}$ & 0.5458 & 0.283 & 313 & 250 \\
\hline $40 \%(\text { air-dried })^{b}$ & 0.6273 & 0.251 & 191 & 125 \\
\hline $40 \%\left(170^{\circ} \mathrm{C}\right)^{c}$ & 0.5169 & 0.275 & 209 & 125 \\
\hline
\end{tabular}

a. $20 \%$ NUCLEOSIL/80\% HTiO microspheres (resin loaded withTc before preparation of beads)

b. $40 \%$ NUCLEOSIL/60\% HTiO microspheres (resin loaded withTc before preparation of beads)

c. $40 \%$ NUCLEOSIL/60\% HTiO microspheres (resin loaded withTc after preparation of beads)

Table 19. Test Conditions at the Start of the Brine Leaching Tests.

\begin{tabular}{|l|c|c|c|c|}
\hline Type Microspheres & $\begin{array}{c}\text { Sample } \\
\text { Wt. } \\
(\mathrm{g})\end{array}$ & $\begin{array}{c}\text { NUCLEOSIL } \\
\text { resin } \\
(\mathrm{g})\end{array}$ & $\begin{array}{c}\text { Sorbed } \\
\text { at the start } \\
(\mu \mathrm{Ci})\end{array}$ & $\begin{array}{c}\text { Amount } \\
\text { of Leachant } \\
(\mathrm{g})\end{array}$ \\
\hline $20 \%(\text { air-dried })^{a}$ & 0.5820 & 0.116 & 122 & 250 \\
\hline $20 \%\left(105^{\circ} \mathrm{C}\right)^{a}$ & 0.4331 & 0.114 & 114 & 250 \\
\hline $20 \%\left(170^{\circ} \mathrm{C}\right)^{a}$ & 0.6224 & 0.194 & 203 & 250 \\
\hline $40 \%(\text { air-dried })^{b}$ & 0.3885 & 0.115 & 172 & 250 \\
\hline $40 \%\left(105^{\circ} \mathrm{C}\right)^{b}$ & 0.5649 & 0.237 & 263 & 250 \\
\hline $40 \%\left(170^{\circ} \mathrm{C}\right)^{b}$ & 0.5746 & 0.298 & 330 & 250 \\
\hline $40 \%($ air-dried) & 0.6753 & 0.270 & 205 & 125 \\
\hline $40 \%\left(170^{\circ} \mathrm{C}\right)^{c}$ & 0.4897 & 0.261 & 198 & 125 \\
\hline
\end{tabular}

a. $20 \%$ NUCLEOSIL/80\% HTiO microspheres (resin loaded ith $^{99}$ Tc before preparation of beads)

b. $40 \%$ NUCLEOSIL/60\% HTiO microspheres (resin loaded withTc before preparation of beads)

c. $40 \%$ NUCLEOSIL/60\% HTiO microspheres (resin loaded withTc after preparation of beads) 
were decanted from the microspheres and replaced with fresh solutions of leachants of equal volumes.

For both the TCLP and brine leaching tests, very little difference was observed for microsphere preparations dried at different temperatures. In the TCLP leaching study, the least amount of ${ }^{99} \mathrm{Tc}$ leaching was observed for the resin loaded withT Tc after preparation of the beads (preparation C). In the brine leaching study the maximum amount of ${ }^{99} \mathrm{Tc}$ leaching was observed for the $40 \%$ NUCLEOSIL/60\% HTiO microspheres, which had been loaded witĥTc prior to bead preparation (preparation B). Approximately one third the amount ol9 $\mathrm{Tc}$ leaching was observed for the other two preparations. In both studies, significantly lešşTc was released upon contact with the second portion of leachant. In all cases, the maximum, cumulative amount ${ }^{9}$ ofc leached by either leachant was less than $1 \%$ of the initial amount ${ }^{90} \mathrm{O} \Gamma \mathrm{c}$ contained in the encapsulated waste form. Furthermore, with few exceptions, the majority of the technetium was leached in the first 24 hour period, indicating the technetium was primarily removed from the surface of the microspheres. This further suggests that washing the microspheres prior to long-term storage would eliminate any potential leaching problem. The minor amount of technetium in any rinse solution could be retreated.

The results of these leaching studies indicate that the encapsulated waste form from all three preparations is very stable with regard to leaching by prolonged contact with solutions of this nature. If the HTiO microspheres are further incorporated into a type of ceramic grout as a final waste form, it may be possible to eliminate leaching of technetium from the encapsulated waste altogether.

Heating and Shielding CalculationsCalculations were performed to estimate the shielding properties for ${ }^{99} \mathrm{Tc}$-loaded silica-based resin beads ( $\$$ um diameter) when encapsulated in HTiO microspheres (1 mm diameter) at a volumetric loading of $20 \%$ silica beads. Calculations were performed for Tc-99 loadings of $1 \mathrm{nCi}, \mu \mathrm{Ci}$, and $1 \mathrm{mCi}$ per bead. A Monte Carlo N-Particle (MCNP) code was used for this analysis. Analyses were performed to calculate a dose rate at the surface of a spherical silica-based resin bead both with and without encapsulation in HTiO. Gross estimates of heat generation in the different cases were also evaluated. The results of these analyses are given in Table 22.

Results of the shielding calculations for unencapsulated beads show that the dose rate at the surface of the bead increases with increasing9Tc loading. This dose rate is due almost entirely to bremsstrahlung-produced photons leaving the surface of the resin bead. Most of this is due to the interaction of electrons with technetium atoms $(Z=43)$ within the resin bead. These interactions increase dramatically as loading increases because the technetium atoms are much closer together. Heating produced by the radioactive decay of ${ }^{99} \mathrm{Tc}$ also increases with increasing loading. 
Table 20. Results of the TCLP Leaching Tests.

\begin{tabular}{|c|c|c|c|c|c|c|c|c|c|c|}
\hline & \multicolumn{6}{|c|}{ Tc-99 Removed by the First Leachant } & \multicolumn{4}{|c|}{ Tc-99 Removed by the Second Leachant } \\
\hline & \multicolumn{2}{|c|}{$24 \mathrm{~h}$} & \multicolumn{2}{|c|}{$96 \mathrm{~h}$} & \multicolumn{2}{|c|}{$168 \mathrm{~h}$} & \multicolumn{2}{|c|}{$24 \mathrm{~h}$} & \multicolumn{2}{|c|}{$96 \mathrm{~h}$} \\
\hline Microspheres & $(\mu \mathrm{Ci})$ & $(\%)$ & $(\mu \mathrm{Ci})$ & $(\%)$ & $(\mu \mathrm{Ci})$ & $(\%)$ & $(\mu \mathrm{Ci})$ & $(\%)$ & $(\mu \mathrm{Ci})$ & $(\%)$ \\
\hline $20 \%$ (air-dried) ${ }^{a}$ & 0.274 & 0.18 & 0.271 & 0.17 & 0.431 & 0.28 & 0.068 & 0.04 & 0.063 & 0.04 \\
\hline $20 \%\left(105^{\circ} \mathrm{C}\right)^{a}$ & 0.101 & 0.07 & 0.104 & 0.07 & 0.358 & 0.25 & 0.090 & 0.06 & 0.106 & 0.07 \\
\hline $20 \%\left(170^{\circ} \mathrm{C}\right)^{a}$ & 0.326 & 0.19 & 0.326 & 0.19 & 0.334 & 0.19 & 0.126 & 0.07 & 0.127 & 0.07 \\
\hline $40 \%$ (air-dried) & 0.465 & 0.16 & 0.476 & 0.17 & 0.700 & 0.25 & 0.108 & 0.04 & 0.127 & 0.05 \\
\hline $40 \%\left(105^{\circ} \mathrm{C}\right)^{b}$ & 0.516 & 0.16 & 0.522 & 0.16 & 0.749 & 0.23 & 0.257 & 0.08 & 0.235 & 0.07 \\
\hline $40 \%\left(170^{\circ} \mathrm{C}\right)^{b}$ & 0.674 & 0.22 & 0.669 & 0.21 & 0.695 & 0.22 & 0.195 & 0.06 & 0.208 & 0.07 \\
\hline $40 \%$ (air-dried) & 0.112 & 0.06 & 0.105 & 0.05 & 0.135 & 0.07 & 0.034 & 0.02 & 0.045 & 0.02 \\
\hline $40 \%\left(170^{\circ} \mathrm{C}\right)^{c}$ & 0.095 & 0.05 & 0.108 & 0.06 & 0.154 & 0.07 & 0.048 & 0.02 & 0.062 & 0.03 \\
\hline
\end{tabular}

a. $20 \%$ NUCLEOSIL/80\% HTiO microspheres (resin loaded withTc before preparation of beads)

b. $40 \%$ NUCLEOSIL/60\% HTiO microspheres (resin loaded withTc before preparation of beads)

c. $40 \%$ NUCLEOSIL/60\% HTiO microspheres (resin loaded withTc after preparation of beads) 
Table 21. Results of the Brine Leaching Tests.

\begin{tabular}{|c|c|c|c|c|c|c|c|c|c|c|}
\hline & \multicolumn{6}{|c|}{ Tc-99 Removed by the First Leachant } & \multicolumn{4}{|c|}{ Tc-99 Removed by the Second Leachant } \\
\hline & \multicolumn{2}{|c|}{$24 \mathrm{~h}$} & \multicolumn{2}{|c|}{$96 \mathrm{~h}$} & \multicolumn{2}{|c|}{$168 \mathrm{~h}$} & \multicolumn{2}{|c|}{$24 \mathrm{~h}$} & \multicolumn{2}{|c|}{$96 \mathrm{~h}$} \\
\hline Microspheres & $(\mu \mathrm{Ci})$ & $(\%)$ & $(\mu \mathrm{Ci})$ & $(\%)$ & $(\mu \mathrm{Ci})$ & $(\%)$ & $(\mu \mathrm{Ci})$ & $(\%)$ & $(\mu \mathrm{Ci})$ & $(\%)$ \\
\hline $20 \%$ (air-dried) ${ }^{a}$ & 0.068 & 0.06 & 0.068 & 0.06 & 0.077 & 0.06 & 0.047 & 0.04 & 0.063 & 0.06 \\
\hline $20 \%\left(105^{\circ} \mathrm{C}\right)^{a}$ & 0.126 & 0.11 & 0.123 & 0.11 & 0.161 & 0.14 & 0.054 & 0.05 & 0.073 & 0.07 \\
\hline $20 \%\left(170^{\circ} \mathrm{C}\right)^{a}$ & 0.285 & 0.14 & 0.286 & 0.14 & 0.275 & 0.14 & 0.094 & 0.05 & 0.123 & 0.07 \\
\hline $40 \%$ (air-dried) & 0.885 & 0.51 & 0.875 & 0.51 & 0.976 & 0.57 & 0.319 & 0.19 & 0.378 & 0.22 \\
\hline $40 \%\left(105^{\circ} \mathrm{C}\right)^{b}$ & 1.470 & 0.56 & 1.490 & 0.57 & 1.490 & 0.57 & 0.401 & 0.15 & 0.457 & 0.14 \\
\hline $40 \%\left(170^{\circ} \mathrm{C}\right)^{b}$ & 1.740 & 0.53 & 1.730 & 0.53 & 1.790 & 0.54 & 0.283 & 0.09 & 0.319 & 0.09 \\
\hline $40 \%$ (air-dried) & 0.314 & 0.15 & 0.312 & 0.15 & 0.322 & 0.16 & 0.112 & 0.05 & 0.125 & 0.06 \\
\hline $40 \%\left(170^{\circ} \mathrm{C}\right)^{c}$ & 0.345 & 0.17 & 0.344 & 0.16 & 0.356 & 0.18 & 0.079 & 0.04 & 0.096 & 0.05 \\
\hline
\end{tabular}

a. $20 \%$ NUCLEOSIL/80\% HTiO microspheres (resin loaded withTc before preparation of beads)

b. $40 \%$ NUCLEOSIL/60\% HTiO microspheres (resin loaded withTc before preparation of beads)

c. $40 \%$ NUCLEOSIL/60\% HTiO microspheres (resin loaded withTc after preparation of beads) 
Table 22. Dose Rate and Heating Calculations for Unencapsulated vs. Encapsulated Beads

\begin{tabular}{|c|c|c|c|c|c|}
\hline $\begin{array}{c}\text { Tc-99 } \\
\text { Loading }\end{array}$ & $\begin{array}{c}\text { Unencapsulated } \\
\text { Bead Surface } \\
\text { Dose } \\
(\mu \mathrm{rem} / \mathrm{hr})\end{array}$ & $\begin{array}{c}\text { Encapsulated } \\
\text { Bead Surface } \\
\text { Dose } \\
(\mu \mathrm{rem} / \mathrm{hr})\end{array}$ & $\begin{array}{c}\text { Fractional } \\
\text { Change in Dose } \\
\text { Rate Due to } \\
\text { Encapsulation }\end{array}$ & $\begin{array}{c}\text { Heating Per } \\
\text { Unencapsulated } \\
\text { Bead (Joules) }\end{array}$ & $\begin{array}{c}\text { Heating Per } \\
\text { Encapsulated } \\
\text { Bead (Joules) }\end{array}$ \\
\hline $1 \mathrm{nCi}$ & $7.740 \mathrm{E}-03$ & $1.594 \mathrm{E}-01$ & 20.59 & $5.050 \mathrm{E}-19$ & $1.632 \mathrm{E}-16$ \\
\hline $1 \mu \mathrm{Ci}$ & $2.142 \mathrm{E}-01$ & $1.670 \mathrm{E}-01$ & 0.78 & $2.543 \mathrm{E}-17$ & $4.068 \mathrm{E}-16$ \\
\hline $1 \mathrm{mCi}$ & $3.915 \mathrm{E}+00$ & $5.941 \mathrm{E}-02$ & 0.15 & $5.211 \mathrm{E}-16$ & $9.148 \mathrm{E}-16$ \\
\hline
\end{tabular}

In the case of the encapsulated beads the calculated dose rate is higher at the $1 \mathrm{nCi}$ loading level than it is for the unencapsulated bead. At this low level ${ }^{99} \mathbf{f} \mathbf{c}$ loading, the technetium atoms are farther apart on average than the range of an electron within the bead. Therefore, there is very little bremsstrahlung production in the unencapsulated bead. When the bead is encapsulated, however,'Tc decay near the surface of the bead results in increased bremsstrahlung production due to some interaction of electrons with the titanium atoms $(Z=22)$. At the higher levels of Tc loading, where there is already significant production of bremsstrahlung photons, there is actually a reduction in surface dose rate on going from the unencapsulated bead to the encapsulated bead due to some shielding from the HTiO. Additional production of bremsstrahlung radiation due to interaction of electrons with titanium atoms is not very significant relative to the amount already produced in the unencapsulated beads. Again, heating due to decay ${ }^{99} \mathrm{fc}$ increases with increasing loading.

Using simplifiying assumptions shielding properties were also estimated for the case where the encapsulated beads were loaded in a 55-gallon drum. A spherical geometry was assumed for the 55-gallon drum and the inner volume was assumed to consist of a homogeneous mixture of air, HTiO, SiOand ${ }^{99} \mathrm{Tc}$. The dose rate at the inner surface of this mixture was estimated to be $1.48 \times 10 \mu \mathrm{rem} / \mathrm{hr}$. The dose rate at the outer surface of the drum was approximately zero. Decay heat calculations showed a heating of $5.83 \times 10^{-7} \mathrm{~J}$ over the inner volume of the barrel.

In summary, the dose rate in any given case is a function of the degree of loading, the resulting bead density, bremsstrahlung production, and scattering and self-absorption of photons. At higher loadings ( $\mu \mathrm{Ci}$ to $1 \mathrm{mCi})$ the $\mathrm{HTiO}$ encapsulation is effective in reducing the dose rate compared to the unencapsulated case. At lower loadings ( $1 \mathrm{nCi}$ ), the HTiO encapsulation can result in a higher surface dose rate. Calculations show there is no dose rate at the outside surface of the steel 55-gallon drum. The dose rate at the inner surface of the mixture of air, HTiO, Si@and ${ }^{99} \mathrm{Tc}$ was much lower than for the individual beads, indicating less bremsstrahlung production. This was attributed to the fact that technetium was spread out over a larger volume, thus reducing the probability for bremsstrahlung conversion to occur. All of the radiation emitted byTc is absorbed inside the drum, and heat generated from the decay of encapsulatêdTc is inconsequential 
for all geometries and levels of loading examined. Therefore, storage of drums containing the encapsulated waste form does not present a radiation or heat generation hazard.

\section{Conclusion}

An improved version of the Tc/I selective resin that resolves many of the outstanding performance issues of the original ABEC-5000 resin has been developed. The new resin is made by attaching PEG-2000 to a polystyrene substrate containing $2 \%$ DVB and $10 \%$ VBC. Due to the higher level of crosslinking the new resin exhibits much less swelling on crossover from load to strip and has a greater bed density than the original ABEC-5000 resin while still exhibiting the desired technetium uptake performance and loading capacity. The original solvent, THF, was successfully replaced by diglyme, a much safer solvent to handle on the production scale. Additional synthetic parameters were optimized in order to maximize the amount of product obtained and minimize production costs while maintaining desirable performance characterisitcs.

The production of the improved ABEC resin has been successfully scaled up in 5liter and 110-liter reactors. The resins obtained from the scale-up reactions were found to have comparable physical properties and $\mathrm{Tc} / \mathrm{Re}$ uptake performance to those prepared at the bench-top scale. A detailed cost evaluation was performed based upon the data collected from running the synthesis in Eichrom's 110-liter reactor. The cost projections are similar to other specialty resins and waste treatment of technetium bearing streams will not be prohibitively expensive.

Batch uptake properties and column load/strip behavior of technetium and rhenium have been determined for the resin produced in the 110-liter reactor (JW-053-155) as well as for resins produced on a smaller scale. The pertechnetate ${ }_{W}$ for this resin from $4 \mathrm{M}$ $\mathrm{NaOH}$ solution was $192 \mathrm{~mL} / \mathrm{g}$ and the $\mathrm{Q}$ was $82 \mathrm{~mL} / \mathrm{mL}$. The technetium capacity at $10 \%$ column breakthrough was 7 umol/mL of resin bed in water $(7.5 \mathrm{~g} \mathrm{Tc} / \mathrm{L}$ of resin bed in water). Based on this loading capacity and a techentium concentration of $5 \mathrm{x}^{-5} 1 \mathrm{M}$ in tank wastes, concentration factors of approximately 150 should be obtainable when technetium is loaded onto ABEC resin and stripped with water.

The loading of technetium onto NUCLEOSIL silica-based anion exchange resin was demonstrated over a $\mathrm{pH}$ range of 1 to 12 . A maximum Dof approximately 10 was obtained in DI water at $\mathrm{pH}$ 6.5, corresponding to a concentration factor in this instance of approximately 70. $\mathrm{D}$ values of greater than $1 \hat{\theta}$ were measured for uptake of technetium from DI water at $\mathrm{pH} 4$ to 4.5 , even at technetium loading equal to approximately $70 \%$ of maximum capacity. Given these very high ${ }_{W}$ Dvalues, concentration factors of at least several hundred should be achievable for this step.

The Tc-loaded NUCLEOSIL resin was successfully encapsulated in HTiO microspheres by the technique of internal gelation. More importantly, it was demonstrated that NUCLEOSIL resin could be encapsulated in HTiO prior to loading technetium, and 
the wet microspheres could then be loaded with technetium before drying to collapse the microspheres. This was a very significant finding in that it eliminates any radiation hazard during microsphere preparation, and the encapsulation process can be carried out without concern for radioactive contamination of the Internal Gelation Apparatus or associated chemical waste streams. This will both simplify and shorten the process as well as reduce associated costs.

Parallel leaching studies were performed on the different encapsulated waste forms using TCLP and abbreviated WIPP brine leachants. The maximum, cumulative amount of technetium released after contact with either leachant was less than $1 \%$ of the amount loaded and encapsulated. Heating and shielding calculations performed for encapsulated and unencapsulated beads showed that at higher levels of technetium loading $(\mathbb{C} i$ to 1 $\mathrm{mCi}$ ) encapsulation resulted in a lower surface dose rate than for the unencapsulated resin. Also, calculations for the case in which the Tc-loaded HTiO microspheres were stored in a 55 -gallon steel drum showed all of the radiation emitted by encapsulatedc was absorbed inside the drum. Heat generated from the decay of encapsulated $\mathrm{9}$ c was inconsequential for all geometries and levels of loading examined.

A summary of the results of the current effort compared with the success criteria originally required is given in Table 23 .

Table 23. Comparison of Required Success Criteria vs. Success Achieved.

\begin{tabular}{|c|c|c|c|}
\hline Task & Task Description & Required Success Criteria & Criteria Achieved \\
\hline 1.1 & Synthesis & & \\
\hline $1.1 \mathrm{~A}$ & Study Alternate Substrates & $\begin{array}{l}\text { Select Best Support Type } \\
\text { Increase Bed Density } \\
\text { Decrease \% Swelling }\end{array}$ & $\begin{array}{l}\text { Yes (gel) } \\
\text { Yes } \\
\text { Yes }(<10 \%)\end{array}$ \\
\hline $1.1 \mathrm{~B}$ & $\begin{array}{l}\text { Optimize PEG Addition } \\
\text { Time }\end{array}$ & $\begin{array}{l}\text { Determine Optimum } \\
\text { Reaction Time }\end{array}$ & Yes $(17 \mathrm{~h})$ \\
\hline $1.1 \mathrm{C}$ & Alternative MW PEG's & Replace PEG-5000 & Yes (PEG-2000) \\
\hline $1.1 \mathrm{D}$ & Alternatives to $\mathrm{NaH}$ & Find Safer Alternative & No - see p. 34 and Table 11 \\
\hline $1.1 \mathrm{E}$ & Cost Evaluation & $\begin{array}{l}\text { Estimate Manufacturing } \\
\text { Costs }\end{array}$ & Yes (Acceptable Costs) \\
\hline $1.1 \mathrm{~F}$ & 110-Liter Scale-Up & $\begin{array}{l}\text { Demonstrate Successful } \\
\text { Scale-Up }\end{array}$ & Yes \\
\hline 1.2 & Testing & & \\
\hline $1.2 \mathrm{~A}$ & $\begin{array}{l}\text { Uptake Properties and } \\
\text { Column Load/Strip Behavior }\end{array}$ & $\begin{array}{l}\mathrm{D}_{\mathrm{W}}>100 \\
\text { Demonstrate Column Loading } \\
\text { Demonstrate Water Elution }\end{array}$ & $\begin{array}{l}\text { Yes } \\
\text { Yes } \\
\text { Yes }\end{array}$ \\
\hline $1.2 \mathrm{~B}$ & $\begin{array}{l}\text { Load Silica-Based Anion } \\
\text { Exchange Resin }\end{array}$ & Demonstrate $>50 \%$ Loading & Yes \\
\hline $1.2 \mathrm{C}$ & $\begin{array}{l}\text { Encapsulate Silica-Based } \\
\text { Anion Exchange Resin }\end{array}$ & $\begin{array}{l}\text { Demonstrate Successful } \\
\text { Encapsulation }\end{array}$ & Yes \\
\hline $1.2 \mathrm{D}$ & $\begin{array}{l}\text { Perform Stability Studies on } \\
\text { Encapsulated Waste Form }\end{array}$ & $\begin{array}{l}\text { Determine Percentage Tc } \\
\text { Leached as a Function } \\
\text { of Time }\end{array}$ & $\begin{array}{l}\text { Maximum Percentage Tc } \\
\text { Leached }<1 \%\end{array}$ \\
\hline
\end{tabular}




\section{Recommendation for Future Work}

The synthesis and scale up of ABEC-2000 resin have been accomplished as proposed. Several recommendations for further work are given below. These recommendations are aimed at making the production of ABEC resin more economical and the physical properties of these resins more suitable for various applications.

Further Study of Crosslinking of CopolymerThe crosslinking level of the substrate used for making ABEC resin has significant influence on the quantity of ABEC resin yielded from the PEG addition reaction and on the swelling character of ABEC resin during stripping with water. Therefore, a fine tuning of crosslinking level between $1 \%$ and $2 \%$ should be further studied in order to enhance the yield of PEG addition reaction to an optimum level. Ideally, this study can give another significant cost reduction for making ABEC resin without sacrificing desirable swelling properties.

Further Study of Sodium Methoxide In the synthesis study using sodium methoxide for PEG addition reaction, the results of rhenium uptake experiments indicate that the products are not sufficiently functionalized with PEG. Changing the substrates to a lower level of crosslinking or changing the substrate matrix to possibly a VBC/acrylate copolymer may improve the yield of PEG addition associated with using sodium methoxide.

Further Study of Particle Size Since PEG-2000 is a relatively large molecule, each individual copolymer bead can probably be functionalized only to a certain depth from the surface. Using copolymer of slightly smaller particle size, such as 60 to 100 mesh, may yield product with a higher loading capacity simply due to the increased surface area.

Study of Substrate Matrix This effort focused on using styrene/VBC matrix as the substrate. Changing the hydrophobic section, styrene, to a more hydrophilic component such as acrylate may give a product with a totally different microenvironment with better metal ion uptake. 


\section{Acknowledgments}

The following individuals contributed to the success of this effort:

Andrew H. Bond, Ph.D. Eichrom Industries; Inc.; Argonne National Laboratory

Doug Bowen

International Techndogy Corporation

Frank W.K. Chang, Ph.D. Eichrom Industries, Inc.

Jack L. Collins, Ph.D. Oak Ridge National Laboratory

Mark L. Dietz, Ph.D. $\quad$ Argonne National Laboratory

Jonathan M. Duffey Eichrom Industries, Inc.

Zane Egan, Ph.D.

Oak Ridge National Laboratory

Richard T. Greene, CHP

International Technology Corporation

Scott T. Griffin

University of Alabama

E. Philip Horwitz, Ph.D.

Argonne National Laboratory

Debbie Johnston

Eichrom Industries, Inc.

Richard Reynolds

Eichrom Industries, Inc.

Robin D. Rogers, Ph.D.

University of Alabama

Anil H. Thakkar

Eichrom Industries, Inc.

Cara Tomasek

Eichrom Industries, Inc.

Joel M. Williamson

Eichrom Industries, Inc.

Heather Willaeur

University of Alabama 
Appendix A 


\section{Flame AA Standard Operating Procedure}

\section{Introduction}

\section{Description}

This document describes the operation of the FAAS, including preventive maintenance and calibration activities, at Eichrom Industries. It applies to all facilities that operate a FAAS.

\section{Definitions}

FAAS: $\quad$ Flame Atomic Absorption Spectrometer

HCL: Hollow Cathode Lamp

\section{Reference Documents}

Document \#QA-0004 -- Control of Inspection and Test Equipment

Model 3110 Atomic Absorption Spectrometer Hardware GuidePerkin Elmer. Part Number 0993-8863, Release C, October 1995. Published in the USA.

Analytical Methods for Atomic Absorption SpectroscopyPerkin Elmer. Part Number 0303-0152, Release C, August 1994. Published in the USA.

\section{Concepts, Instrumentation, and Techniques in Atomic Absorption} Spectroscopy. Perkin Elmer. Part Number 0993-9533, Release B, 1993. Published in the USA.

Appendices contain standard conditions and parameters for specific analytes.

\section{Preparation}

Read MSDS sheets for chemicals listed in 2.3.

\section{Equipment}

FAAS.

Burner Head (acetylene or $\mathrm{NO}$ )

Hollow Cathode Lamps (HCLs)

Class A volumetric flasks, if dilution required.

$1 \mathrm{~mL}$ adjustable autopipettor (calibrated, record ID number in laboratory notebook) and pipet tips.

$5 \mathrm{~mL}$ adjustable autopipettor (calibrated, record ID number in laboratory notebook) and pipet tips.

\section{Chemicals}

Metal standards for element(s) of interest.

Calibration Verification Standards for component(s) of interest. If using previously prepared standards, ensure that standards are less than 90 
days old, and that enough standard exists for at least two runs. If not, prepare new standards. Newly prepared standards shall be compared with the standards which they are replacing, if available. The preparation of standards is recorded in the QC/Maintenance Log.

Samples

Distilled or Deionized water, ASTM Type I

Acetylene Gas, AA Grade

Nitrous Oxide Gas, AA Grade

$\mathrm{KCl}$ for controlling ionization interferences

\section{Safety Equipment}

Disposable gloves, with appropriate chemical resistance

Safety glasses

Lab jacket

\section{Procedures}

Safety Checks

General

Turn the vent on and ensure it is properly drawing before proceeding.

Close the flame door.

Ensure cylinders contain sufficient gas for the intended analysis.

Ensure a fire extinguisher is located near the equipment and ensure it is charged.

Burner Head

Ensure the proper burner head has been selected for the samples.

If changing the burner head, ensure the O-ring is in good condition. If the O-ring is damaged, replace it.

Ensure the burner head slot is clean.

Ensure the burner head is fully seated into the spray chamber, and secure the restraining cables and the interlock pin.

Drain System

Ensure the drain system has been properly installed.

If the level of waste in the drain vessel is high, properly dispose of the waste and reassemble the drain system. See section 7 for disposal guidelines. 


\section{Parameters}

This section describes each of the parameters. The parameter settings for the elements are specified in the appendices to this procedure.

Lamp Current-Set this to the appropriate value, in $\mathrm{mA}$, for the desired element to be tested.

Integration Time- The time the FAAS waits between sample replicates. Set to 1 second for quality procedures.

Replicates - The number of sample replicates. Set to 10 for quality control procedures.

Calibration Type-Linear, non-linear, or method of additions. Use the default value, non-linear, for quality procedures.

AA Technique - Flame, PK area, Peak height. The default is Flame, and this is the only option available on our 3110 model.

Standards 1-8- You have the option of using up to 8 standards. Three standards are the minimum. The decimal point is automatically set based on the first standard entered.

Reslope Standard-resets the calibration line based on the value entered. Do not use this option.

Read Delay Time- The spectrometer will delay reading the signal of the aspirated sample for the specified time. Use the default value, 0 .

Print Calibration Curve- Default value is Yes. Set this parameter to No because the FAAS has no printer attached.

\section{Calibration}

Additional details and guidelines for calibration of the FAAS are on pages 119121 of Model 3110 Atomic Absorption Spectrometer Hardware Guide

The calibration consists of a blank and at least three standards.

$\mathrm{S} 1$ should be equal to the high end of the linear range, $\mathrm{S} 2$ is three times $\mathrm{S} 1$, and

$\mathrm{S} 3$ is six times $\mathrm{S} 1$. For additional explanation, refer to pages 16-23 of the Analytical Methods for Atomic Absorption Spectrometry

Standards should be matrix matched to the samples being run for best results.

The FAAS software automatically creates a calibration curve.

Re-analyze standards as samples during runs.

\section{Igniting and optimizing the FAAS}

Turn on the FAAS.

Dial the wavelength to the appropriate setting for the element to be analyzed. Use the first wavelength listed unless another is required. Record deviations in the QC/Maintenance Log.

Set the slit width to the correct setting for the element being analyzed, as specified in the appendices. Record deviations in the QC/Maintenance Log. 
Install the applicable HCL into the lamp holder and set the lamp current to the correct $\mathrm{mA}$ for the element being tested. Record the HCL energy in the QC/Maintenance Log.

Align the lamp to achieve the maximum energy.

Turn on the gas supply at the tanks.

Adjust the burner height.

Ignite the flame.

Adjust the horizontal and rotational position of the burner.

Adjust the nebulizer.

Record the energy level in QC/Maintenance Log.

Autozero the instrument in the Continuous Mode using deionized water. Then check the characteristic concentration solution and record the absorbance value in the QC/Maintenance Log.

Record the date and analyst's initials next to the entries in the QC/Maintenance Log.

\section{Running Samples}

Samples must be bracketed by the standards. If the samples are beyond the range of the standards, dilute the samples or prepare a new set of standards bracketing the samples.

Prepare solutions.

Enter parameters. The parameters are specified in the appendix for the element.

Enter the data collection mode.

Run the standard blank.

Run the standards.

Analyze DI water between the standards and the samples. Also analyze DI water before and after each check standard.

Run the samples.

Re-analyze the standards after every set of 10 samples. If the standards deviate by more than $20 \%$, recalibrate and rerun the last batch of samples.

Run one duplicate sample for every set of 10 samples run. If duplicate value deviates by more than $20 \%$, recalibrate and rerun the batch of samples. 


\section{Powering Down the System}

Aspirate de-ionized water for a few minutes to clean the burner head.

Turn the gas control switch on the pneumatics control panel to OFF.

Close all gas source valves.

Turn the gas control switch to Air to allow acetylene and oxidant to bleed.

Turn the gas control switch to OFF.

Turn the instrument OFF.

Turn the vent OFF.

\section{Calculations}

Calculate metal concentration in the sample using the following equation: $\mathbf{p p m}=\mathbf{C} \times \mathbf{D}$

Where: $\quad \mathrm{ppm}=$ The actual concentration of metal in the sample. $(\mathrm{ppm})$

$\mathrm{C}=$ The reading from the FAAS. (ppm)

$\mathrm{D}=$ The dilution factor.

\section{Maintenance}

\section{Burner Head}

Clean burner head at least monthly. Record in QC/Maintenance Log.

If aspirating samples with high solids content, clean the burner daily. Record in QC/Maintenance Log.

Clean the slot in the burner with the thin metal strip provided with the instrument before each use. Record in QC/Maintenance Log.

The burner head can also be soaked overnight in a mild detergent and then rinsed with deionized water and blown dry.

\section{Air compressor}

Drain the air compressor of water monthly. Record in QC/Maintenance Log.

\section{Sample Retention and Disposal}

Retain samples for metal analyses one month (30 days). Retain samples longer when requested by the client. Identify each collection of samples so the contents of the samples can be identified. Mark disposal date on each collection of samples.

Segregate samples for disposal by matrix type. Collect waste in 5 gallon or smaller containers, as appropriate for the expected volume during a 180 day period.

Separate RCRA listed metals from the other metals.

Label each waste storage container with its contents and start date.

\section{Records}

Record all data in a lab notebook. Record Maintenance and HCL energy in QC/Maintenance Log. 
Data should include the element tested, wavelength, slit width, and the energy of the HCL.

A copy of the data should accompany the quality report for the test performed.

Maintain laboratory notebooks as specified in document(HEN-0010, Control of Quality Records.

\section{List of Appendices}

Appendix A - Europium

Appendix B - Strontium

Appendix C - Nickel

Appendix D - Lead 


\section{Appendix F - Rhenium}

\section{Standard Atomic Absorption Conditions for Rhenium}

\begin{tabular}{cccccc}
\hline Wavelength & Slit & $\begin{array}{c}\text { Relative } \\
\text { Noise }\end{array}$ & $\begin{array}{c}\text { Characteristic } \\
\text { Concentration }\end{array}$ & $\begin{array}{c}\text { Characteristic } \\
\text { Concentration } \\
\text { Check } \\
(\mathrm{mg} / \mathrm{L})\end{array}$ & $\begin{array}{c}\text { Linear } \\
\text { Range }\end{array}$ \\
\hline 346.0 & 0.2 & 1.0 & $(\mathrm{mg} / \mathrm{L})$ & 650.0 & 500.0 \\
\hline
\end{tabular}

1. Use a nitrous oxide - acetylene flame.

2. Use calibration standards of 100, 300, and 500 ppm Re.

$\begin{array}{ll}\text { Parameters } & \\ \text { Lamp Current } & 60 \mathrm{~mA} \\ \text { Integration time } & 1 \mathrm{sec} . \\ \text { Replicates } & 10 \\ \text { Calibration Type } & \text { linear } \\ \text { AA Technique } & \text { flame } \\ \text { Read Delay Time } & 0 \mathrm{sec} .\end{array}$


Appendix B 


\section{0-Liter Reactor Temperature Profile}

\begin{tabular}{|c|c|c|c|c|c|}
\hline Time & $\begin{array}{c}\text { Rxn Temp } \\
\text { C } \\
\end{array}$ & $\begin{array}{l}\text { Heater } \\
\text { Temp. } \\
\text { C } \\
\end{array}$ & $\begin{array}{c}\text { Heat In } \\
\text { C } \\
\end{array}$ & $\begin{array}{c}\text { Heat Out } \\
\text { C } \\
\end{array}$ & Comments \\
\hline 12/9/97 10:21 AM & 18.8 & 22.3 & 21.6 & 20.6 & \\
\hline 12/9/97 10:26 AM & 19.2 & 26.6 & 26.1 & 23.7 & \\
\hline 12/9/97 10:31 AM & 19.7 & 30.4 & 29.5 & 27.1 & \\
\hline 12/9/97 10:36 AM & 21.2 & 33.7 & 32.9 & 30.5 & \\
\hline 12/9/97 10:41 AM & 23.0 & 36.9 & 36.1 & 33.8 & \\
\hline 12/9/97 10:46 AM & 25.0 & 39.7 & 38.9 & 36.7 & \\
\hline 12/9/97 10:51 AM & 26.8 & 42.6 & 41.6 & 39.3 & \\
\hline 12/9/97 10:56 AM & 29.1 & 45.4 & 44.5 & 42.4 & \\
\hline 12/9/97 11:01 AM & 31.5 & 41.8 & 41.5 & 41.9 & \\
\hline 12/9/97 11:06 AM & 33.2 & 40.9 & 40.4 & 40.9 & \\
\hline 12/9/97 11:11 AM & 34.3 & 40.2 & 39.8 & 40.4 & \\
\hline 12/9/97 11:16 AM & 34.9 & 39.4 & 39.1 & 39.6 & \\
\hline 12/9/97 11:21 AM & 35.4 & 39.1 & 38.6 & 39.2 & \\
\hline 12/9/97 11:26 AM & 35.8 & 38.8 & 38.6 & 39.1 & \\
\hline 12/9/97 11:31 AM & 35.7 & 38.6 & 38.3 & 38.9 & \\
\hline 12/9/97 11:36 AM & & & & & Paper Jammed \\
\hline 12/9/97 12:58 PM & 38.8 & 46.1 & 45.6 & 46.1 & Ramp Set point slowly to 67 \\
\hline 12/9/97 1:03 PM & 39.5 & 48.3 & 46.8 & 44.9 & \\
\hline 12/9/97 1:08 PM & 40.1 & 51.8 & 50.5 & 48.6 & \\
\hline 12/9/97 1:13 PM & 41.4 & 54.7 & 53.5 & 51.6 & \\
\hline 12/9/97 1:18 PM & 42.9 & 57.3 & 56.1 & 54.2 & \\
\hline 12/9/97 1:23 PM & 44.7 & 59.8 & 58.4 & 56.8 & \\
\hline 12/9/97 1:28 PM & 46.6 & 59.3 & 59.9 & 59.1 & \\
\hline 12/9/97 1:33 PM & 48.3 & 61.5 & 60.1 & 58.6 & \\
\hline 12/9/97 1:38 PM & 50.1 & 64.4 & 62.9 & 61.3 & \\
\hline 12/9/97 1:43 PM & 51.9 & 66.9 & 65.3 & 63.9 & \\
\hline 12/9/97 1:48 PM & 54.1 & 69.1 & 67.7 & 66.2 & \\
\hline 12/9/97 1:53 PM & 56.1 & 71.1 & 69.7 & 68.4 & \\
\hline 12/9/97 1:58 PM & 57.9 & 66.0 & 65.2 & 66.3 & \\
\hline 12/9/97 2:03 PM & 59.4 & 68.2 & 66.4 & 65.2 & \\
\hline 12/9/97 2:08 PM & 60.4 & 71.8 & 70.1 & 68.8 & \\
\hline 12/9/97 2:13 PM & 61.8 & 74.1 & 72.6 & 71.2 & \\
\hline 12/9/97 2:18 PM & 63.7 & 76.4 & 74.8 & 73.6 & Set point set to 67 \\
\hline 12/9/97 2:23 PM & 65.2 & 78.6 & 76.9 & 75.7 & \\
\hline 12/9/97 2:28 PM & 66.5 & 75.2 & 74.1 & 75.4 & \\
\hline 12/9/97 2:33 PM & 68.2 & 73.8 & 72.8 & 74.1 & \\
\hline 12/9/97 2:38 PM & 69.2 & 72.8 & 71.7 & 73.2 & \\
\hline 12/9/97 2:43 PM & 69.7 & 72.1 & 71.1 & 72.6 & \\
\hline 12/9/97 2:48 PM & 70.0 & 71.6 & 70.5 & 72.0 & \\
\hline 12/9/97 2:53 PM & 69.7 & 70.9 & 69.8 & 71.3 & \\
\hline 12/9/97 2:58 PM & 69.7 & 70.4 & 69.3 & 70.8 & \\
\hline 12/9/97 3:03 PM & 69.6 & 70.1 & 69.1 & 70.4 & \\
\hline 12/9/97 3:08 PM & 69.4 & 69.7 & 68.6 & 69.9 & \\
\hline 12/9/97 3:13 PM & 69.0 & 69.1 & 68.2 & 69.6 & \\
\hline
\end{tabular}




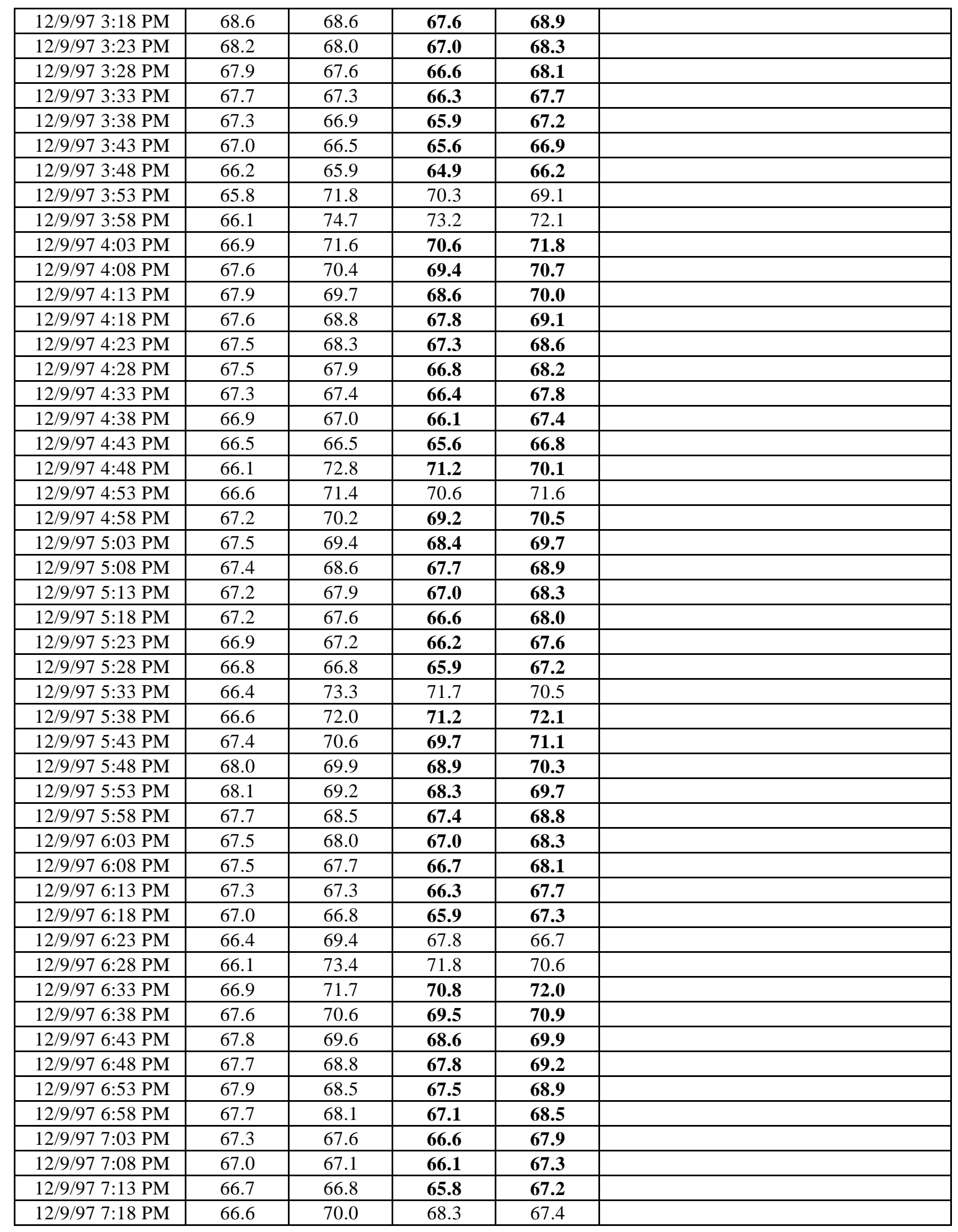




\begin{tabular}{|c|c|c|c|c|c|}
\hline 12/9/97 7:23 PM & 66.5 & 73.9 & 72.4 & 71.2 & \\
\hline 12/9/97 7:28 PM & 66.8 & 71.5 & 70.6 & 71.7 & \\
\hline 12/9/97 7:33 PM & 67.4 & 70.2 & 69.3 & 70.6 & \\
\hline 12/9/97 7:38 PM & 68.0 & 69.7 & 68.6 & 70.0 & \\
\hline 12/9/97 7:43 PM & 68.1 & 69.1 & 68.2 & 69.5 & \\
\hline 12/9/97 7:48 PM & 67.8 & 68.6 & 67.5 & 68.8 & \\
\hline 12/9/97 7:53 PM & 67.6 & 68.0 & 67.0 & 68.2 & \\
\hline 12/9/97 7:58 PM & 67.6 & 67.7 & 66.8 & 68.1 & \\
\hline 12/9/97 8:03 PM & 67.4 & 67.4 & 66.4 & 67.8 & \\
\hline 12/9/97 8:08 PM & 67.2 & 67.1 & 66.2 & 67.6 & \\
\hline 12/9/97 8:13 PM & 66.6 & 66.7 & 65.7 & 66.9 & \\
\hline 12/9/97 8:18 PM & 66.2 & 70.4 & 68.9 & 67.8 & \\
\hline 12/9/97 8:23 PM & 66.4 & 74.3 & 72.8 & 71.6 & Set point at 74 \\
\hline 12/9/97 8:28 PM & 67.2 & 77.2 & 75.6 & 74.6 & \\
\hline 12/9/97 8:33 PM & 68.6 & 79.6 & 77.9 & 76.8 & \\
\hline 12/9/97 8:38 PM & 70.0 & 81.9 & 80.1 & 79.0 & \\
\hline 12/9/97 8:43 PM & 72.2 & 84.3 & 82.4 & 81.4 & \\
\hline 12/9/97 8:48 PM & 74.6 & 81.4 & 80.3 & 81.9 & \\
\hline 12/9/97 8:53 PM & 76.2 & 80.0 & 78.3 & 79.7 & \\
\hline 12/9/97 8:58 PM & 77.1 & 78.9 & 77.6 & 79.3 & \\
\hline 12/9/97 9:03 PM & 77.9 & 78.5 & 77.2 & 78.9 & \\
\hline 12/9/97 9:08 PM & 78.6 & 78.2 & 77.0 & 78.8 & \\
\hline 12/9/97 9:13 PM & 78.8 & 78.0 & 76.7 & 78.3 & \\
\hline 12/9/97 9:18 PM & 78.9 & 77.8 & 76.5 & 78.2 & \\
\hline 12/9/97 9:23 PM & 79.4 & 78.0 & 76.6 & 78.1 & \\
\hline 12/9/97 9:28 PM & 79.6 & 78.0 & 76.6 & 78.3 & \\
\hline 12/9/97 9:33 PM & 79.6 & 77.8 & 76.4 & 78.0 & \\
\hline 12/9/97 9:38 PM & 79.6 & 77.8 & 76.4 & 78.2 & \\
\hline 12/9/97 9:43 PM & 80.1 & 78.1 & 76.8 & 78.5 & \\
\hline 12/9/97 9:48 PM & 80.6 & 78.4 & 77.1 & 78.6 & Cooling water turned on \\
\hline 12/9/97 9:53 PM & 78.1 & 73.4 & 23.6 & 12.1 & Cooling water turned off \\
\hline 12/9/97 9:58 PM & 71.2 & 30.6 & 29.6 & 28.3 & \\
\hline 12/9/97 10:03 PM & 64.3 & 39.6 & 38.4 & 37.0 & \\
\hline 12/9/97 10:08 PM & 58.9 & 45.1 & 44.2 & 42.4 & \\
\hline 12/9/97 10:13 PM & 54.9 & 49.2 & 48.2 & 46.5 & \\
\hline 12/9/97 10:18 PM & 52.7 & 52.6 & 51.7 & 50.0 & \\
\hline 12/9/97 10:23 PM & 51.6 & 55.6 & 54.7 & 53.1 & \\
\hline 12/9/97 10:28 PM & 51.1 & 58.4 & 57.2 & 55.6 & \\
\hline 12/9/97 10:33 PM & 50.9 & 60.4 & 59.3 & 57.8 & \\
\hline 12/9/97 10:38 PM & 51.7 & 62.9 & 61.7 & 60.4 & \\
\hline 12/9/97 10:43 PM & 52.8 & 65.2 & 64.0 & 62.6 & \\
\hline 12/9/97 10:48 PM & 54.0 & 67.3 & 66.1 & 64.7 & \\
\hline 12/9/97 10:53 PM & 55.5 & 69.4 & 68.1 & 66.8 & \\
\hline 12/9/97 10:58 PM & 57.3 & 71.7 & 70.4 & 69.1 & \\
\hline 12/9/97 11:03 PM & 59.2 & 73.5 & 72.4 & 71.2 & \\
\hline 12/9/97 11:08 PM & 61.0 & 75.4 & 74.0 & 72.8 & \\
\hline 12/9/97 11:13 PM & 63.4 & 77.5 & 76.1 & 75.0 & \\
\hline 12/9/97 11:18 PM & 66.1 & 79.7 & 78.2 & 77.2 & \\
\hline 12/9/97 11:23 PM & 68.3 & 81.8 & 80.2 & 79.4 & \\
\hline
\end{tabular}




\begin{tabular}{|c|c|c|c|c|c|}
\hline 12/9/97 11:28 PM & 70.6 & 79.6 & 78.6 & 80.1 & \\
\hline 12/9/97 11:33 PM & 73.0 & 78.3 & 77.2 & 78.9 & \\
\hline 12/9/97 11:38 PM & 74.2 & 77.9 & 76.7 & 78.4 & \\
\hline 12/9/97 11:43 PM & 74.6 & 77.4 & 76.3 & 77.9 & \\
\hline 12/9/97 11:48 PM & 75.4 & 77.4 & 76.2 & 78.0 & \\
\hline 12/9/97 11:53 PM & 76.3 & 77.7 & 76.5 & 78.2 & \\
\hline 12/9/97 11:58 PM & 76.8 & 77.7 & 76.5 & 78.2 & \\
\hline 12/10/97 12:03 AM & 77.2 & 77.7 & 76.3 & 78.0 & \\
\hline 12/10/97 12:08 AM & 77.3 & 77.6 & 76.4 & 78.2 & \\
\hline 12/10/97 12:13 AM & 77.3 & 77.6 & 76.3 & 78.1 & \\
\hline 12/10/97 12:18 AM & 76.3 & 77.0 & 75.8 & 77.4 & \\
\hline 12/10/97 12:23 AM & 75.6 & 76.6 & 75.3 & 76.9 & \\
\hline 12/10/97 12:28 AM & 75.1 & 76.2 & 75.1 & 76.6 & \\
\hline 12/10/97 12:33 AM & 74.4 & 75.8 & 74.7 & 76.2 & \\
\hline $12 / 10 / 97$ 12:38 AM & 73.5 & 75.2 & 73.9 & 75.4 & \\
\hline 12/10/97 12:43 AM & 72.9 & 80.8 & 79.2 & 78.2 & \\
\hline $12 / 10 / 97$ 12:48 AM & 72.9 & 83.9 & 82.2 & 81.1 & \\
\hline $12 / 10 / 9712: 53 \mathrm{AM}$ & 73.1 & 86.2 & 84.3 & 83.3 & \\
\hline 12/10/97 12:58 AM & 73.6 & 82.6 & 81.4 & 82.7 & \\
\hline 12/10/97 1:03 AM & 74.3 & 81.0 & 79.8 & 81.3 & \\
\hline 12/10/97 1:08 AM & 74.5 & 79.9 & 78.7 & 80.2 & \\
\hline 12/10/97 1:13 AM & 74.1 & 78.8 & 77.4 & 79.1 & \\
\hline 12/10/97 1:18 AM & 74.3 & 78.1 & 76.9 & 78.5 & \\
\hline 12/10/97 1:23 AM & 74.1 & 77.4 & 76.3 & 77.9 & \\
\hline 12/10/97 1:28 AM & 73.4 & 81.9 & 80.0 & 79.2 & \\
\hline 12/10/97 1:33 AM & 73.4 & 84.9 & 83.0 & 82.0 & \\
\hline 12/10/97 1:38 AM & 74.0 & 81.8 & 80.7 & 82.1 & \\
\hline 12/10/97 1:43 AM & 74.4 & 80.3 & 79.2 & 80.7 & \\
\hline 12/10/97 1:48 AM & 74.2 & 79.1 & 77.8 & 79.4 & \\
\hline 12/10/97 1:53 AM & 74.1 & 78.2 & 77.0 & 78.6 & \\
\hline 12/10/97 1:58 AM & 74.2 & 77.6 & 76.4 & 78.0 & \\
\hline 12/10/97 2:03 AM & 73.7 & 81.0 & 79.0 & 78.3 & \\
\hline 12/10/97 2:08 AM & 73.4 & 84.2 & 82.3 & 81.3 & \\
\hline 12/10/97 2:13 AM & 73.7 & 83.8 & 83.7 & 83.8 & \\
\hline 12/10/97 2:18 AM & 74.3 & 81.4 & 80.2 & 81.8 & \\
\hline 12/10/97 2:23 AM & 74.3 & 79.9 & 78.7 & 80.3 & \\
\hline 12/10/97 2:28 AM & 74.3 & 79.0 & 77.8 & 79.4 & \\
\hline 12/10/97 2:33 AM & 74.4 & 78.2 & 77.1 & 78.7 & \\
\hline 12/10/97 2:38 AM & 74.0 & 77.5 & 76.3 & 77.9 & \\
\hline 12/10/97 2:43 AM & 73.5 & 80.4 & 78.4 & 77.8 & \\
\hline 12/10/97 2:48 AM & 73.4 & 83.9 & 82.2 & 81.3 & \\
\hline 12/10/97 2:53 AM & 73.8 & 85.4 & 84.7 & 83.8 & \\
\hline 12/10/97 2:58 AM & 74.1 & 81.4 & 80.1 & 81.6 & \\
\hline 12/10/97 3:03 AM & 74.3 & 80.1 & 78.8 & 80.4 & \\
\hline 12/10/97 3:08 AM & 74.6 & 79.2 & 77.9 & 79.6 & \\
\hline 12/10/97 3:13 AM & 74.3 & 78.3 & 77.1 & 78.7 & \\
\hline 12/10/97 3:18 AM & 74.1 & 77.4 & 76.2 & 77.7 & \\
\hline 12/10/97 3:23 AM & 73.9 & 80.3 & 78.3 & 77.8 & \\
\hline 12/10/97 3:28 AM & 73.7 & 83.7 & 82.2 & 81.2 & \\
\hline
\end{tabular}




\begin{tabular}{|c|c|c|c|c|c|}
\hline 12/10/97 3:33 AM & 73.7 & 82.8 & 81.8 & 83.1 & \\
\hline 12/10/97 3:38 AM & 74.1 & 80.6 & 79.4 & 80.8 & \\
\hline 12/10/97 3:43 AM & 74.5 & 79.6 & 78.3 & 80.0 & \\
\hline 12/10/97 3:48 AM & 74.4 & 78.7 & 77.4 & 79.0 & \\
\hline 12/10/97 3:53 AM & 74.0 & 77.7 & 76.4 & 77.9 & \\
\hline 12/10/97 3:58 AM & 73.9 & 80.9 & 78.9 & 78.3 & \\
\hline 12/10/97 4:03 AM & 73.7 & 84.3 & 82.5 & 81.6 & \\
\hline 12/10/97 4:08 AM & 73.8 & 81.9 & 80.9 & 82.3 & \\
\hline 12/10/97 4:13 AM & 74.1 & 80.2 & 79.0 & 80.6 & \\
\hline 12/10/97 4:18 AM & 74.6 & 79.3 & 78.1 & 79.7 & \\
\hline 12/10/97 4:23 AM & 74.3 & 78.3 & 77.2 & 78.8 & \\
\hline 12/10/97 4:28 AM & 73.9 & 77.5 & 76.3 & 77.8 & \\
\hline 12/10/97 4:33 AM & 73.7 & 83.1 & 81.1 & 80.3 & \\
\hline 12/10/97 4:38 AM & 73.9 & 85.9 & 83.9 & 83.1 & \\
\hline 12/10/97 4:43 AM & 74.1 & 81.1 & 79.8 & 81.3 & \\
\hline 12/10/97 4:48 AM & 74.4 & 79.8 & 78.5 & 80.1 & \\
\hline 12/10/97 4:53 AM & 74.7 & 78.9 & 77.7 & 79.3 & \\
\hline 12/10/97 4:58 AM & 74.4 & 78.1 & 76.8 & 78.4 & \\
\hline 12/10/97 5:03 AM & 73.9 & 77.2 & 75.9 & 77.4 & \\
\hline 12/10/97 5:08 AM & 73.8 & 82.9 & 81.1 & 80.1 & \\
\hline 12/10/97 5:13 AM & 73.9 & 85.7 & 83.9 & 83.0 & \\
\hline 12/10/97 5:18 AM & 74.1 & 81.2 & 80.0 & 81.5 & \\
\hline 12/10/97 5:23 AM & 74.4 & 79.9 & 78.6 & 80.2 & \\
\hline 12/10/97 5:28 AM & 74.6 & 78.9 & 77.8 & 79.4 & \\
\hline 12/10/97 5:33 AM & 74.3 & 78.0 & 76.8 & 78.4 & \\
\hline 12/10/97 5:38 AM & 73.9 & 77.2 & 75.9 & 77.4 & \\
\hline 12/10/97 5:43 AM & 73.9 & 81.8 & 79.9 & 79.2 & \\
\hline 12/10/97 5:48 AM & 73.7 & 84.7 & 82.9 & 81.9 & \\
\hline 12/10/97 5:53 AM & 74.0 & 82.3 & 81.2 & 82.6 & \\
\hline 12/10/97 5:58 AM & 74.2 & 80.4 & 79.2 & 80.7 & \\
\hline 12/10/97 6:03 AM & 74.7 & 79.4 & 78.2 & 79.8 & \\
\hline 12/10/97 6:08 AM & 74.6 & 78.6 & 77.4 & 79.0 & \\
\hline 12/10/97 6:13 AM & 74.1 & 77.6 & 76.3 & 77.9 & \\
\hline 12/10/97 6:18 AM & 73.7 & 81.3 & 79.3 & 78.6 & \\
\hline 12/10/97 6:23 AM & 73.8 & 84.7 & 82.8 & 81.9 & \\
\hline 12/10/97 6:28 AM & 74.1 & 80.8 & 79.6 & 81.1 & \\
\hline 12/10/97 6:33 AM & 74.1 & 79.3 & 78.0 & 79.6 & \\
\hline 12/10/97 6:38 AM & 74.3 & 78.3 & 77.2 & 78.8 & \\
\hline 12/10/97 6:43 AM & 74.2 & 77.7 & 76.4 & 78.1 & \\
\hline 12/10/97 6:48 AM & 73.5 & 82.9 & 80.8 & 80.0 & \\
\hline 12/10/97 6:53 AM & 73.7 & 85.4 & 83.7 & 82.7 & \\
\hline 12/10/97 6:58 AM & 74.3 & 81.2 & 80.1 & 81.6 & \\
\hline 12/10/97 7:03 AM & 74.7 & 79.9 & 78.7 & 80.2 & \\
\hline 12/10/97 7:08 AM & 74.4 & 78.7 & 77.5 & 79.0 & \\
\hline 12/10/97 7:13 AM & 74.3 & 77.9 & 76.8 & 78.3 & \\
\hline 12/10/97 7:18 AM & 74.2 & 77.3 & 76.2 & 77.8 & \\
\hline 12/10/97 7:23 AM & 73.6 & 82.7 & 80.9 & 80.1 & \\
\hline 12/10/97 7:28 AM & 73.7 & 85.5 & 83.7 & 82.6 & \\
\hline 12/10/97 7:33 AM & 74.4 & 87.8 & 86.0 & 85.1 & Set point ramp to 92 begins \\
\hline
\end{tabular}




\begin{tabular}{|c|c|c|c|c|c|}
\hline 12/10/97 7:38 AM & 75.5 & 89.8 & 87.9 & 87.0 & \\
\hline 12/10/97 7:43 AM & 76.4 & 91.7 & 89.7 & 88.7 & \\
\hline 12/10/97 7:48 AM & 78.0 & 93.6 & 91.6 & 90.8 & \\
\hline 12/10/97 7:53 AM & 79.3 & 95.2 & 93.3 & 92.6 & \\
\hline 12/10/97 7:58 AM & 80.8 & 97.3 & 95.1 & 94.3 & \\
\hline 12/10/97 8:03 AM & 82.1 & 98.7 & 96.6 & 96.0 & \\
\hline 12/10/97 8:08 AM & 83.4 & 100.2 & 98.1 & 97.5 & \\
\hline 12/10/97 8:13 AM & 84.7 & 102.0 & 99.5 & 98.9 & \\
\hline 12/10/97 8:18 AM & 86.3 & 103.6 & 101.3 & 100.8 & \\
\hline 12/10/97 8:23 AM & 87.9 & 105.3 & 102.9 & 102.6 & Set point to 92 \\
\hline 12/10/97 8:28 AM & 93.8 & 103.6 & 102.3 & 103.9 & \\
\hline 12/10/97 8:33 AM & 98.4 & 100.7 & 99.0 & 101.1 & \\
\hline 12/10/97 8:38 AM & 95.8 & 99.1 & 97.4 & 99.6 & \\
\hline 12/10/97 8:43 AM & 96.3 & 97.8 & 96.1 & 98.3 & \\
\hline 12/10/97 8:48 AM & 95.6 & 96.5 & 94.9 & 97.0 & \\
\hline 12/10/97 8:53 AM & 94.6 & 95.3 & 93.7 & 95.8 & \\
\hline 12/10/97 8:58 AM & 93.3 & 94.2 & 92.6 & 94.6 & \\
\hline 12/10/97 9:03 AM & 92.5 & 93.3 & 91.7 & 93.7 & \\
\hline 12/10/97 9:08 AM & 91.5 & 97.9 & 95.7 & 95.3 & \\
\hline 12/10/97 9:13 AM & 91.3 & 100.6 & 98.4 & 97.8 & \\
\hline 12/10/97 9:18 AM & 91.8 & 102.5 & 100.3 & 99.7 & \\
\hline 12/10/97 9:23 AM & 92.3 & 98.7 & 97.1 & 98.9 & \\
\hline 12/10/97 9:28 AM & 92.4 & 96.6 & 94.9 & 96.9 & \\
\hline 12/10/97 9:33 AM & 92.6 & 95.3 & 93.7 & 95.7 & \\
\hline 12/10/97 9:38 AM & 92.4 & 94.2 & 92.5 & 94.6 & \\
\hline 12/10/97 9:43 AM & 91.9 & 100.3 & 98.0 & 97.4 & \\
\hline 12/10/97 9:48 AM & 91.9 & 102.2 & 100.0 & 99.4 & \\
\hline 12/10/97 9:53 AM & 92.6 & 97.7 & 96.0 & 98.0 & \\
\hline 12/10/97 9:58 AM & 92.8 & 96.0 & 94.4 & 96.4 & \\
\hline 12/10/97 10:03 AM & 92.6 & 94.7 & 93.1 & 95.1 & \\
\hline 12/10/97 10:08 AM & 92.1 & 99.4 & 97.2 & 96.7 & \\
\hline 12/10/97 10:13 AM & 91.9 & 101.7 & 99.4 & 98.9 & \\
\hline 12/10/97 10:18 AM & 92.4 & 98.9 & 97.3 & 99.1 & \\
\hline 12/10/97 10:23 AM & 92.8 & 96.9 & 95.3 & 97.3 & \\
\hline 12/10/97 10:28 AM & 92.9 & 95.4 & 93.8 & 95.9 & \\
\hline 12/10/97 10:33 AM & 92.6 & 94.3 & 92.7 & 94.6 & \\
\hline 12/10/97 10:38 AM & 92.1 & 100.2 & 98.0 & 97.4 & \\
\hline 12/10/97 10:43 AM & 92.3 & 102.5 & 100.2 & 99.6 & \\
\hline 12/10/97 10:48 AM & 92.6 & 97.9 & 96.2 & 98.1 & \\
\hline 12/10/97 10:53 AM & 92.6 & 96.0 & 94.4 & 96.4 & \\
\hline 12/10/97 10:58 AM & 92.6 & 94.7 & 93.1 & 95.2 & \\
\hline 12/10/97 11:03 AM & 92.2 & 98.8 & 96.6 & 96.2 & \\
\hline 12/10/97 11:08 AM & 91.9 & 101.4 & 99.2 & 98.6 & \\
\hline 12/10/97 11:13 AM & 92.6 & 98.9 & 97.4 & 99.2 & \\
\hline 12/10/97 11:18 AM & 92.5 & 96.6 & 94.9 & 96.8 & \\
\hline 12/10/97 11:23 AM & 92.6 & 95.2 & 93.5 & 95.6 & Cooling water turned on. \\
\hline 12/10/97 11:28 AM & 89.6 & 82.7 & 27.9 & 12.5 & \\
\hline 12/10/97 11:33 AM & 77.5 & 79.7 & 18.7 & 12.4 & \\
\hline 12/10/97 11:38 AM & 64.8 & 71.3 & 16.9 & 13.4 & \\
\hline
\end{tabular}




\begin{tabular}{|l|l|l|l|l|l|}
\hline $12 / 10 / 9711: 43 \mathrm{AM}$ & 54.9 & 61.4 & $\mathbf{1 5 . 1}$ & $\mathbf{1 2 . 4}$ & \\
\hline $12 / 10 / 9711: 48 \mathrm{AM}$ & 46.6 & 58.0 & $\mathbf{1 3 . 9}$ & $\mathbf{1 2 . 1}$ & \\
\hline $12 / 10 / 9711: 53 \mathrm{AM}$ & 40.9 & 55.1 & $\mathbf{1 3 . 6}$ & $\mathbf{1 2 . 2}$ & \\
\hline $12 / 10 / 9711: 58 \mathrm{AM}$ & 36.2 & 52.2 & $\mathbf{1 3 . 3}$ & $\mathbf{1 2 . 4}$ & \\
\hline $12 / 10 / 9712: 03 \mathrm{PM}$ & 32.3 & 49.7 & $\mathbf{1 3 . 0}$ & $\mathbf{1 2 . 4}$ & \\
\hline $12 / 10 / 9712: 08$ PM & 29.3 & 47.9 & $\mathbf{1 3 . 0}$ & $\mathbf{1 2 . 4}$ & \\
\hline $12 / 10 / 9712: 13 \mathrm{PM}$ & 26.4 & 45.3 & $\mathbf{1 2 . 7}$ & $\mathbf{1 2 . 3}$ & \\
\hline $12 / 10 / 9712: 18 \mathrm{PM}$ & 24.1 & 43.6 & $\mathbf{1 2 . 4}$ & $\mathbf{1 2 . 1}$ & \\
\hline
\end{tabular}

Bold face indicates jacket is cooling. 
Appendix C 
ABEC ${ }^{R}$ Copolymer Flow Sheet

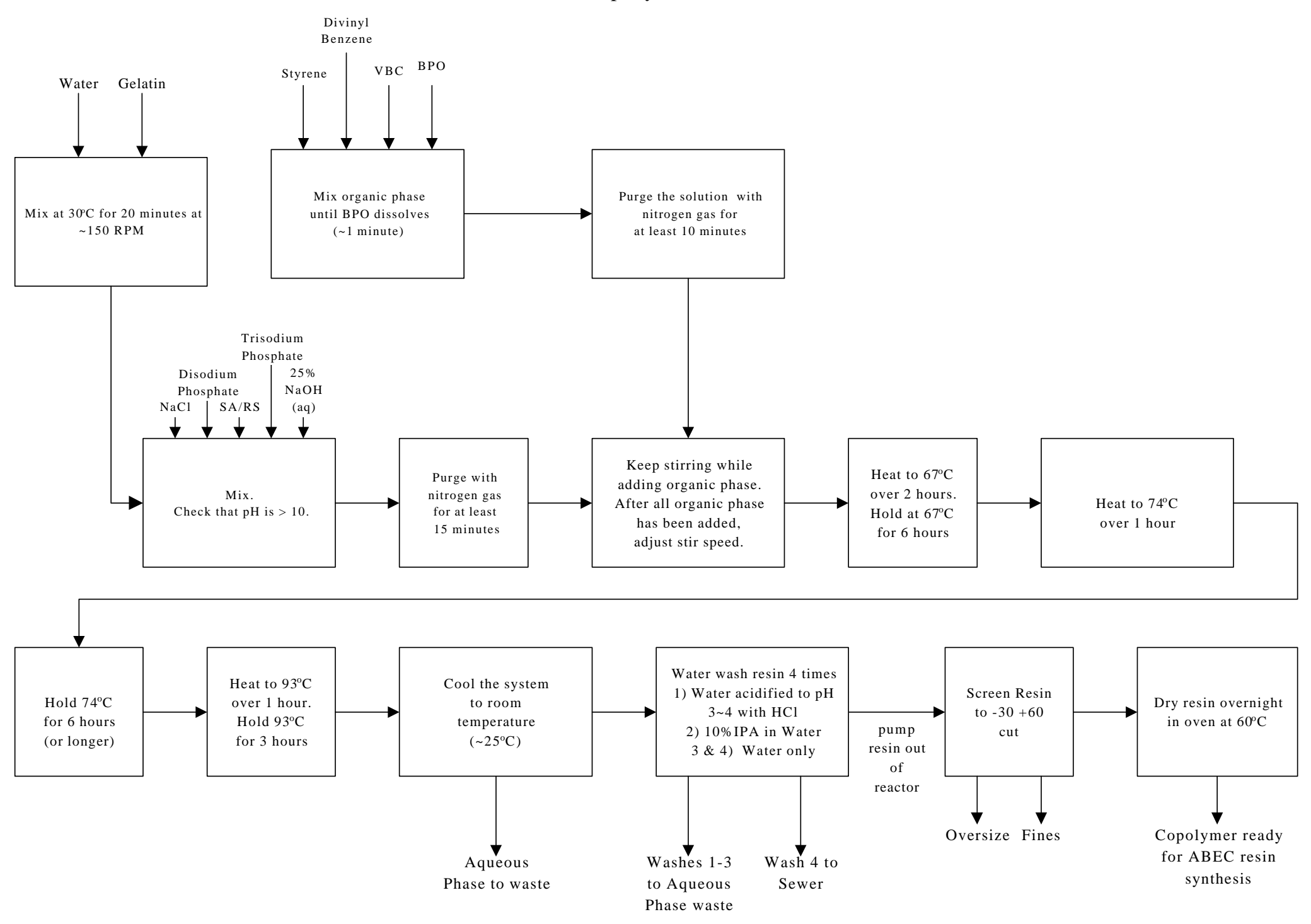


$\mathrm{ABEC}^{(\mathrm{R})}$ Resin Flow Sheet

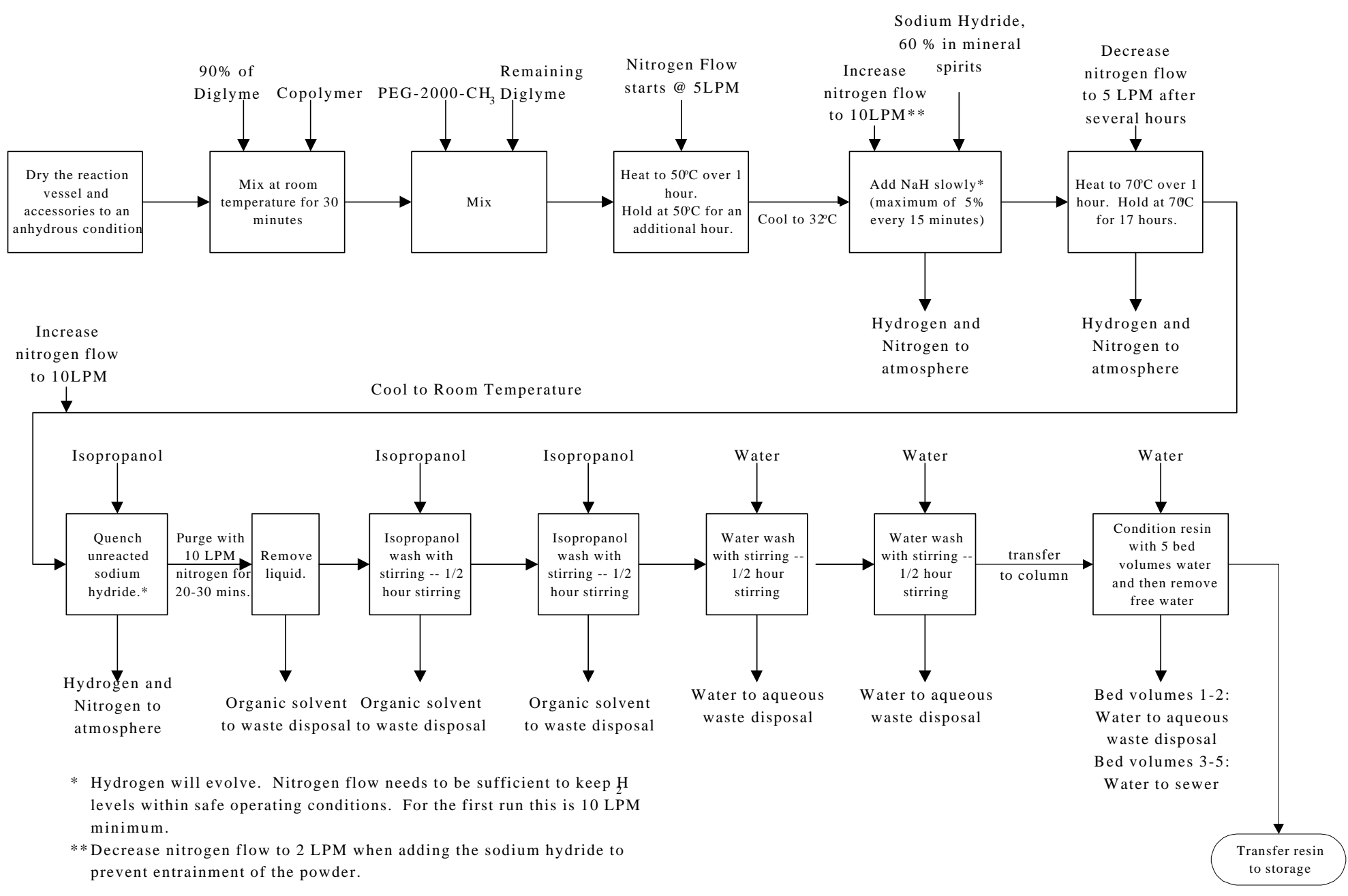




\section{$\mathrm{ABEC}^{\mathrm{R}}$ Copolymer Equipment Table}
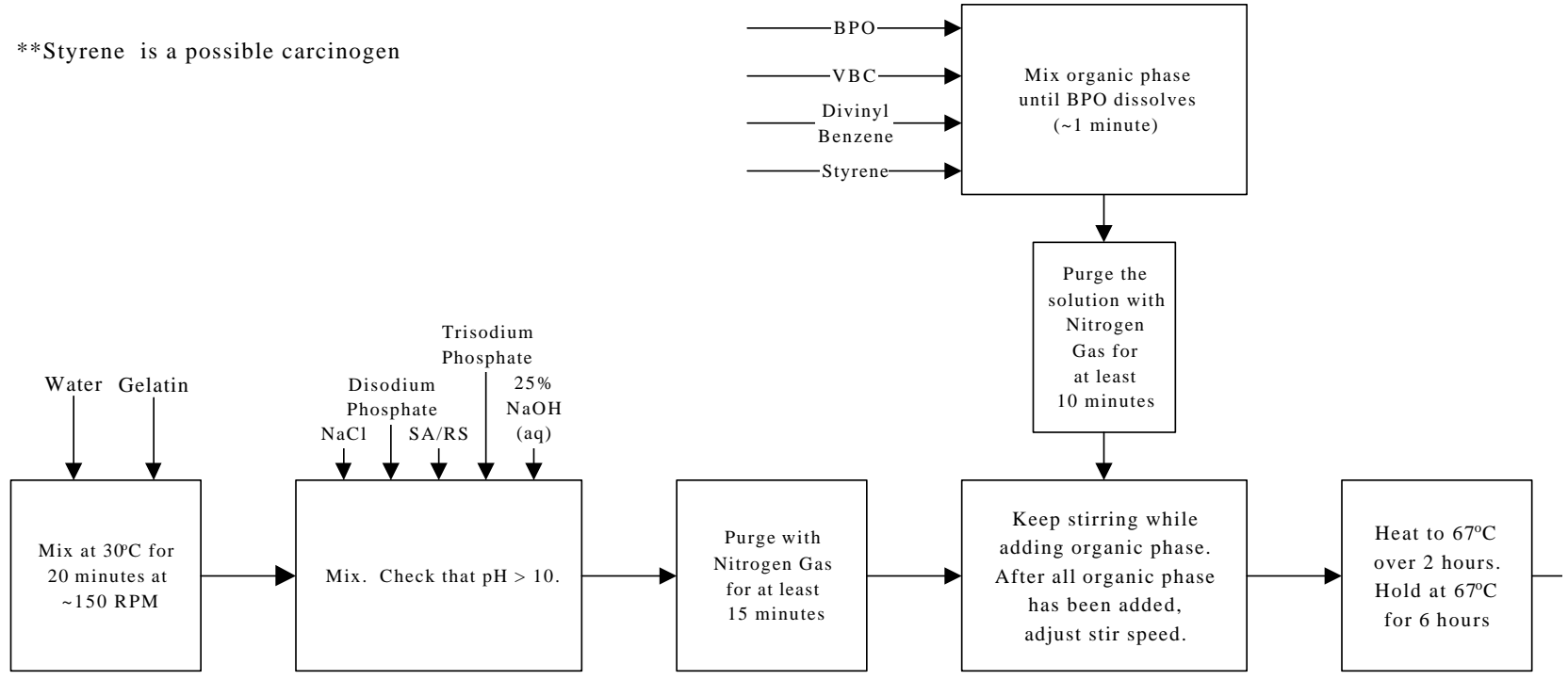

Equipment

Equipment

Reaction Vessel (Open)

Reaction Vessel (Open)

Equipment

Reaction Vessel (Open)

\section{Nitrogen Tank}

PPE / Mechanical

Controls

Safety Glasses

Protective Clothing

Safety Shower

Eye Wash Controls

Respirator (Dust)

Safety Goggles

Chemical resistant

gloves

Protective Clothing

Chemical Fume Hood

Safety Shower

Eye Wash
PPE / Mechanical
PPE / Mechanical Controls

Respirator (Dust)

Safety Goggles

Chemical resistant

gloves

Protective Clothing

Chemical Fume Hood

Safety Shower

Eye Wash
Equipment

Reaction Vessel (Open

Nitrogen Tank

PPE / Mechanical Controls

Respirator (Organic) Safety Goggles Chemical resistant gloves

Rubber Suit

Chemical Fume Hood Safety Shower

Eye Wash
Equipment

Reaction Vessel (Ope Heater

Condenser

PPE / Mechanical Controls

Respirator (Organic) Safety Goggles Chemical resistant gloves

Protective Clothing

Chemical Fume Hood Safety Shower

Eye Wash 


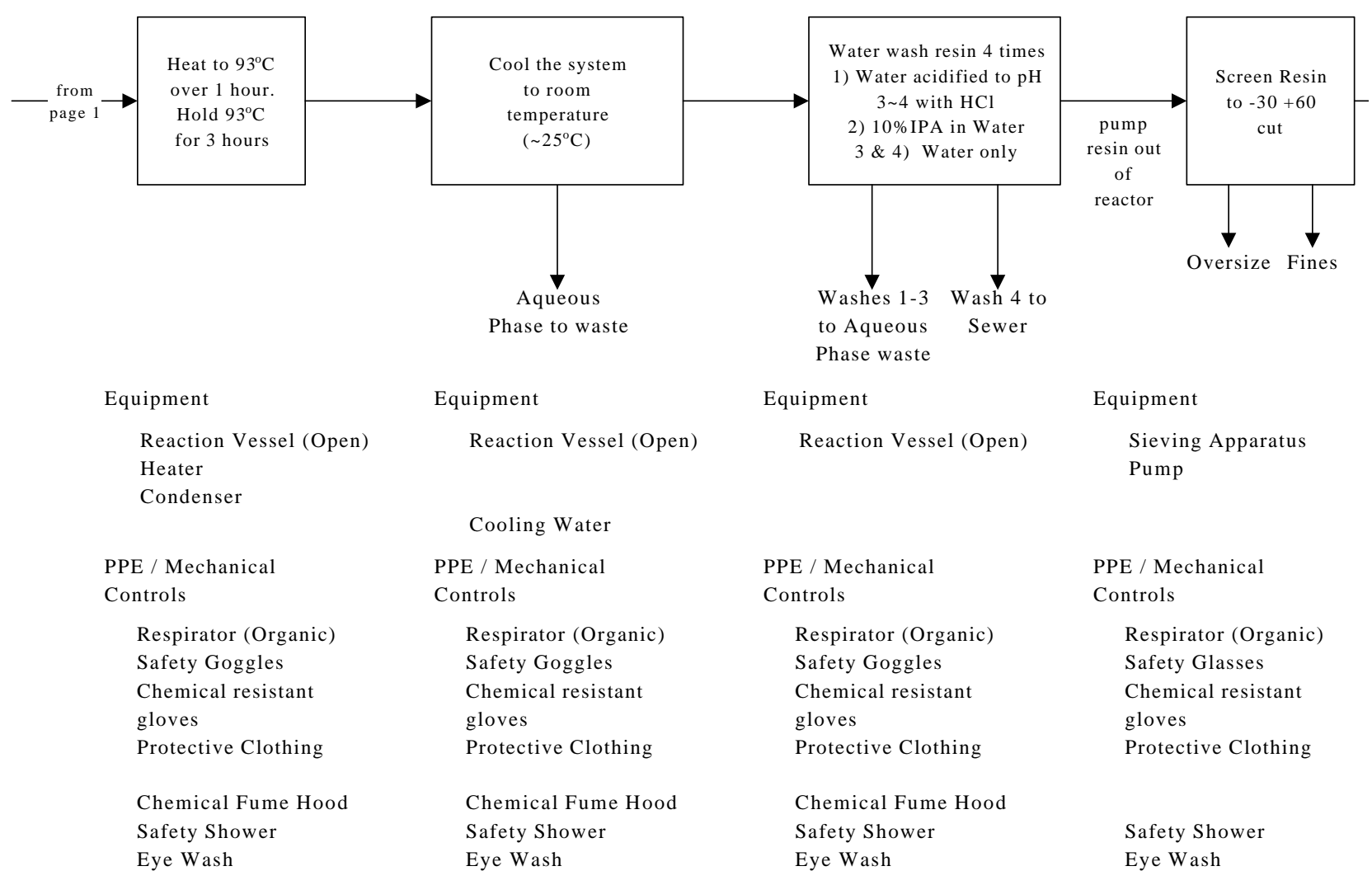




\section{$\mathrm{ABEC}^{\mathrm{R}}$ Resin Equipment Table}

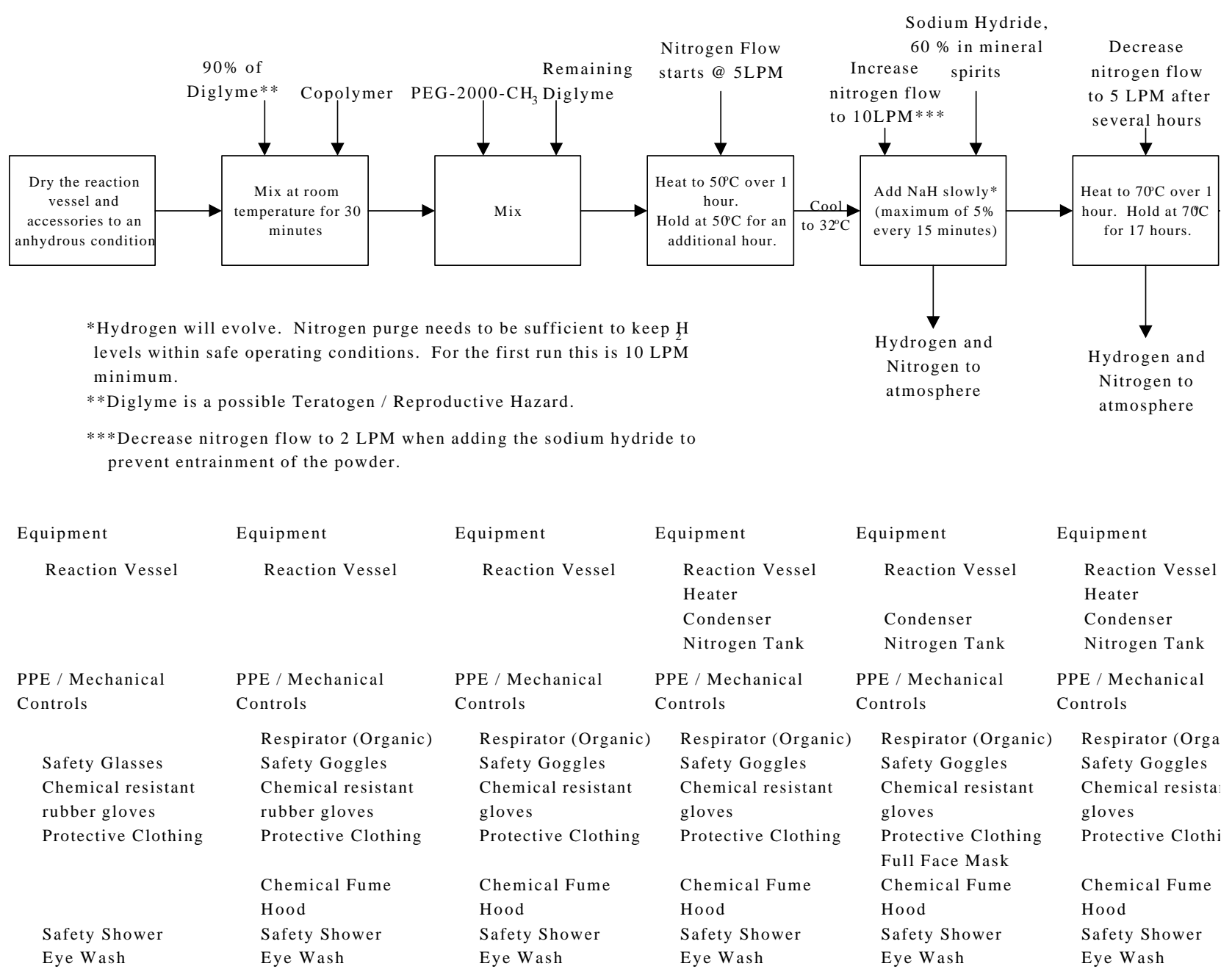


$\mathrm{ABEC}^{\mathrm{R}}$ Resin Equipment Table (continued)

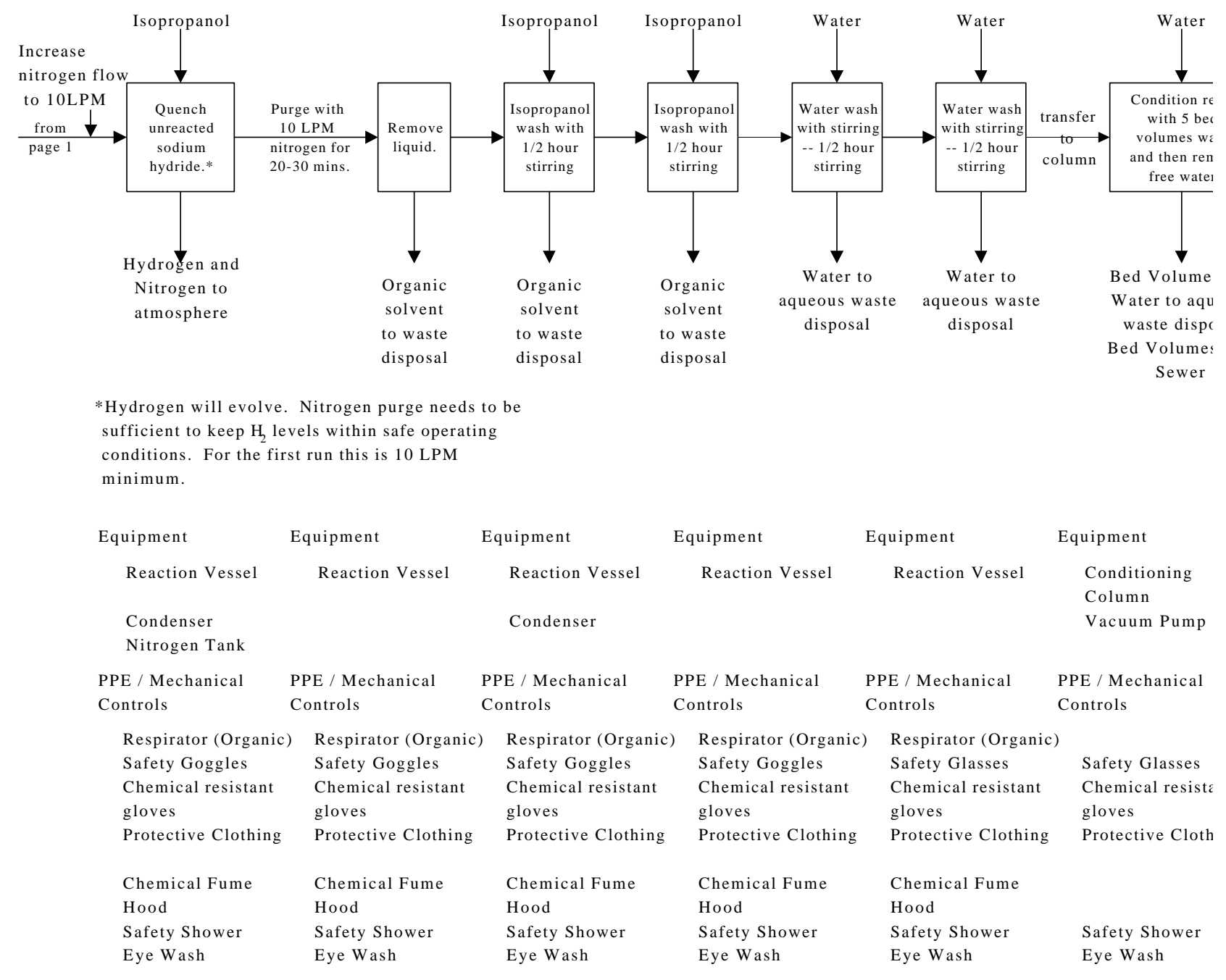

